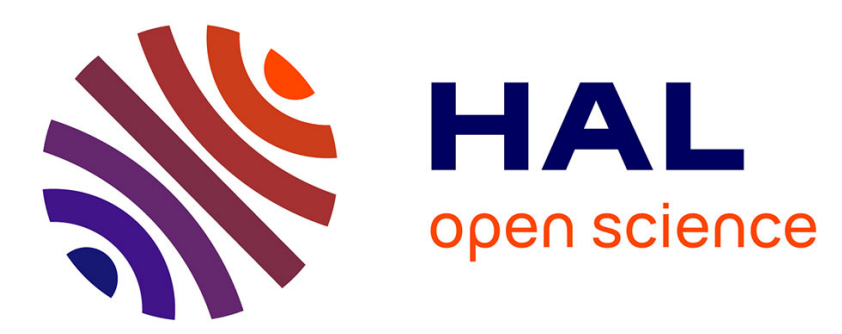

\title{
La diffusion du IIIe style pompéien en Gaule (deuxième partie) \\ Alix Barbet
}

\section{To cite this version:}

Alix Barbet. La diffusion du IIIe style pompéien en Gaule (deuxième partie). Gallia - Fouilles et monuments archéologiques en France métropolitaine, 1983, 41 (1), pp.111-165. 10.3406/galia.1983.1884 . hal-01940239

\section{HAL Id: hal-01940239 \\ https://hal.science/hal-01940239}

Submitted on 27 Feb 2020

HAL is a multi-disciplinary open access archive for the deposit and dissemination of scientific research documents, whether they are published or not. The documents may come from teaching and research institutions in France or abroad, or from public or private research centers.
L'archive ouverte pluridisciplinaire HAL, est destinée au dépôt et à la diffusion de documents scientifiques de niveau recherche, publiés ou non, émanant des établissements d'enseignement et de recherche français ou étrangers, des laboratoires publics ou privés.

\section{(이) $\$$}

Distributed under a Creative Commons Attribution - NonCommercial - NoDerivatives| 4.0 


\title{
LA DIFFUSION DU III* STYLE POMPÉIEN EN GAULE
}

\author{
Deuxième Partie
}

par Alix BARBET

Dans une première partıe' nous avons présenté quelques ensembles majeurs de peintures provenant de la vallée du Rhône et du Sud-Ouest de la Gaule, leurs caractères communs et les éléments de datation qui ont pu y être recueillis. Avant d'esquisser une conclusion provisoire du phénomène culturel que constitue l'expansion de cette mode décorative, nous présenterons d'autres peintures du Sud-Ouest et les décors connus pour le Centre et le Nord de la Gaule.

\section{Roquflaure (Gers)}

Les fouilles entreprises à la Sioulal par M.M. Cantet et Péré en 1962 ont très vite révélé des substructions qui n'ont pas été complètement explorées. Le résultat des fouilles, publié dès 1964, s'est soldé par des trouvailles de céramiques et une grande quantité de fragments de peintures murales qui ont été recollés et remontés par C. Bassier². Les panneaux sont actuellement exposés dans l'entresol du musée d'Auch.

Le plan de la villa de la Sioulal est resté incomplet, on y reconnait une série de pièces qui devaient ouvrir sur un couloir (fig. 1). Les peintures proviennent de l'extérieur des pièces $\mathrm{A}$ et $\mathrm{B}$ et, semble-t-il, de l'intérieur de la pièce $\mathrm{A} 1$, dont la fouille est demeurée inachevée, et qui est la plus grande de la série. Si l'on a pu isoler le matériel céramique plus ancien extrait d'un dépotoir à amphores, le reste des documents, qui nous aidera à situer le contexte, provient en majeure partie de la zone de démolition des peintures mais aussi des environs.

1 Cf. Ciallia, 40, 198:, p. 53 i $\times 2$.

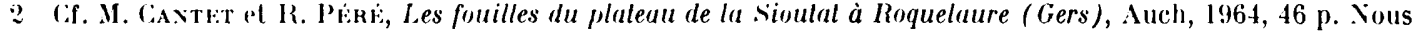
remercions .I. R. Péré pour son accueil et les autorisations de publications qu'il m'a données, II J.-P. Cantet qui m'a confie le matériel de fouille utile, .1 me Bordaz conservaleur du .lusé d'Auch qui a facilite nos recherches au musee, M. R. I'rudhomme qui avait attire mon altention sur l'importance de ces peintures ot mien avait confie des photographites. 


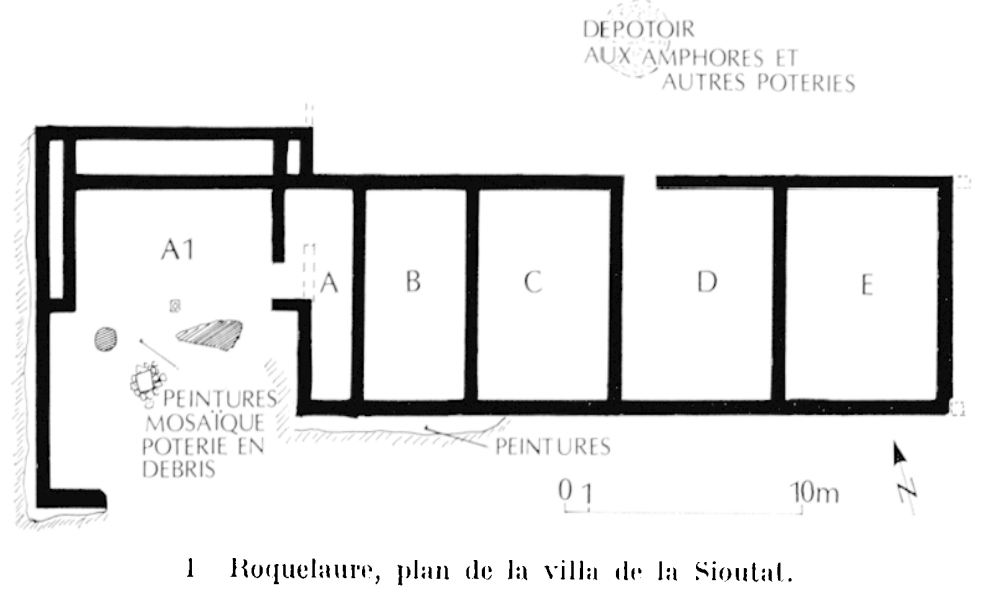

Nous disposons done du remontage muséographique de peintures, dont la totalite des fragments n'a pas été collectée, et de matériel céramique dont le gisement d'origine n'est pas toujours précisé ${ }^{3}$. Notre tâche est double : essayer de cerner une datation avec ces éléments incomplets et retrouver le schéma d'origine des déeors pour pouvoir les comparer à d'autres et en tirer une datation par le style.

\section{Eléments de dalation.}

J. Santrot, conservateur au musée d'Aquitaine, a bien voulu examiner les céramiques confiées par J.-P. Cantet et en rédiger un petit rapport dont j'extrais les points suivants: pour l'essentiel, le matériel doit être attribué à l'époque augustéenne et aux premières. années du règne de Tibère. Ene faible quantité indique une oecupation probalblement plus brève sous les Flaviens, voire au début de l'époque antonine.

Dans le mobilier augustéen, ou augusto-tibérien, on note la présence de críramiques communes indigènes non tournées, peignées et décorées par impression sur l'épaule, dont la fabricalion disparait avec le changement d'ère, des céramiques à vernis noir de type campanien $B$, du tout début du Ier s. ap. J.-C., des céramiques grises lustrées à pseudo-engohe, du type lerra nigr't. La sigillée précoce est représentée (I)rag. 15/17 ou 17 a) ; des céramiques lissées grises (Śant rot 294 et 295) sont présentes ainsi que des lèvres d'amphores vinaires italiques (Dressel 1 B précoces) de li deuxième moilié du Ier s. av. J.-C. et du début du Ier s. ap. J.-C.; un fragment de lampe à volutes de mème époque a été repéré et plusieurs fibules à ressort nu, à arc filiforme el corde interne du lype I $\Lambda$ d'Alésia (Lerat 12) antérieurs à 30 ap. J.-G. ; enfin une fibule à charnière (Lerat 2:32) utilisée à la fin du règne d'Auguste et dans la première moitié du Ier s. ${ }^{5}$. Les monnaies coïncident avee le mème lap)s de temps (quatre as et un denier d'Augusle). 1977.

3 Lne partie des archives at des journaux de fonilles a te perdue lors de l'inondiation dramal ique d'Auch en

4 Bapport de J. Santrot dictylegraphic du 12 févier l9s: ; assielles deriveres de la lorme santrot 5xh, coupes S 1:26 126a, fragments de vase a flanes concaves, decor de baguelles extermes ol ombilic s 175. Ceelle forme est dans

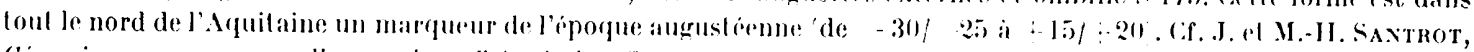
Céramiques communes gallo-romaines d Aquilaine, Paris, 1979.

5 I. Lerat, Les fibules d'Alesia, Dijon, Bibliothergur P'ro . Alesia, n" VII, 1979. 
Le mobilier trouvé à Roquelaure confirme donc une occupation précoce du site qui a pu débuter dans le dernier tiers du $\mathrm{I}^{\mathrm{er}}$ s. av. J.-C. et au plus tard dans le premier tiers du $\mathrm{I}^{\mathrm{er}}$ s. ap J.-C. Le second lot de poteries, peu abondant, date de la fin du $\mathrm{g}^{\mathrm{er}}$ s. ap. J.-C. et il faut noter que certaines trouvailles, dont le contexte précise qu'elles étaient mêlées aux peintures, sont toutes prérores. On peut donc poser pour première hypothèse que les peintures appartiennent à la première phase de construction de la villa, laquelle remonte au plus tòt au début du règne d'Auguste of au plus tard à la fin du règne du même empereur. L'analyse des peintures va nous permette de préciser cette fourchette chronologique qui s'étend sur presque un demi-siède.

\section{Panneaux de peinlure reslaurés.}

Seuls, sur la dizaine qui existe, trois panneaux de peinture restaurés seront examinés ici, car ce sont les plus complets; nous forons référence à certains détails relevés sur les autres, en cas de nécessité.

La restauration effectuée est un essai d'assemblage de fragments originaux sur une surface théorique et, pour reprendre l'expression de c. Bassier, à propos des peintures de la cave Pinel à Périgueux : "la peinture... n’est pas une reconstitution, mais un essai de présentation d'assemblages de fragments originaux... il a été procédé à un assemblage didarlique, mais non pas arehéologique $\|^{6}$.

Nous avons affaire à une juxtaposition d'éléments qui ne se recollent pas réellement et qui, dans certains cas, se situaient ailleurs. La démarche de l'archéologue consiste à "désosser" l'assemblage, à retrouver toutes les ruptures pour proposer une autre vision plus conforme aux modèles romains dont les peintres de Roquelaure se sont inspirés.

Pour rendre claire la démarche suivie, nous arons reproduit les panneaux tels quels, selon notre méthode habituelle de relevé sur plastique transparent et feutre indélébile, à l'échelle 1/1, qui a été ensuite réduite (fig. 2). Au cours de ce travail, nous arons été amené à utiliser une lumière rasante pour mettre en evidence les lacunes réelles et les ruptures d'enchaînements des motifs qui sont signalés par un triangle. Cne attention particulière a été portée sur les éléments-clefs, ceux qui prowent un lien entre deux motifs et qui seront repérés au moyen d'un astérisque (fig. :3).

\section{Panneau 1.}

L'ordonnance proposée est la suivante : une sous-plinthe noire, mouchelée de vert et de marron pour imiter une pierre ou un marbre, supporte les éléments d'un podium à siallants et à rentrants très décorés, à fond rose violet, où l'on reconnail des figures ailées tenant des rimceaux el des masques parmi des rinceaux également. L'interruption du podium à droite donne place a une figure de génie ailé accostée d'un cercle. Sur les parties saillantes du podium, des colonnes massives sortent d'une base à deux tores et d'une collerette de feuilles. I.e fùt des colonnes est lisse, orné par endroits d'ornements divers, d'une bague avec tenons groupes par trois, de calices lotiformes a enroulements de volutes, d'oiseaux a aigrelles plaqués de profil, de dauphins au-dessus d'un molif cordiforme. Iees colonnes se délachent, sur un brillant fond rouge vermillon, comme le génie ailé lui-mème (fig. j).

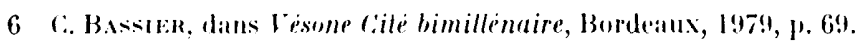




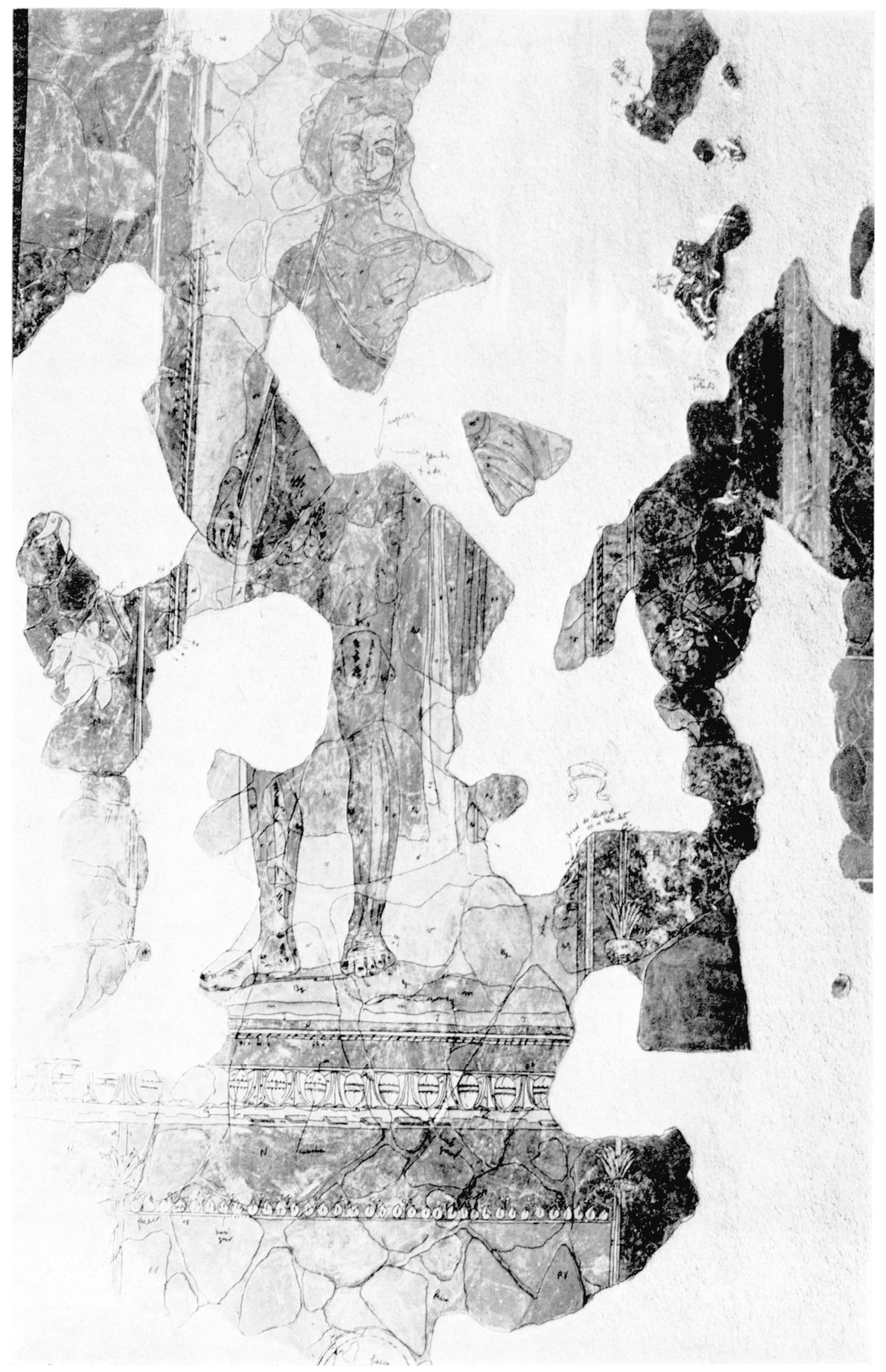

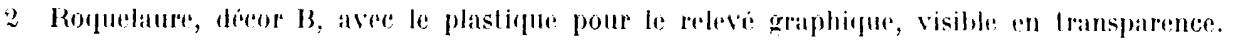



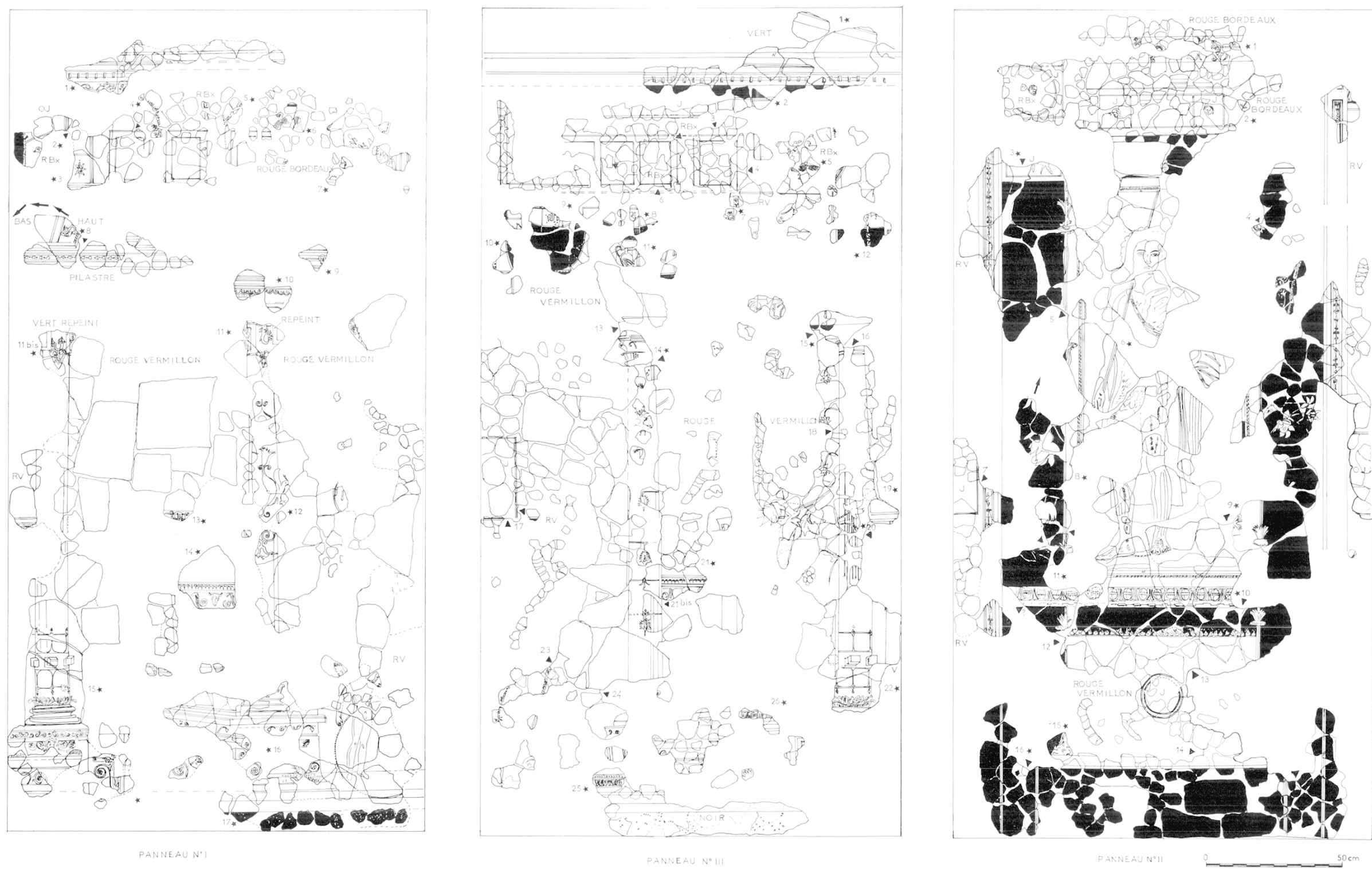

3 Roquelaure, panneraux restaures an musce d'Auch 
Les panneaux médians sont séparés de la zone supérieure par une sorte de frise à creurs et points violette et a tableautin orné d'un dauphin nageant sur le dos. dont nous verrons qu'il n'est pas a sa place $(* 8$.

La zone supérieure parait hétéroclite. Il y a plusieurs petits compartiments aux décors différent; un oiseau sous une arcature ${ }^{*} z$, un fleuron $* 3$. des cadres rouge bordeaux vides i bordures verles, des éléments finement quadrillés de jaune sur fond rouge bordeaux ( 6 i, qui n'ont, rien a faire à cet endroit, car ils évoquent un ouvrage de vannerie (fig. : $:$. Ju-dessus, une frise i ornements llexibles incomplets est surmontée d'une pseudo-moulure à pelits rectangles à ombre portée, très caractéristique (*1). Si le lien entre le podium. les colonnes. le fond rouge, le génie ailé et la sous-plinthe sont évidents, attestés par des collages, la partie haute reste conjecturale el certains éléments appartiennent à d'autres décors. Ainsi la frise a cceurs et points horizontale avec dauphin. dans une position sur le dos insolite, est en réalité à placer verticalement : r'est un pilastre décoré dans sa rainure centrale par des cours et points superposés. Il est arcosté d'un enlablement aver denticules et corbeaux cubiques, sous lequel court une frise rose violet portant le dauphin, vu en position plongeante normale (*8) (figr. 4). De mème les éléments quardrillés imitent un ouvrage de vannerie; d'autres fragments ont été placés en zone supérieure du panneau III ("5). Ils suggèrent, grâce à leurs angles obliques, le bord d'une surface de jardin enclose de barrieres fines comme il en existe à Pompéi (fig. 6). Nous aurions là les restes d'un horlus conclusus dont la plare normale est en prédelle, entre panneaux médians et plinthe el, qui provient d'un toul autre décor ( $v$. infra, notes il et 52 .

Quant aux petits compartiments rouge bordeaux, on ne conmait pas leurs dimensions réelles ni si leur place proposée est logique. Parmi les éléments épars dans le champ rouge vermillon, le bord d'entablement admirablement peint de consoles en $s$ et d'un burrane, appartient varisemblablement. a un mur-cloison adjacent aux colonnes, comme le suggère la grande plaque reconstituée du panneau III (cf. infra, restitution du décor A) (fig.. ¿) et 8).

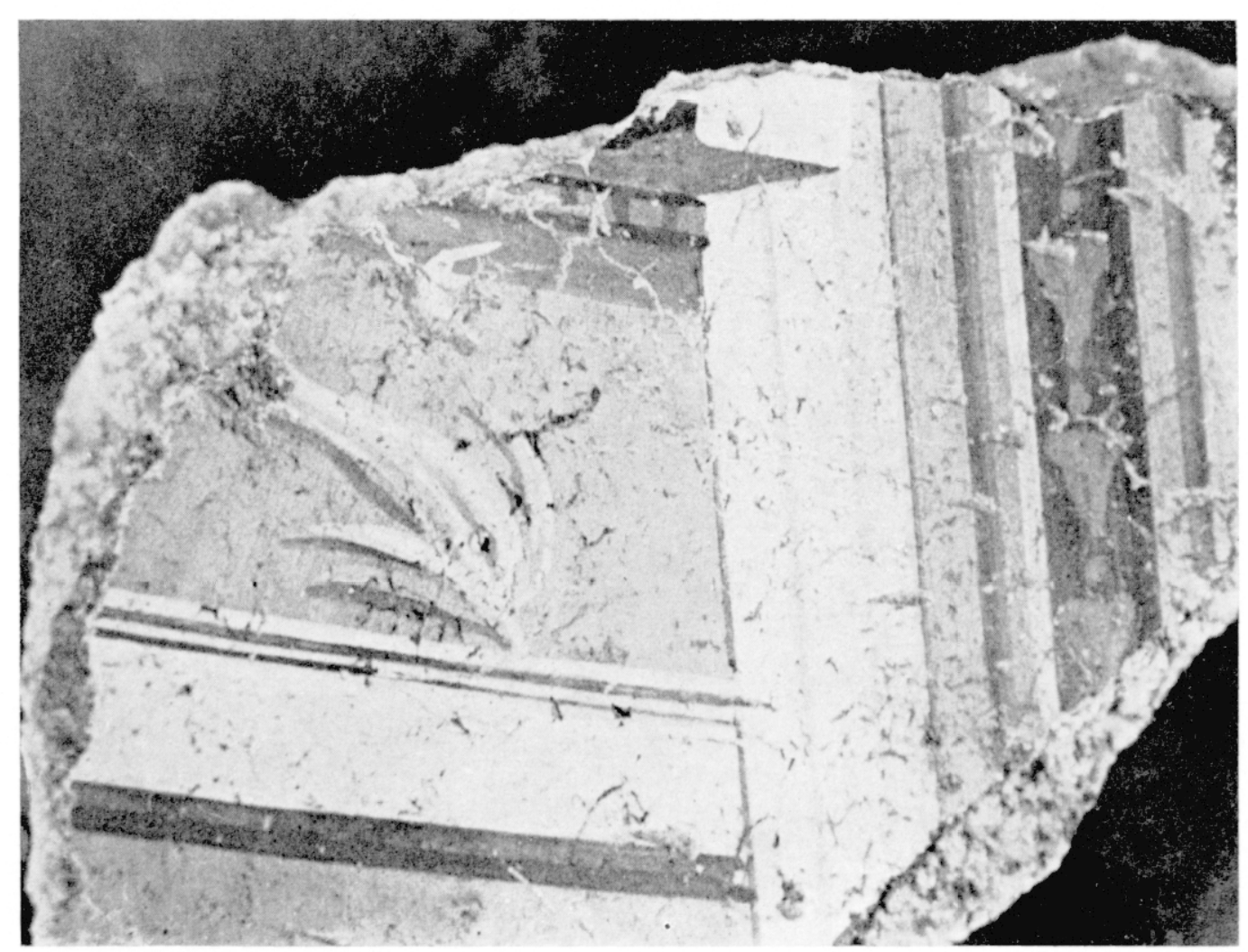

4 Rocquelaure, détail du pilastre ot du dauphin dans la position restiluee sur la figure $x$. 


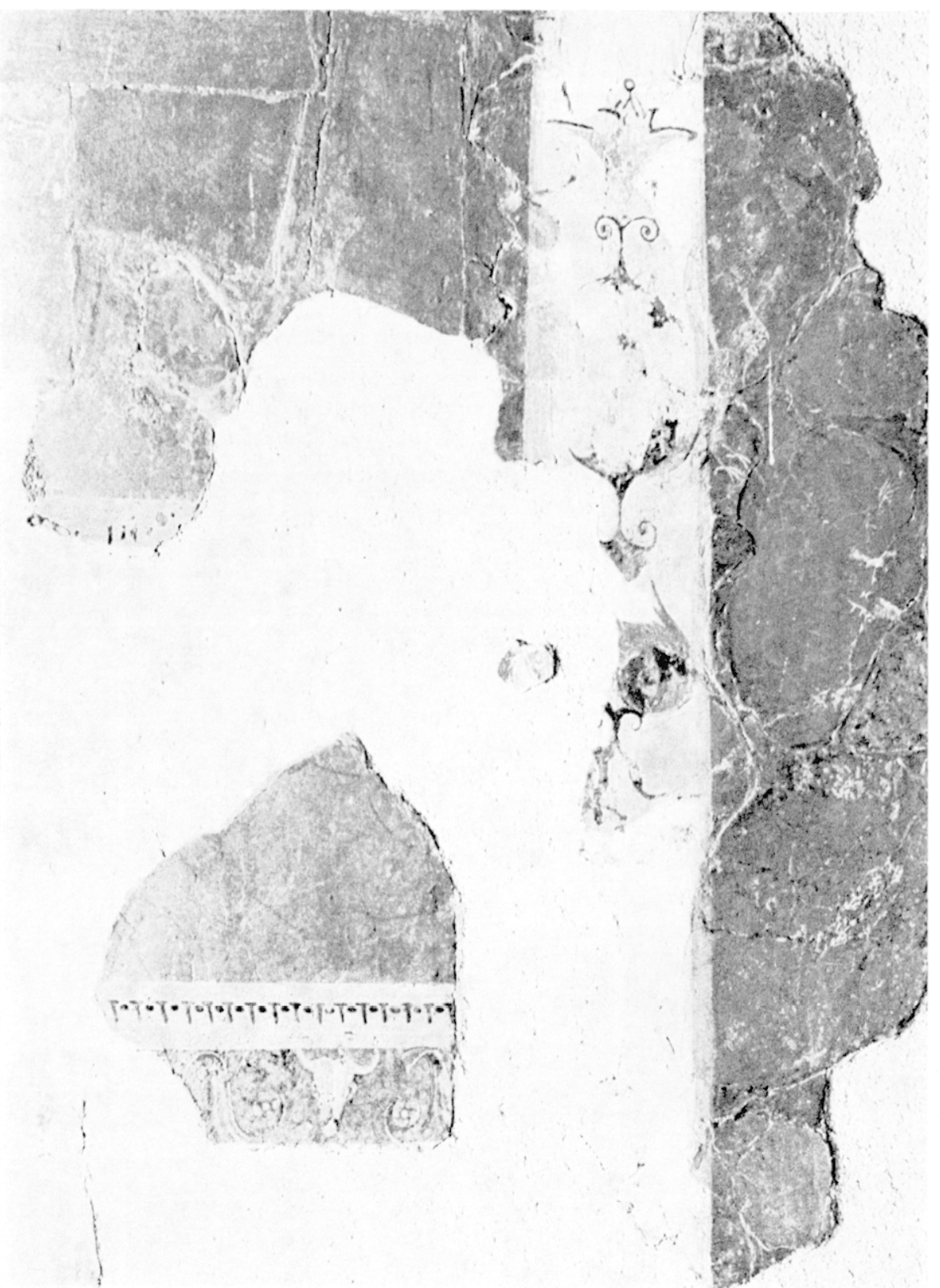

j Roquelaure, détail du mur-cloison avec consoles et bucrane, de la colonne avec oiseau et lotus.

\section{l'anneau 111.}

Il présente une composition assez proche de la précédente, avec la mème sous-plinthe, un podium analogue moins complet et les mèmes bases de colonnes à collerettes jaunes et à tenons. Cependant d'autres ornements apparaissent sur les füts, qui semblent ombrés de fines cannelures par endroils. Ce sont des palmeltes tronquées ou des fleurons de profil, relies it un bord de rorniche ou d'entablement, ou bien des belles feuilles de vigne épanouies qui s'acrorhent, an fül lui-même. Le fond est loujours rouge vermillon, avec, pour la base de la colonne de droite, une bordure verte verticale. Les chapiteaux de ces colonnes sont incertains car incomplets ; celui de droite, qui suggrepre une forme dorique, est hypothétique. 
L.A DIFFLSION IDU HIE STYLE POMPÉILA LA G.ALLE
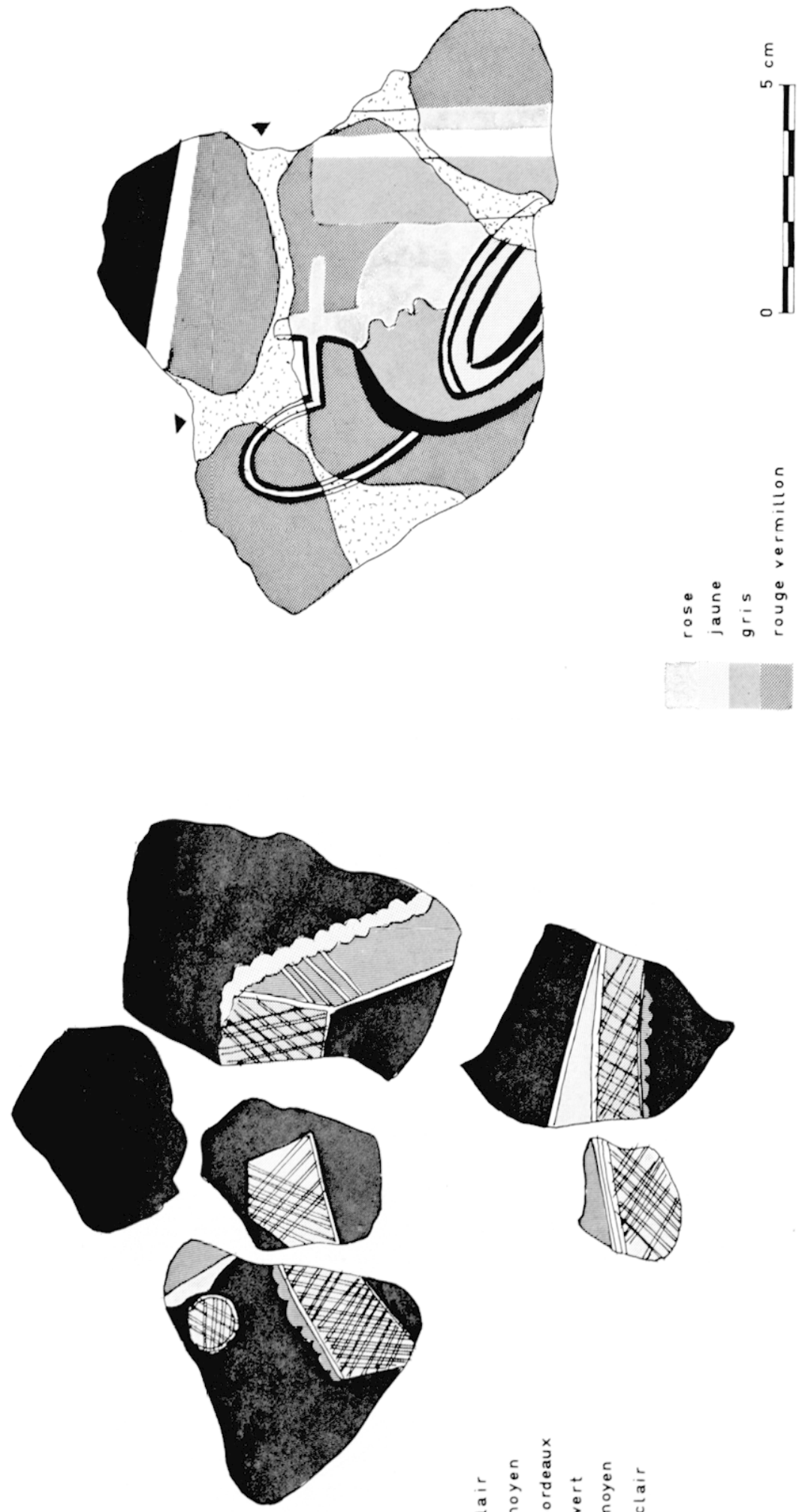

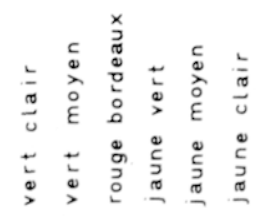

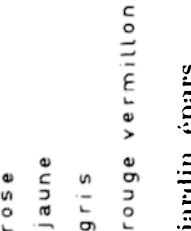

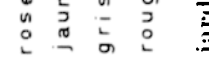

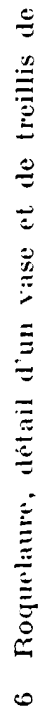


Comme dans le panneau précédant la zone supérieure est une juxtaposition de motifs hétéroclites : on reconnaît des éléments de panneaux noirs géométriques ( ${ }^{\star} 8,9$ ), un joli vase de profil, du type oenochoé ( 11 ), et un morceau de galon brodé à cours et points ( 7 . Des compartiments rouge bordeaux vides surmontent l'ensemble (fig. 6), la pseudo-moulure habiluelle, à rectangles dressés et a ombre portée, se termine par un champ vert. bizarrement coupe par une ligne oblique qui pourrait cioquer un fronton.

\section{Restilulion graphique du décor A.}

Si l'on élimine les éléments parasites comme nous l'avons fait pour le premier panneau, on reconnait une trame analogue, faite de colonnes espacées sur un fond rouge vermillon, mais qui semblent appartenir à des types différents. Le premier type est mi-lisse à tenons et mi-cannelé du fait du collage de la plaque de droite qui semble cohérent ( 22 ). Ce type de colonnes serait lié à des guirlandes de feuilles de vigne en festons. Un autre type, scandé par des barreltes décoratives, orné de fleurons de profil, est lié à un mur-cloison couronné par un entablement fait de consoles en $S$ et de bucranes $\left({ }^{*} 21\right)$. I.es oiseaux plaqués de profil et les dauphins pourraient orner un Iroisième type de support (fig. 7).

La présence de types divers de colonnes sur une même paroi existe dans les peintures pompéiennes du IIe style, et suppose une grande ampleur pour le décor. La partie intermédiaire entre sommet des colonnes et sommet de la décoration reste inconnue, seule la frise finale est a sa place comme les comparaisons qui seraient faites le prouveront. Ja ligne oblique retrouvée est, à l'évidence, le début de la courbe de la lunette d'une pièce à voùte surbaissée, comme il en existe plusieurs spécimens bien conservés dans les ville; campaniennes autour du Vésuve. Celte lunette atteste qu'une partie de la composition retrouvée appartient à un mur court, puisque la voûte est toujours jetée sur la portée la plus courte, sauf cas particulier.

Nolons que le vase appartient aussi a une composition à fond rouge vermillon el ne serait pas déplaré en milieu de panneau médian, comme il est courant en peinture romaine. La bordure noire n'est pas absolument certaine, car nous ne sommes pas en mesure de vérifier l'exactitude des collages opérés autour.

Si nous lentons une restitution théorique, en utilisant les éléments majeurs qui sont à notre disposition, nous obtenons une toute autre composition (iig. 8). Bien des détails resteront dans l'ombre, faute de témoins. Nous placerons au centre de la paroi un panneau avec ligures symboliques en grande partie disparu et dont seul un génie ailé ou un amour subsiste (?) sur le còlé gauche. Il faut imaginer au moins un à deux probagonistes à une échelle double du pelil personnage ailé qui mesure environ $50 \mathrm{~cm}$. De part et d'autre, nous sommes sùre de pouvoir restituer une colonne sur podium en perspective fuyante, qui appelle un symétrique et un contrepoint archilectural dans la partie en retrait ainsi créée. Nous y avons placé des pilastres, avec rainure ornée de cours el points, qui sont associés a un bord de corniche a denticules et a corbeaux rubiques vus en biais el sous lequel ligure une frise violette; sur la frise sont représentés des dauphins nageant, dont un seul exemplaire est conserve (fig. 4). La partie inférieure du morceau-clef (panneau $I, n^{\circ} 8$ ) indique une surface d'un bleu violacé qui pourrait correspondre justement a la mème surface visible sur le no 17 du mème panneau. En revanche nous sommes obligé de prévoir une certaine largeur pour cet espace intermédiaire entre colonne et pilastre, car il n'y a pas trace de la base du pilastre sur la plaque no 17 où la ligne de fuile est la plus longue.

Enfin nous arons disposé. aux extrémilés de la paroi restituée, des colonnes qui semblent aroir eté isolées en angle et longées par une bande verte verticale. Nous avons élé conduit à penser à une ordonnance de rinq panneaux au minimum avec quatre inter-panneaux, lesquels ont dù être limilés en partie haute par une corniche décorée qui les transforment en murs-cloisons. Nous avons installé la frise a bucranes ef a consoles en si en sommel de cloison car elle semble avoir pu remplir ce ròle. Entre les colonmes. nous devons également placer de grosses quirlandes de leailles de vigne. dont plusieurs lémoins sur le pamnealu $11 \mathrm{l}$ prouvent lexistence. La grosseur des feuilles et l'epaisseur previsible de la gruirlande nous ont imposé pour ces panneaux une cert aine ampleur. 


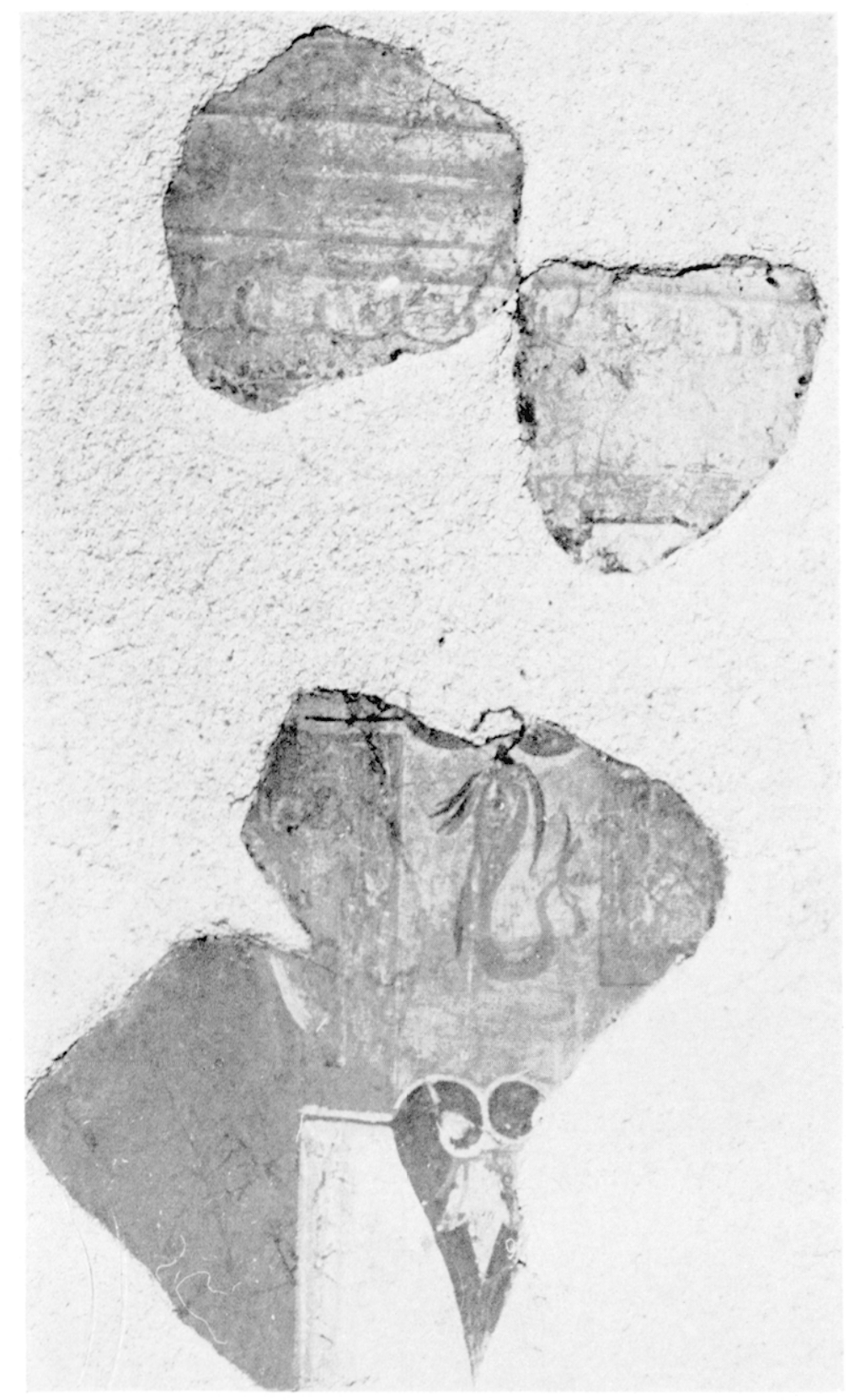

7 Lorquelaure, détail de la frise de languetles avec caisson incomplet, dessous, dauphin el motif rordiforme sur colonne.

Au-dessus des colonnes, dont les chapiteaux comportaient des volules, le morceau-ref $n^{\circ} 10$ du panneau I pourrait fort bien convenir comme entablement. En effel. alu-dessous, une ligne oblique est à interpréter comme l'exl rémilé d'un caisson vue en perspective (figr. 7 ). Entre cet ent ablement et la corniche de sommet, au ras de la voùte, a dù se trouver une ornement ation du type compartiments géométriques et l'on pourra provisoirement utiliser à cette fin les nombreux petits compartiments rouge bordeaux a bordure verte.

Cette restitution globale ainsi établie, nous donne toul de mème un ordre de grandeur de la surface couverte et une idée du schéma d'origine employé. La hauteur du décor devait ètre au minimum de $3,15 \mathrm{~m}$ et la longueur de $8,50 \mathrm{~m}$ pour une cadence compliete. La salle .11 de la villia. est la seule à avoir été suffisamment vaste pour accueillir une telle scénogrraphie. le mur le plus 
long dépassait $11,50 \mathrm{~m}$ et la restitution minimum de $8,50 \mathrm{~m}$ pouvait donc prendre encore une certaine extension (fig. 1 et 8).

Au fur et à mesure de notre analyse d'une restitution graphique différente, nous avons été appelée à comparer les éléments principaux avec certains schémas venus essentiellement d'Italie. Ces schémas appartiennent tous au répertoire de la fin du IIe slyle el du début du Ille style.

\section{Eilude romparalin's.}

Colonnes à lenons. On connaît les plus anciens exemplaires copiés en peinture murale, soil, reux de la maison des Griffons sur le Palatin (datés des années 100 av. J.-C.) de la villa de Publius Fannius Synislor a Boscoreale dans le salon dit d'Aphrodite et dans le lriclinium (milieu du Ier s. ar. J.-C.) ainsi qu'à la mème époque, ceux de la villa de Poppée a Oplontis et un peu plus tard ceux de la façade des bains de la maison du Cryptoportique à Pompéi (vers 30 ar. J.-C..). Dans tous les cas les tenons sont uniformément répartis sur toute la hauteur du fùt, séparés par des anneaux en creux. Parfois ils alternent avec d'autres motifs, comme dans la maison du Labyrinthe ou dans la villa de Poppée à Oplontis, ou sont peints des losanges contenant le foudre ${ }^{7}$. La maison d'Obellius Firmus a Pompéi (IX, 10, 1; montre une des dernières utilisations des tenons sur colonne végétalisée ; elle annonce cette mode caracléristique du premier âge augustéen dont les décors sont en transition entre Ile el IIle style 8 .

A Roquelaure les tenons sont inclus dans une bague décorative qui semble avoir éte toujours siluée prís de la base du fùt et non répétée. Ils sont accompagnés de filets ornementaux qui les mettent en valeur et posés sur une base d'une extrême richesse, qui n'a pas d'équivalent facile à repérer.

Coolonnes à ornements el à ètres animés. Déjà au II style les colonnes sont ornées non seulement de tenons, mais de petites figures qui alternent avec des cubes et des bagues décoratives diverses. Il semble cependant que les oiseaux appliqués se soient développés à la phase mùre du IIIe style, a en juger par le seul parallèle vraiment convaincant que nous ayons trouvé, dans la maison de Casca Longus ou des Cialari (Pompéi, $1,6,11$ ). Deux oiseaux, ailes en coquille de profil, comme celui de Roquelaure, ornent la base d'un fût à feuillages et à masques (fig. 9), surmontés, semble-t-il, d'un candélabre ou d'un trépied ${ }^{9}$. Quant aux motifs lotiformes, ils apparaissent très tôt an $1 l^{e}$ style dans la villa d'A Igrippa l'oslume à Boscotrecase ${ }^{10}$ dès le début de not re ère.

P'ilastres à cadres dicorés. L'habitude de décorer le cadre central d'un pilastre est en fin de compte peu fréquente. car très longtemps on lui a préféré un placage de marbre. Néanmoins il en subsiste quelques exemples a Pompéi, dans la maison I, 11, 14 sur la paroi latérale de l'ocus 1 (fig. 10), récemment publiée par .I. de Vos ${ }^{11}$. A Rome, sur des peintures tardives le motif est repris,

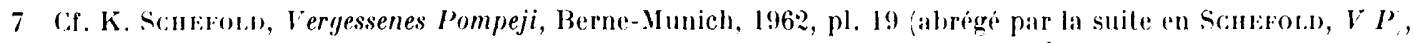
A. de Fraxciscis, Neue Furschungen in Pompeji, Recklinghausen, 1975, fig. 7 et 13. Egalement dans la maison de Popidius l'riscus P'ompéa, VII 2, 20) dans le lablinum o, ef. M. Dr: Vos, Scavi nuovi sconosciuli (1, 9, 1:3), pilture e pavimenti della casa di Cerere a Pompei, .Yeded Nederl Inst te Rome, XXXVIII, 1976, pl. 55, 39. Abrége par la suilo en I): Vos, Casa di Cerere.

$x$ K. Sconerol.1, VP, pl. 2x, decor d'une paroi de l'recus 3. cf. aussi, Ampurias, tenons et tambours d'un décor de II style lardif: J. Nieto Prielo, Los esquemas composilinos de la pinlura mural romana de Ampurias, XI'o Congreso Nacional de Arqueologia, p. $\times 51-868$, surtout fig. 5.

9 Cf. Chronique dans Notizia degli Scavi di Anlichilà, 1929, fig. 30) ; d'apres F. L. Bastet et M. de Vos ce décor est de la phase IIb soil entre 35 et t5ap. J.-C. Voir, Proposte per una classificazione del terzo stile pompeiano, Archeologische Studiën van het Yederlands Instituat te Rome, IV, 1979. Abrégé par la suite, BastET- DE Vos, Terzo slile pompeiano.

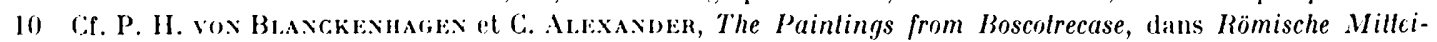
lungen, 6, 1962, pl. 19, détails 1 et 5, piece rouge; phase Ic, entre 1-25 ap. J.C. d'après Bastet-I)E Vos, Terzo stile pompeiano, et également pl. XXXVI, 66, maison au Bel Impluvium à Pompéi (1, 9, 1).

11 I. De Vos, Scavi nuovi sconosciuli $(I, 11,14 ; 11,12)$ I'illure memorande di Pompei con una tipologia proveisoria dello slile a candelabri, Veded VederlInst le Rome, XXXVII, 1975, pl. 11, fig. 13 ; également I): Vos, Casa 

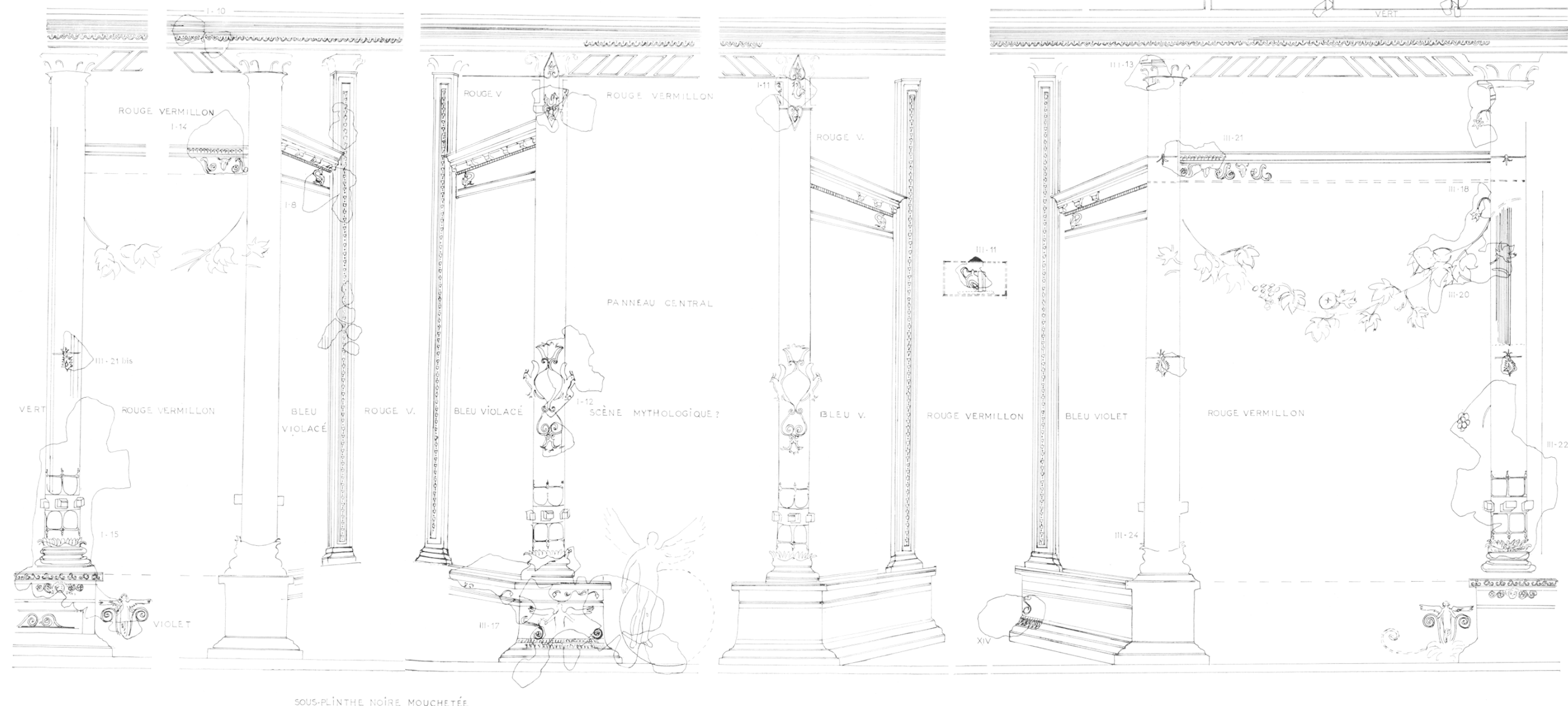
ainsi à la Farnésine dans le cubiculum I), sur les grands piliers projetés tictivement en avant, et a l'Esquilin sur ceux qui séparent les différents paysages ${ }^{12}$. Dans ce dernier exemple les motifs allongés ressemblent aux feuilles de laurier qui ont été utilisées sur le panneau II de Roquelaure (voir infra, décor B).

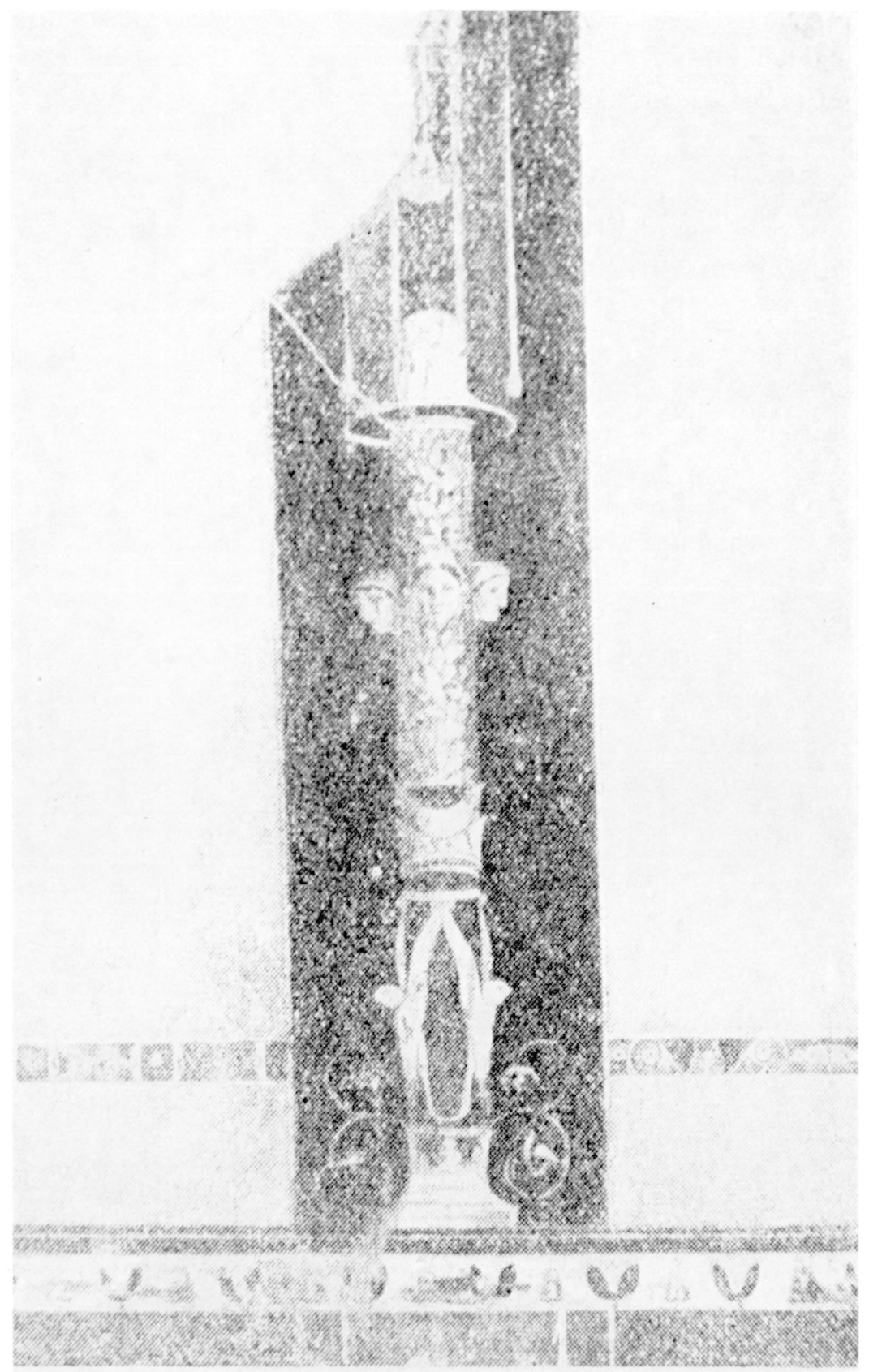

9 Pompéi, maison de Casca Longus (I, VI, 11), détail d'une colonnette.

di Cerere, tableau șinoptique proposé des pilastres ornés p. 191, ou cing exemples en tout sont relevís ; out re cen quue nous citons, ajouter la maison des Noces d'argent, la maison du Cryptoportique a Pompeit, soil des exemples du Ile st ylu lardif, et la maison d'Augusle sur le P'alatin.

12 Cf. H. G. Bryex, Die Pompejanische Wanddelioralion vom zweitem bis zum rierlen Slil, Lat Haye, 1960, nos 944 at 105b. Abrégé par la suite en Beyex, $P W$ I et II. 


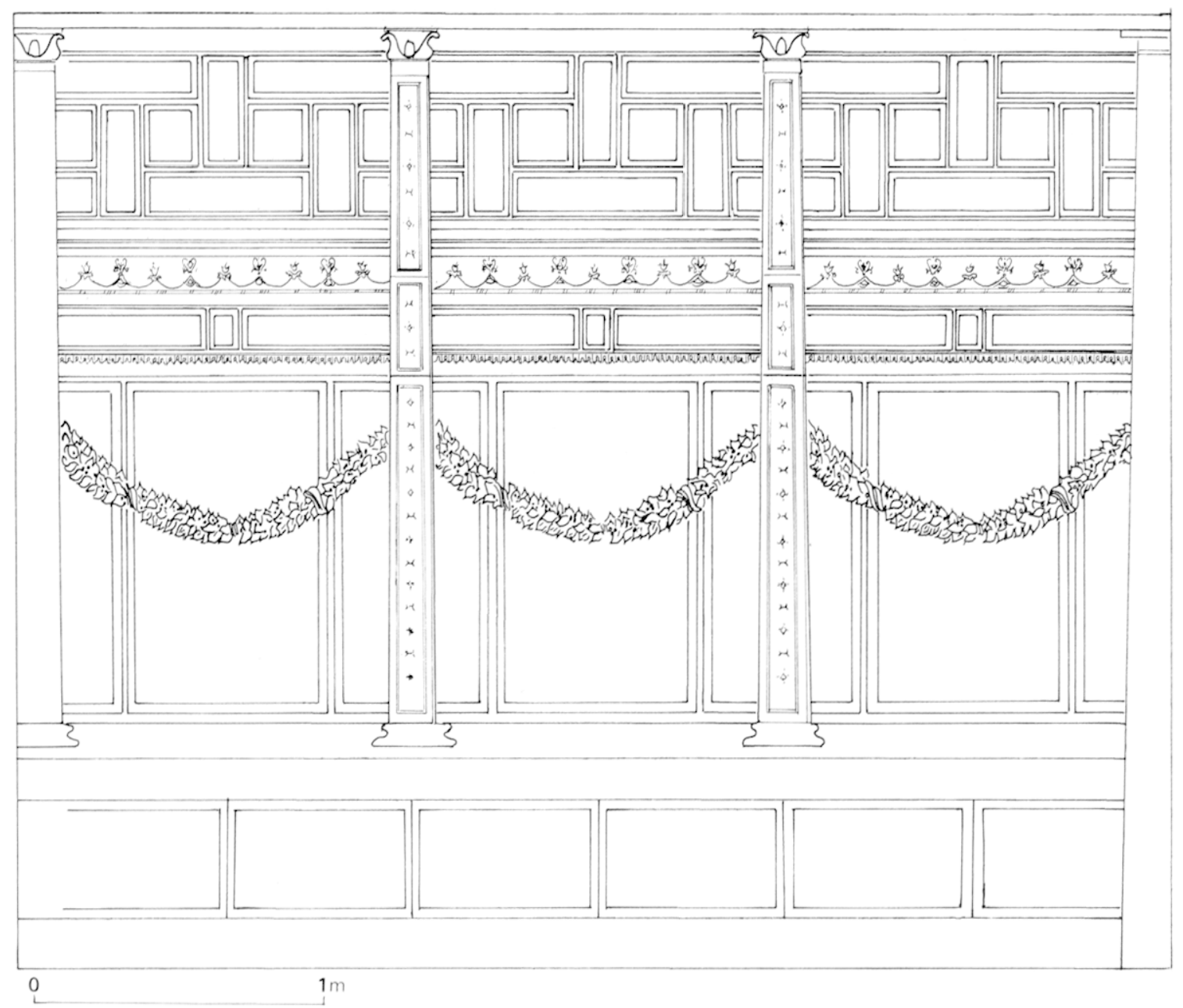

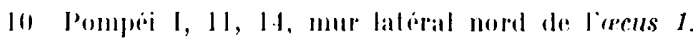

lin risumi. si la présence d'un décor sur les radres de pilastre est manifeste à l'époque dépanouissement majeur du lle style. elle est altestée plus largrement à une période basse, au tournant entre Ile et II Ie slyle, soit vers 25 ar. J.-C.

Bords de porlium el de murs-cloisons à corniche. Les personnages hiératiques, ailés, vus de face el tenant des rinceaux sont, un poncif bien connu dis la fin du Ile style, par exemple dans la maison de Livie, sur le Palatin : il y a des analogies de traitement de moulures du podium dans un décor de Portici, mais moins riches ${ }^{13}$. Sur une des peintures de la maison de la Farnésine (Musée National des Thermes à Rome. les colonnes cannelées, à base végétalisée, sont posées sur une base saillante el le podium porte dans des encadrements une frise de figures féminines ailées de profil aux corps terminés en volutes, i cote d'ornements variés ${ }^{14}$.

Pour les dauphins sous la corniche à denticules el à corbeaux cubiques, ils étaient censés, à l'origine. servir de consoles et se relier à ces mèmes corbeaux. A Roquelaure ils deviennent une simple frise. Ils entrent tout de même dans la catégorie des petits êtres qui jouent ce ròle et que

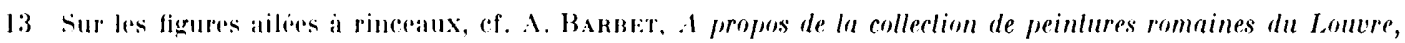
2a partir, dans Revue Archologique, 1978, p. 91-95, fig. $7, x$

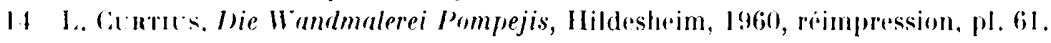


Beyen a analysé : on compte, outre des télamons classiques, des centaures, des griffons, des aigles et mème des boucs à corps volutiforme ${ }^{15}$. Il n'y a pas d'exemple d'un bord de mur-cloison à bucranes et consoles aussi fin et traraillé, si ce n'est dans la maison du Cryptoportique, au sommet du murcloison qui passe derrière les télamons ${ }^{16}$. Nilleurs, surtout à la villa des Iystères, dont l'exécution remonte au milieu du $\mathrm{I}^{\mathrm{er}} \mathrm{s}$. av. J.-G., les consoles en $\mathrm{S}$ sont plus grandes et n'alternent pas avec des bucranes, mais le principe de base est le même et l'utilisation probablement identique.

Guirlandes de fenillages en festons. Le thème de la guirlande de lourds feuillages entremêlés de fruits, en forme de festons reliant des colonnes ou des pilastres les uns aux autres, est fréquemment employé à l'époque la plus florissante du IIe style, soit au milieu du I $^{\text {er }}$ s. av. J.-C. ; il y en a des spécimens variés à Boscoreale dans la villa de Publius Fannius Synislor, à Pompéi dans la villa des Mystieres et dans la maison du Labyrinthe ; partout la guirlande se déploie devant des murs-cloisons bas ou devant des orthostates, comme dans la splendide pièce à la frise monochrome jaune égyptisante de la maison de Livie sur le Palatin ${ }^{17}$ (fig. 10).

Avec l'époque de transition des années 20 av. J.-G., la guirlande s'amenuise jusqu'à devenir filiforme, en accord avec les supports qui sont devenus de frêles colonnettes ou des candélabres grèles ; les meilleurs modèles sont la maison de Livie et la caserne des Gladiateurs à Pompéi (V, 5, 3). La mode en disparaîl ensuile complètement dans l'habitat privé, dès la fin de ce style-candélabre qui peut être assigné aux années 20 av. J.-C. ${ }^{18}$. Nous tenons lá un indice qui vient se cumuler avec les autres pour une datation dans les années 25 av. J.-C.

Pseudo-moulure à reclangles à ombre portée. Est-ce la traduction des triglyphes? ou la simplification d'un ornement qui nous échappe? Ie fait est que ce type de moulure couronne le haut des parois en Campanie et nous cilerons l'exemple tris proche d'une pièce peinte en IIIe style à la villa San Marco à Stabies, qui a été ensuite coupée par l'adjonction du grand péristyle et du bassin ${ }^{19}$. L'entablement filiforme de la piece noire $n^{0} 15$ de Boscotrecase, de la villa d'Agrippa Postume, présente des motifs en U renversé, un peu de même conception ${ }^{20}$.

Sujels figurés. Quant au personnage ailé de plain-pied avec le podium, il reste difficile à analyser et à comparer à d'autres documents. La signification même du cercle situé derrière et qui n'est pas une sphère armillère, seule comparaison qui nous vienne à l'esprit pour l'instant, est un élément important pour l'interprétalion de la scène qui était symbolique, à caractère mythologique ou religieux. Le thème est étrange, de même la présentation sur le fond même du panneau et non pas dans un tableau limité, comme sur le panneau reconstitué voisin no II.

Si on laisse de cóté celte interprétation, nous retiendrons l'aspect qui nous intéresse dans cette élude, soit l'identification du style : la vogue des grands tableaux ouverts comme des fenêtres, dans la partie centrale d'une paroi, remonte aux années 25 av. J.-G., où les peintres illustrent quelques grands thimes mythologiques comme Io et Argus, ou bien dessinent des paysages idyllico-sacrés ${ }^{21}$. Yous nous trouvons la devant une conception originale du tableau figuré qui n'a pas, pour l'instant, de correspondant exact. On peut penser que l'original copié provient de régions différentes de celles qui nous ont conservé le plus d'exemples, a savoir les villes campaniennes, vers lesquelles nous sommes contraints de tourner les yeux, au risque de fausser la vision des rapports qui s'établissaient entre province et métropole.

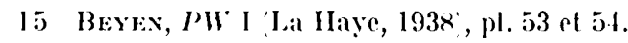

16 (f. M. Bonna, La piltura romana, Milan, 1958, p. I83. Abrégé par la suite en Borda, PR.

17 (if. Bonus, IPl, p. 22, 24, 28, couleur ont re p. 40 et $41,41,182$.

ls (if. Schleot.n, VP, pl. 36-37.

19 L'étude de la villa San . Marco est en cours par une équipe franco-italo-allemande dont nous faisons partie.

20 Cf. P. H. vox Biavcikexiariex et C. Arexaxder, op. cit., pl. 7, détail du mur ouest dans la pièce noire, avec allırnance d'un autre motif.

21 Gf. G. E.. IRızo, Le pillure della casa di Livia, Monumenti della pillura antica scoperli in Italia, III, 2, 3. 
Vases accostés d'une colonne tronquée. Les pelites natures-mortes en vignette au centre des parois ou posées sur une corniche ou dans des petits panneaux sont couranles. Si l'on relient la restitution d'un petit compartiment, il faut alors se référer aux vignetles de ce type qui ornent les parois plates du IIIe style. A Roquelaure la colonne volive tronquée est reconnaissable; le cercle en bas semble jaune et plein ; plutôt qu'une couronne il faut y voir peut-être une patère.

Nous décrirons plus loin d'autres pelits vases intégrés ou non dans des encadrements, à Bordeaux, aux Bolards (Nuits-Saint-Georges) et dans l'Ile Sainte Marguerite. Ils se caractérisent tous par une échelle très réduite et une exécution minial urisite (fig̣. 16, 17, 22).

\section{Dalalion slylislique du décor $A$ de Roquelaure.}

Tous les éléments rassemblés concourent à la restitution d'une ordonnance à colonnes sur bases saillantes, à effet de trompe-l'wil évident, dont l'organisation générale est celle d'un décor du IIe style de la fin de l'évolution, mais avec un vocabulaire ornemental déjà nouveau d'époque augustéenne. On pensera à une exécution faite à l'époque de transition entre II et IIJe style où le décorateur a encore dans les yeux et dans la main les schémas en usage au début de sa carrière. Cíest un décor unique pour la Gaute à l'heure actuelle et qu'il faut placer vraisemblablement dans les vingt cinq dernières années avant l'ère chrétienne, en concordance avec les éléments fournis par l'étude du matériel céramique et numismatique. Les bribes de décors hétéroclites, dont certains sont restituables, appartiennent à d'autres pièces et se situent plus francliement dans l'orbite du II le style.

Il est difficile de proposer un emplacement pour le décor A, lequel appartenait à une pièce. couverte d'une voûte surbaissée. La pièce à laquelle nous pensons, A 1, était située bien en vue dans le quartier des maîtres; on songera à une fonction de lriclinium, si l'on se réfëre aux thèmes accordés à la destination des locaux durant le IJe style ${ }^{22}$. Les guirlandes en festons sur colonnes, qui évoquent une vieille tradition de décoration éphémère sur les colonnes réelles des péristyles, ont été peintes de préférence dians les portiques, les exèdres et dans les salles d'apparat du type oecus ou triclinium. On ne les trouve pas dans les petites. chambres à coucher. La place du décor A de Roquelaure se trouverail en conformití aree les conclusions de notre enquète préliminaire sur l'adéquation du décor aux loraux.

\section{Panneau II.}

Il présente une composition totalement différente des deux autres analysées précédemment, dans une tonalité où le noir est dominant. La partie basse est un fond noir parcouru de filets triples qui appartenaient plus vraisemblablement à des panneaux médians. 1 cette partie basse devait se superposer la base des candélabres dorés à patles de félin dont un bel échantillon nous a été conservé (*15). Sur un fond vermillon se détache un disque jaune limité par une bande décorative faite de feuilles vertes schématisées en pois, sans lige, auxquelles se rarcordent des petites baies deux à deux (fig. 2,3).

Entre cette partie basse et la zone moyenne se déroule une frise à oves et fers-de-lance richement décorés et posés sur des corbeaux rus en perspective mais aplatis et réduits à l'extrème. La zone moyenne est ornée d'un tableau mythologique à fond hleu-gris ou se délache la silhouette d'un homme nu, portant un thyrse dans le creux du bras droit. le bras gatuche vraisemblablement entouré

22 Cf. These d'Élat de l'auteur, I'eintures de Bolsenu. Recherches sur la peimlure romaine en Ilalie du I’r au III' siècle, Universile de Paris I, 19×1. Tableau synoplique XII. 
d'un mant eau. De part el d'autres du tableau, une hampe enrubannée est doublée par un candélabre doré. sur les còtés extérieurs gauche el droite un pilastre très fin est décoré dans son cadre central violet de feuilles de laurier schématisées alternant avec des volutes. De lourds feuillages de vigne sont reliés aux candélabres ( 8 ).

En zone supérieure ont été placés plusieurs petits compartiments, les uns jaunes, carrés, à lête fantastique, les autres rouge bordeaux circulaires inscrits dans un carré jaune au motif interne peu déterminé. Enfin en couronnement, une frise décorative à base de volutes est limitée par un champ rouge bordeaux incomplet.

\section{Restilulion graphique du décor 13 .}

Plusieurs points de ce remontage effectif sont à modifier pour un essai de restitution du rythme réel d'origine. L'incertitude demeure pour la partie basse, qui, cependant, était de tonalité noire. Pour la partie moyenne le tableau mythologique central avait bien plus d'ampleur et comportait peut-être plusieurs personnages autour de Dionysos dont l'allribut du thyrse n'est pas douteux. Le sommet de la hampe qu'il porte est bien fait d'une pomme de pin aux écailles très reconnaissables. sur le còté droit de la scène, près du candélabre auquel il est lié, subsiste le pied en forme de patte d'animal d'un siège, sans doute un tabouret; la scène se déroulait donc à l'intérieur d'une pièce. Des éléments épars d'autres figures, trouvées à Roquelaure, ne permeltent pas toutefois d'identifier le sujet.

Si l'on passe en revue les thèmes connus où Dionysos joue un rôle de premier plan, les seuls épisodes susceptibles de convenir pourraient être l'abandon d'Ariane endormie, ou Dionysos renversant un canthare, assisté par Siline. Cependant pour les versions connues de l'abandon d'Ariane, celle-ci est étendue près d'un rivage en plein air, ce que dément la présence du siège en bas à droite. Bien entendu le siège pourrait appartenir à un tableau des autres parois, identique, dans la même pièce, puisqu'il y en avait sûrement au centre de chacune d'elle ${ }^{23}$.

Les panneaux noirs qui encadraient la scène centrale à figures étaient traversés par des guirlandes de feuillages et de fruits, dont quelques morceaux retrouvés montrent la qualité. L'attache sur les candélabres dorés était plus haut comme nous le suggóróns par une flèche. Il faut donc restituer ici également des panneaux bien plus larges. Les pilastres servent de support aux guirlandes ainsi que nous l'avons déjà vu dans les décors pompéiens de la fin du IIe style. On ne peut rien conjecturer pour la partie haute de la paroi.

Le lableau central aviit un peu plus de la hauteur qui a été proposée. Én effet, le développement du torse restitué est un peu court par rapport aux jambes, sur le panneau du musée, et il faut lui ajouter quelques centimètres. Nous aurions $1,50 \mathrm{~m}$ à $1,60 \mathrm{~m}$ de hauteur réelle, puisque les collages sont quasiment continus ou plausibles du point de vue anatomique. La largeur du tableau, en supposant un seul protagoniste debout à droite de Dionysos, nous donnerait $1 \mathrm{~m}$ a $1,10 \mathrm{~m}$, ce qui est d'un bon rapport avec la hauteur quasi certaine de $1,50 \mathrm{~m}^{24}$.

Les panneaux latéraux noirs portant des guirlandes, comme dans le décor $\mathrm{A}$, nécessitent une certaine largeur pour le déroulement d'une courbe harmonieuse, soit au moins $1 \mathrm{~m}$ à $1,20 \mathrm{~m}$ si l'on croit à une symétrie entre panneau central et panneaux latéraux, ou plus. En comptant les pilastres et les encadrements, y compris les candélabres dorés et les tiges enrubannées, le motif d'un minimum de trois panneaux devait occuper $4 \mathrm{~m}$ de long et même davantage avec les raccords d'angle inconnus.

23 (.f. S. Jisixach, Répertoire des peinlures gréco-romaines, Paris, 1922, p. 105-117. Parmi les autres personnages conservés de Rorquelaure, il y a un jeune homme étendu sur le dos, conservé au llusée de Lectoure, une têle do femme de profil, tous deux à fond bleu vert.

24 On observera que les proportions générales sont de deux unités en largeur pour trois unités en hauteur. Six oves et fers de lance de la même frise ont été remontés à part sur un autre panneau ; ils pourraient se raccorder au décor B. L'étude des autres panneaux en réserve peut modifier à l'avenir certains détails de nos restitutions. 
Il ne faut pas négliger l'existence de panneaux noirs plus simples, avec encadrement intérieur de filets triples (placés en partie basse au musée) et qui pouvaient prendre place aux extrémités de ce noyau décoratif central, ce qui suppose donc un développement en longueur plus important. De surcroît, la présence d'un champ rouge vermillon à gauche du pilastre de gauche et à droite du pilastre de droite suggère d'autres développements possibles avec champs rouges. Certains motifs sur fond rouge, comme le petit vase dans un cadre ou sans cadre, sont interchangeables entre décors restitués A et $B$ (fig. 6 ).

Du fait de l'incertitude de cette restitution dans sa longueur, il est difficile de proposer comme pièce d'origine $\mathrm{B}$ ou $\mathrm{C}$, dont les murs longs sont identiques $(4,20 \mathrm{~m} \times 8 \mathrm{~m}$ et $5,60 \mathrm{~m} \times 8 \mathrm{~m})$. Notons toutefois la richesse des thèmes choisis dans une tonalité sombre alors que dans le décor que nous avons attribué à la pièce voisine, Al, le rouge vermillon prédominait.

\section{Étude comparative.}

De la même façon que pour l'analyse précédente, nous prendrons les motifs les plus caractéristiques et les plus complets qui ne font pas de doute. Il s'agit essentiellement des tableaux mythologiques à personnages de grande échelle, des pilastres à cadres ornés, des candélabres dorés séparant deux champs contrastés, des guirlandes en festons, des frises d'oves ornementales, des hampes enrubannées et des filets d'encadrement triples. Pour certains motifs nous avons déjà procédé à des comparaisons qui nous ont conduit à la fin du II e style au plus tard; c'est le cas pour les pilastres à cadres décorés et pour les guirlandes en festons.

Tableaux mythologiques : à grands personnages, ils sont une création de la fin du Ier s. av. J.-C. qui s'est perpétuée durant le premier tiers du $\mathrm{I}^{\mathrm{er}} \mathrm{s}$. ap. J.-C. A Roquelaure la nudité héroïque, l'anatomie naturaliste et classique du personnage indiquent l'imitation d'un tableau célèbre plus ancien. La facture est très soignée, les muscles et les volumes sont traduits par de fines hachures croisées. Comme exemple nous citerons, à Pompéi, Hercule dans le jardin des Hespérides, dans la maison dite du prêtre Amandus $^{25}$ qui est un des plus tardifs.

Dans les cas considérés de la fin du IIe style et ceux du IIIe style, le tableau mythologique occupe tout l'espace de l'édicule encadré et les personnages sont à grande échelle, bien qu'il existe une tendance à grands paysages et petits personnages. Plus Lard, dans les derniers développements du IIIe style et surtout au IVe style, les tableaux sont beaucoup plus petits avec des personnages d'échelle moindre, sauf cas particulier.

Candélabres dorés séparant deux champs conlrastés. C'est un mode de partition nouveau que de disposer un candélabre entre deux champs là où, autrefois, les bordures et les plaques de séparation tenaient cet office. Un exemple, un peu différent cependant, est à relever dans la maison du Viroir à Pompéi, dans le triclinium, où un candélabre beige aussi filiforme, avec seulement quelques touffes de feuilles aiguës, sépare un champ rouge d'un champ ocre jaune en diagonale. Au-dessous une frise d'oves court tout du long ${ }^{26}$. Nous verrons une même utilisation d'un motif en guise de séparation entre deux champs sur d'autres peintures provinciales, à Commugny (Suisse).

Hampes enrubannées. Ces hampes lisses et de couleur claire sont entourées de sortes de rubans qui s'enroulent en hélice et qui sont de plusieurs tons. İne petite plaque conservée à Narbonne

25 Cf. Bastet-De Vos, Terzo stile pompeiano, la décoralion est assignée à la phase IIb, entre 35-45 ap. J.-C. Voir d'autres exemples, pl. V; XIII, 23 ; XIX, 41 ; XXII, 42.

26 Cf. I. Bragantixi, dans Pompei 1748-1980, I lempi della documenlazione, catal. exposition, Rome, 1981, p. 108 , fig. 4 . 


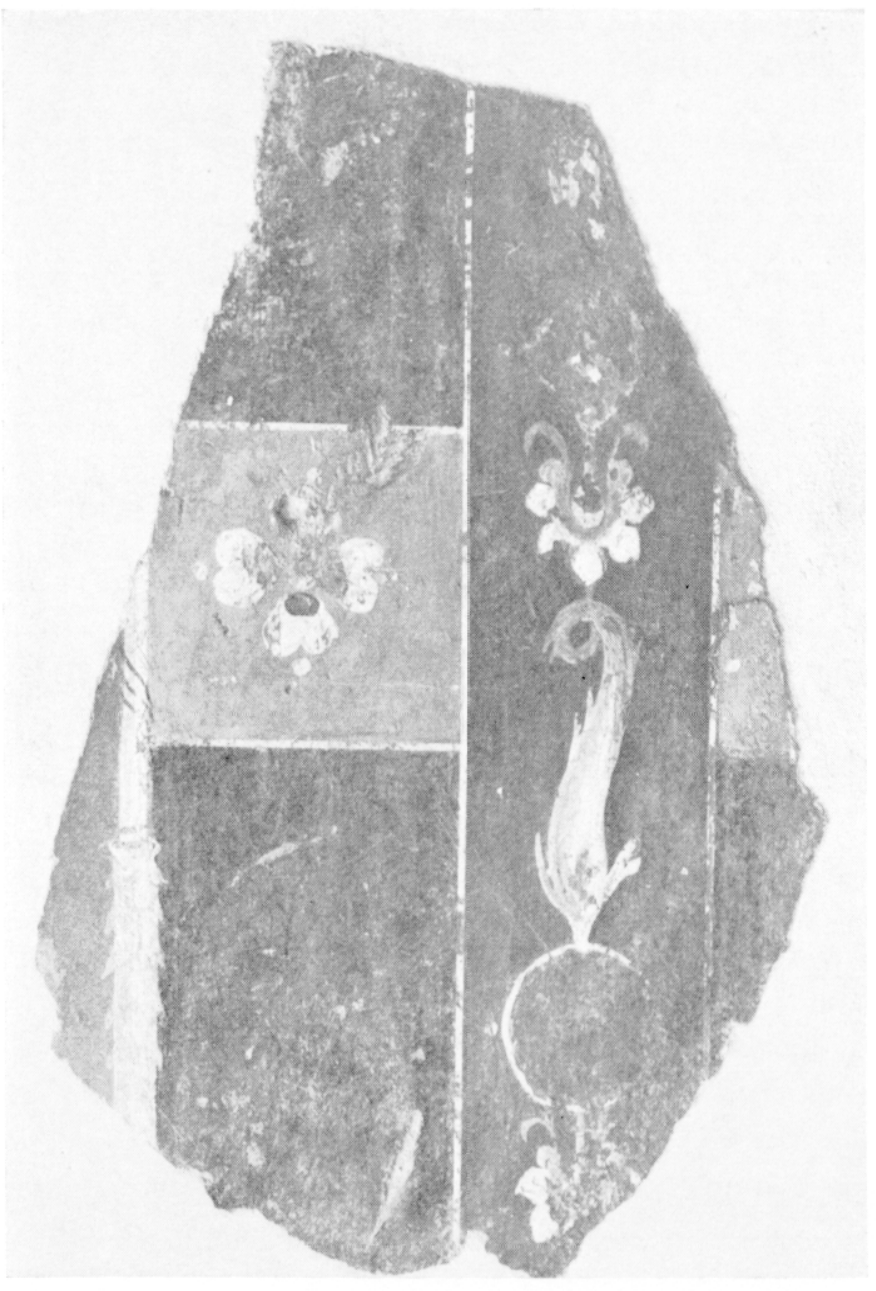

11 Narbonne, clos de la Lombarde, remblais.

12 Pompéi, maison de Paquius Proculus, pièce $n^{\circ} 18$, détail de la partie supérieure.

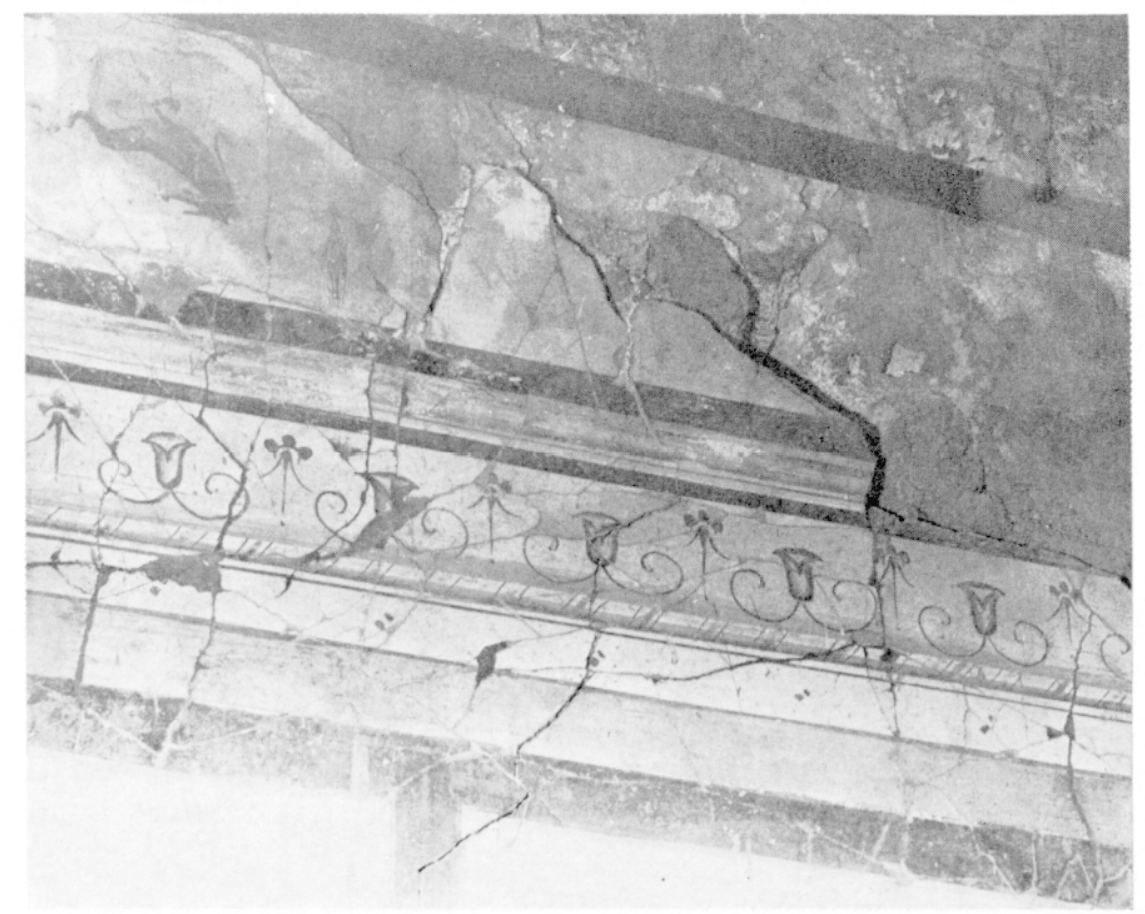


trouvée dans les fouilles du Clos de la Lombarde dans des remblais, montre une telle hampe à rubans, surmontée d'une tige épineuse à côté d'un fleuron à quatre pétales cordiformes et d'un dauphin dans une bande ornementale. Nous retrouverons le même fleuron de facture identique à Plassac ${ }^{27}$ (fig. 13). Quant au motif de hampe à rubans en hélice nous l'avons mentionné à Périgueux dans la cave Pinel et nous y avons recensé les exemples les plus connus ${ }^{28}$, qui appartiennent tous au dernier tiers du I ${ }^{\mathrm{er}} \mathrm{s}$. av. J.-G. et au premier tiers du $\mathrm{I}^{\mathrm{er}} \mathrm{s}$. ap. J.-C. Ajoutons que la hampe peut être hori\%ontale, comme une bordure de panneau ou de frise, ainsi dans la partie supérieure de la pièce 18 de la maison de Paquius Proculus à Pompéi $(\mathrm{I}, 7,1)$, en concordance avec une frise de lotus et de fleurons de $\mathrm{IIe}^{\mathrm{e}}$ style $^{29}$ (fig. 12).

Filets d'encadrement triples. Nous définissons de la manière suivante ce type d'encadrement: il consiste en deux filets blancs encadrant un filet sombre central, souvent bleu ou gris. Les filets sont d'ailleurs tellement fins parfois qu'il s'agil plutòt de traits inférieurs à $0,5 \mathrm{~cm}$ de largeur. Ce type d'encadrement est pour nous extrêmement utile à repérer car il est caractérislique des décors du IIIe style. On l'a rencontré à Lyon sur les peintures de la rue des Farges, du tout début de l'ère chrétienne ${ }^{30}$, puis à Vaison-la-Romaine, à Champlieu, de mème qu'à l'Ile sainte llarguerite (lles de Lérins) et sur bien d'autres documents provinciaux dont nous ne parlerons pas iri ( $c$ f. infra). Ils ont remplacé les filets simples en deux couleurs distinctes selon les còtés éclairés et non-éclairés des orthostates du IIe style et ils précèdent la mode des bordures ajourées des années 40-45) ap. J.-C.

Frises ornementales d'oves. La frise d'oves et fers-de-lance est employée durant tout le II style en guise de motif de moulure pour les corniches couronnant un podium ou un mur-cloison. Leur rendu est réaliste, dans des tonalités de beige, de brun et de jaune pour simuler un original sculpté ou du stuc moulé. Les ombres et les lumières sont alors traduites très soigneusement et aucun motif annexe ne vient se surimposer. A Roquelaure, au contraire, les oves sont ciselés d'un motif ourragé délicat, comme s'ils avaient été entourés d'un ruban brodé. Cependant l'aspect sculptural est sauvegardé gràce à un rendu du modelé des volumes par des ombres et des lumières simulées, qui proviendraient du côté droit. La présence de pseudo-caissons sur corbeaux plats renforce bien cette origine architecturale (fig. 2). Il n'y a pas d'équivalent de ce décor à notre connaissance. Le seul parallèle qu'on puisse tenter est d'identifier une mème transformation décorative, avec agrandissement d'échelle, par exemple sur les frises à perles et pirouettes, qui témoignent du mème esprit ornemental que celui qui a présidé à l'enrichissement des oves et fers-de-lance à Roquelaure ${ }^{31}$. Iin sculpture, la même tendance décorative se fait jour dans l'Auditorium de Mécéne à Rome, ou l'intérieur de l'ove est surchargé d'une palmette, tête en bas ${ }^{32}$.

Bordures de feuilles et de baies. L'idée de border un panneau par de loutes petiles feuilles régulièrement disposées comme des pois verts, à peine rehaussées de nervures blanches et alternant avec des fruits sur tige en $\mathrm{Y}$ minuscules, est un parti décoratif nouveau dont un équivalent peut être trouvé en Gaule, mais de rendu beaucoup plus naturaliste, nous le constaterons à Champlieu (figr. 32).

Masques fanlastiques, du lype lunaire. Notons que rien ne prouve que la tête fanlastique de Roquelaure appartienne au décor B ; elle devait plutòt orner un compartiment d'une autre composition, au choix parmi les panneaux remontés au musée et que nous n'examinerons pas. Ces masques

27 Ce fragment est étudié par M. Sabrié dans sa these de III e cycle, consacrée aux peintures de Narbonne. Nous la remercions de nous avoir autorisée à nous servir de cel exemple.

28 C. A. Barbet, La diffusion du III slyle pompéien en Gaule, dans fiallia, 40, 1982, p. 82, note 5i).

29 Cf. nouvelle numérotation dans P'illure e pavimenli di Pompei, publication de l'Islitulo Cenlrale per il Calalogo e la Documentazione, $1^{\text {re }}$ partie qui traite des régions I à III de Pompéi.

30 Barbet, op. cil., fig. 13.

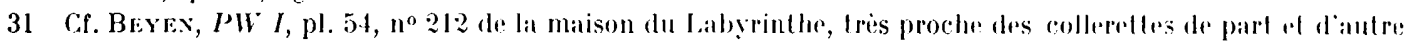
de perles sur des fragments inédits d'Ensérune.

32 Cf. Bastet-Dr: Vos, Terzo stile pompeiano, pl. L.X, 113. 


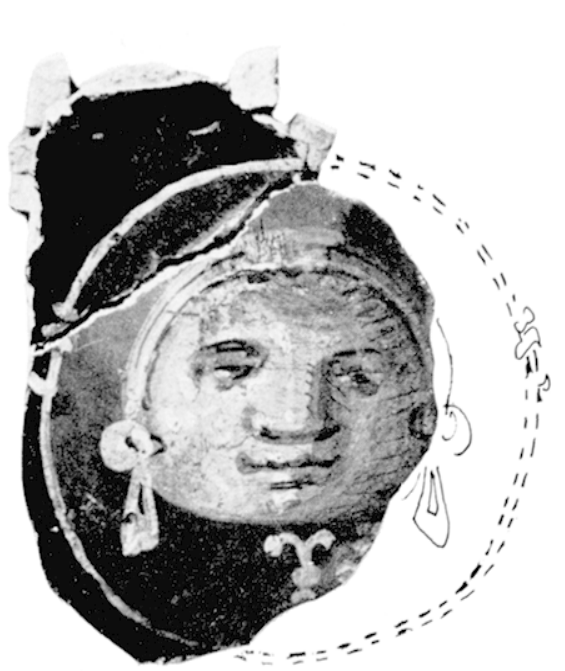

A
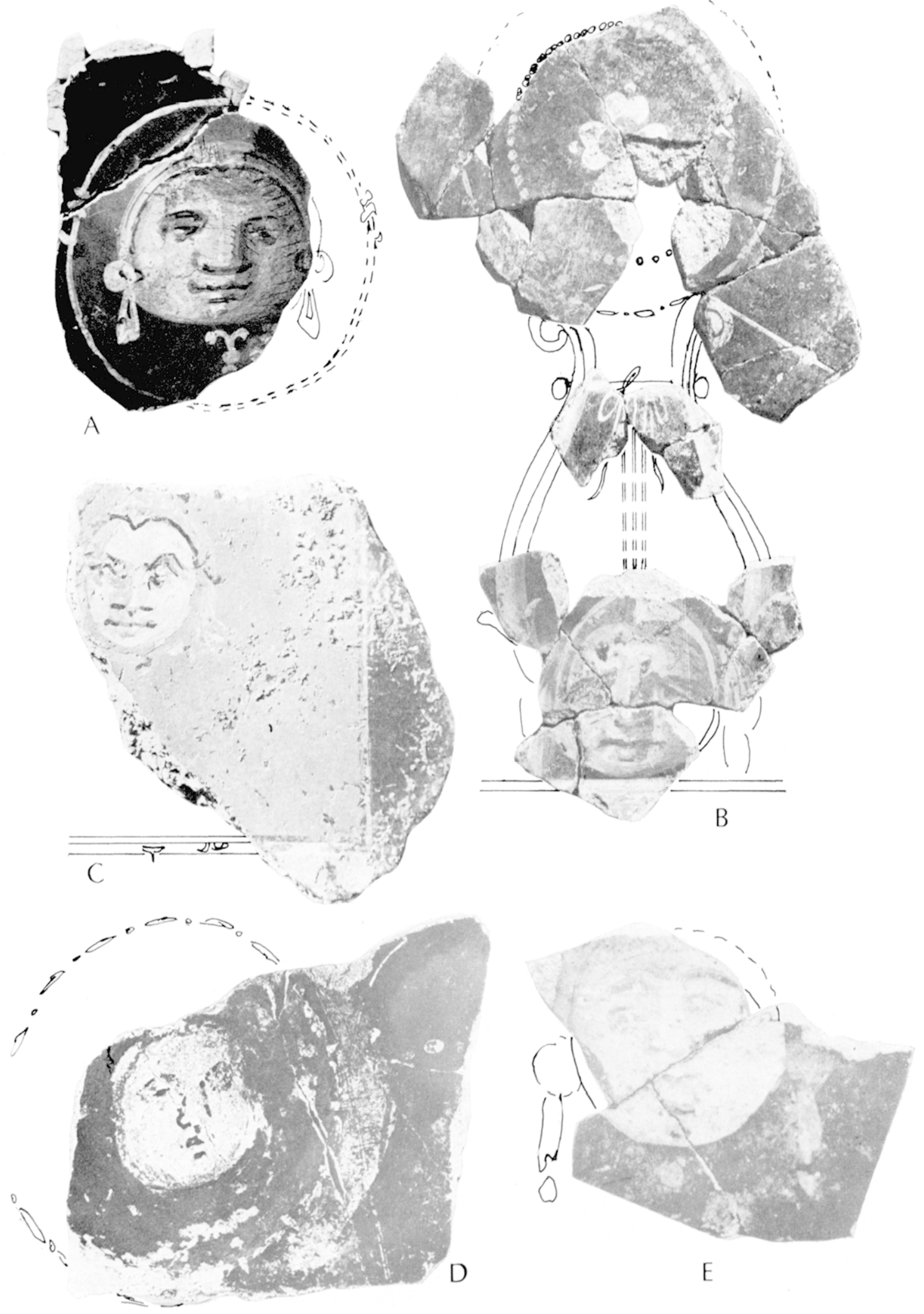

13 Masques lunaires en Camle : A, clermont-Ferrand; B, Plassac; c, Rorfuelaure; D, Port-sur-Saone; E, Lyon. Echelles diverses: 
se caractérisent par une tête toute ronde, sans cou et sans cheveux, à lia coiffure factice variable, éclairée comme par un éclairage lunaire violent, avec des touches de blanc très affirmées, d'ou l'expression "lunaire " choisie, qui ne fait pas allusion à la divinité elle-même. Citer tous les exemples connus serait fastidieux, car le motif est d'usage courant dans la peinture romaine italienne; il commence avec la vogue du $\mathrm{III}^{\mathrm{e}}$ style mais se maintient ensuite au IVe style $\mathrm{e}^{33}$. Si nous nous limilons aux exemples provinciaux, nous citerons un petit fragment trouvé place de l'abbé-Larue à Lyon, un décor reconstitué d'Avenches, et de beaux exemples de la villa romaine de Plassac dont il sera question ci-dessous. On doit aussi mentionner des inédits des réserves du Yusée de ClermontFerrand, et un fragment trouvé à Port-sur-Saòne ${ }^{34}$ (fig. 13). Très souvent le motif remplit un médaillon rond ou un autre cadre quadrangulaire de petite taille et sert à agrémenter une surface réduite.

\section{Dalation slylistique du décor $B$ de Roquelaure.}

Comme pour le décor A, l'armature générale est celle du IJe style finissant avec grand tableau mythologique encadré à la fois de candélabres et de pilastres auxquels s'attachent de lourdes guirlandes. La tendance au monochrome, avec choix du noir, est un aspect intéressant d'une mode qui s'est répandue à Pompéi durant le règne d'Auguste et même au-delà mais qui commence en même temps que le IIIe style. Il y a eu des précédents au IJe style, avec des pièces vertes, ocre jaune ou rouges, mais pas noires. Le répertoire ornemental est encore celui du JIe style mais déjà en cours de transformation.

Donc, sans examiner les décors plus fragmentaires issus des autres pièces, on peut déjà dire que deux peintures reconstituées de Roquelaure datent du dernier tiers du $\mathrm{I}^{\mathrm{er}}$ s. av. J.-C. Pour les autres pièces, les galons brodés de cours et points, semblables à ceux de Vienne et de Périgueux, les galons à lotus et à volutes, le motif de prédelle à jardin clos de la barrière en vannerie, ont pu être réalisés à la fin de la même période, lors de l'éclosion du III ${ }^{\mathrm{e}}$ style. On suppose la simultanéité de l'adoption des morles décoratives, entre l'Italie et la Gaule à l'époque d'Auguste. Roquelaure a dù être en chantier pendant une période d'une quinzaine d'années car on y voit des schémas du IIe style finissant à côté de nouvelles compositions du IIIe style.

\section{Plassac: (Gironde)}

Le dégagement d'une grande villa, en bordure de la Gironde, a surtout donné de magnifiques mosaïques tardives (fig. 28). Des sondages menés par J.-P. Bost et R. Monturet, et l'étude de la liaison des murs ont mis en évidence d'autres phases de construction, dont la plus ancienne est du ier s. ap. J.-C. C'est au cours d'un sondage de vérification en 1978 qu'ont été trouvés des débris nombreux d'enduits peints jetés dans une tranchée. L'étude et la recomposition des peintures ont été effectuées dans notre laboratoire de Soissons,

33 Les exemples les plus proches sont à chercher dans la maison de Lucrelius Fronlo à Pompéi, cf. BASTETDe Vos, ibid., pl. XXVIII à XXXII et sur le plafond des bains inédit de la maison de Fabius liufus linsula occidentalis).

34 Cf. A. AtDix, Le mur d'enceinte de Lugdunum, dans Bullelin des .Musées el Monumenls lyonnais, $1 \mathrm{~V}, 1967$ $1971, \mathrm{n}^{\circ}$ 1, p. 178, fig. 5. C.f. 1. Lenst, Informalions archéologiques, dans fiallia, XXII, 1963, p. 38?, fig. 10. Lne ricente visite à Clermont-Ferrand a confirmé l'importance de ces inedits : il y a au moins trois ensembles du IIle style dont un à plinthe avec thyrses inclinés, absolument semblables à ceux de Vienne, place Saint-l'ierre; cf. nolre article dans Gallia, 40, fig. 4, p. 59 . 
LA DHFUSION IU IIE STYLE POMPEALN LA G.AULE

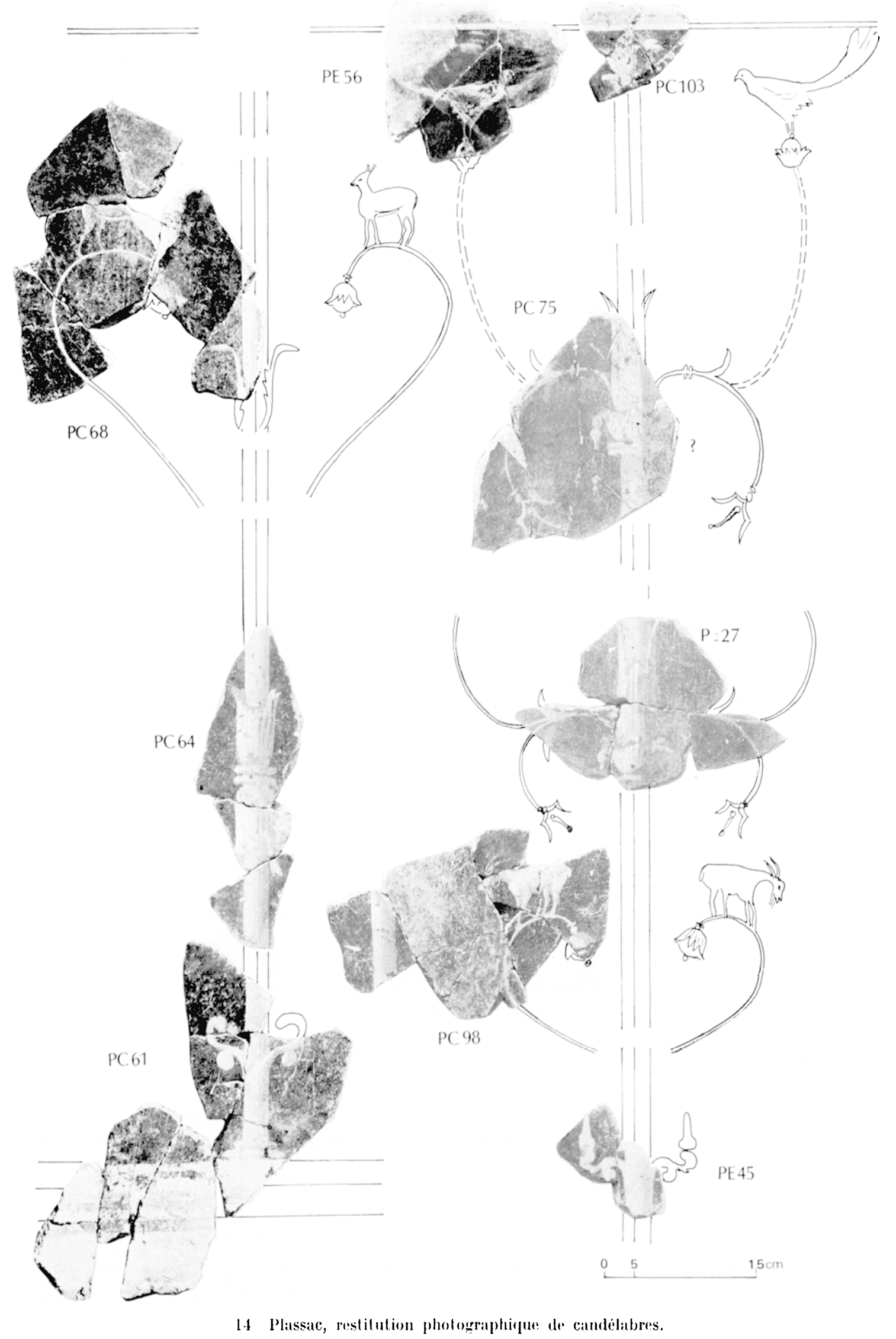


sous notre direction, par Mme Savarit-Dubbick, aidée par des étudiants. Nous en dirons seulement l'essentiel, dans l'optique du phénomène de relations artistiques que nous analysons, la publication complète étant imminente ${ }^{35}$.

\section{Eléments de dalation donnés par la fouille.}

D'après les formes de céramiques recueillies et les monnaies, une première villa A est attestée dans les années 40 à 60 ap. J.-C., pour laquelle la tranchée de fragments de peintures représenterait la phase de destruction. Le contenu de la tranchée est hétérogène malheureusement, car maintes fois remanié par des apports postérieurs. Ciependant, on peut fixer le premier remplissage avec les peintures aux débuts du $\mathrm{II}^{\mathrm{e}} \mathrm{s}$. environ, car la céramique la plus précoce est de la fin du $\mathrm{I}^{\mathrm{er}}$ et du début du $\mathrm{II}^{\mathrm{e}} \mathrm{s}^{36}$. Il s'agit donc d'un terminus ante quem pour les peintures qui sont forcément antérieures à la fin du $\mathrm{I}^{\mathrm{er}} \mathrm{s}$. Mais à quelle période du $\mathrm{I}^{\mathrm{er}}$ s. doit-on les rattacher ? Car si la villa A est du milieu du I $^{\mathrm{er}}$ s., il existe un état Is de la deuxième moitié.

\section{Restitution d'ensemble.}

C'est encore l'analyse stylistique des décors reconstitués qui va nous aider à préciser cette chronologie. Malgré la petitesse des fragments et la difficulté d'assembler les motifs, il a été possible de reconstituer les grandes lignes d'un décor quasiment monochrome à fond noir. Au-dessus d'une plinthe à imitations de marbres variés, le champ est divisé en grands panneaux au moyen de supports excessivement amincis et qui conservent assez mal les formes d'une base et d'un chapiteau de colonnes. Des filets verts encadrent les panneaux à l'intérieur, tandis que de magnifiques candélabres gris nervurés peuplent les inter-panneaux (fig. 14). Au-dessus, une corniche moulurée, bien imitée en trompe-l'xil, avec ombres et lumieres, clôt la partie moyenne. La zone supérieure, moins facile à reconstituer, montre une alternance de tableaux avec canards nageant et de masques fantastiques (fig. 13). Il y a également des médaillons enfermant des têtes de lléduse, des divinités masculines.

\section{Analyse des principaux molifs connuts.}

D'après cette brève description, on aura reconnu au passage certains thèmes repérés déja ailleurs. Ainsi le candélabre gris nervuré, sans ombelle, avec des tiges cordiformes, se rapproche étonnement de la facture des candélabres, également à fond noir, de Vienne-les-.Yymphéas ${ }^{37}$. Comme a Vienne il y a des oiseaux juchés sur de minces tiges ; s'y ajoutent des cervidés et des capridés. On comparera aussi avec les décors de Commugny où l'oiseau et la petite chère se retrouvent (fig. 29).

Les médaillons à décor perlé portant des têtes variées sont apparus au II ${ }^{\mathbf{e}}$ style mais ont continué avec succès plus tard. Néanmoins la facture trè̀s fine de la tête de léduse, dont la joue est délicatement croisillonnée comme l'anatomie du Dionysos de Roquelaure, la présence d'un perlage

35) Nous remercions .I. Gauthier d'avoir facilite les contacts of la collatoration avec l’équipe: de l'assac. Il me Savarit-Dubbick a soutenu un mémoire de maîtrise en juillel 1982 intitulé : Les peinlures murales de Plassac (Gironde) Essais de restilulion el d'interprétation. Cet ensemble sera public dans les dcles des Séminaires de LisienxBordeaux, 1983 ol présenté au Musée d'Aquitaine à Bordeaux, cf. Ia peinlure romaine en Gironde, Bordeaux 1983, catal. expo.

36 Cf. Mímoire de maîlrise de .1.-(). Savarit-l)ubbick, p. 33 el V. Gsirutre, Informalions archéologiques, dans Ciallia, 39, 1981, p. 480 .

37 C. A. Barmer, Découmerles archéologiques récenles à l゙ienne, dans .Momumenls et .Memoires, Fondation E. Piol, 64, 1981, 3 partic, fig. 36, pl. 11 ; In, La diffusion du II/e slyle pompéien en Gaule, Ire partie, dans Gallia, 40, 1982, p. 57, fig. 2 . 
raffiné, nous indiquent une haute époque. On pourra aussi effectuer des rapprochements avec le médaillon bien incomplet de llartizay ${ }^{38}$ associé aussi à un candélabre nervuré.

Nous avons déjà fail allusion au thème du masque dit "lunaire" présent ailleurs en peinture provinciale. L'originalité de ceux de Plassac réside en leur emploi en caisse de résonance d'une lyre, dont les branches sont bien perceptibles. Il existe à Pompéi, dans la maison de Lucrelius Fronto, une tète surmontée de deux branches auxquelles se raccorde une barre horizontale avec des rondelles jouant librement (fig. 15). Dans ce cas il s'agirait d'une sorte de sistre ${ }^{39}$. linfin, méme le petit vase enfermé dans un compartiment est présent, avec des nouds de ruban retombant de l'anse haute.

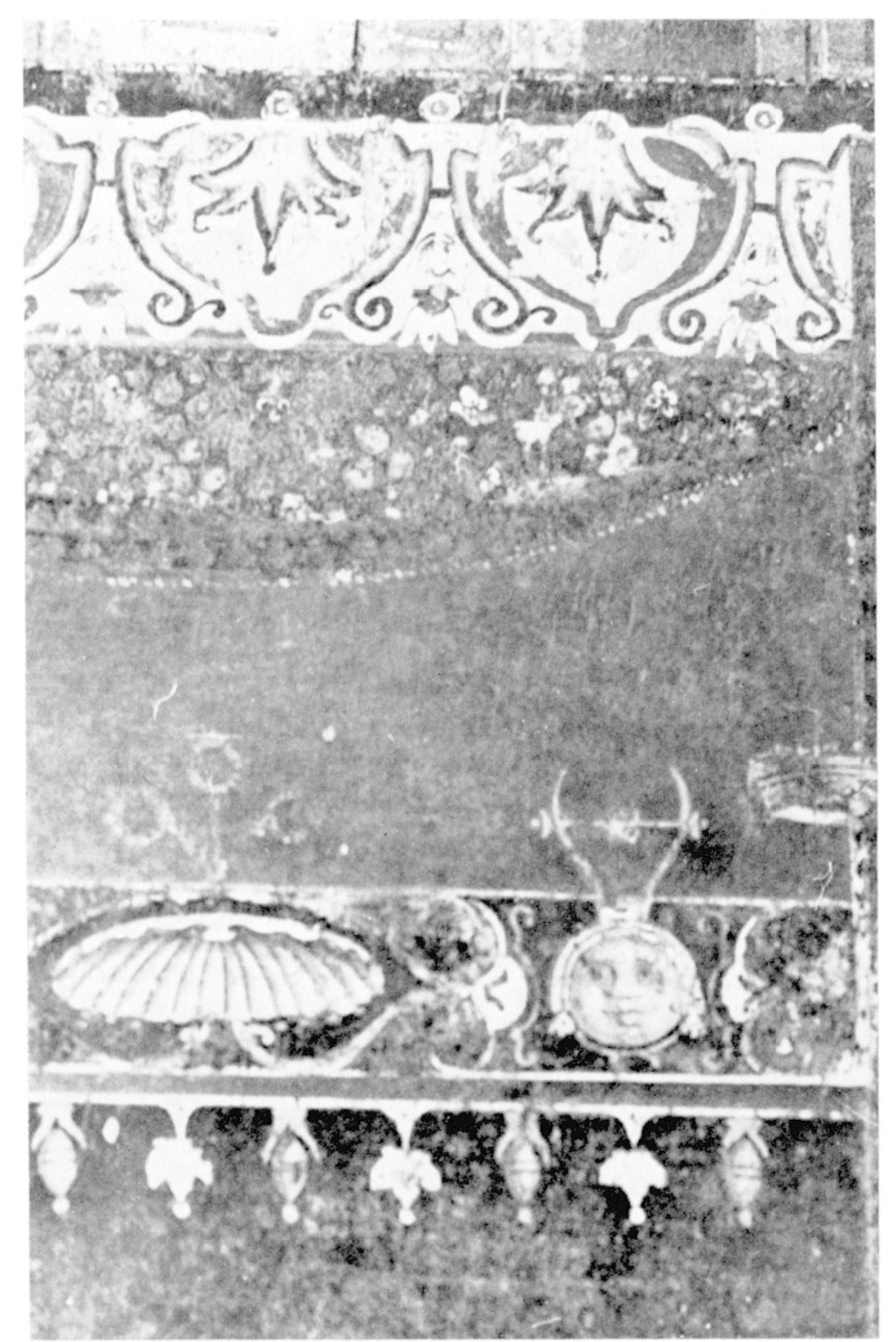

li Pompéi, maison de .Marcus Lucrelius fronto, détail du mur de droite du lablinum.

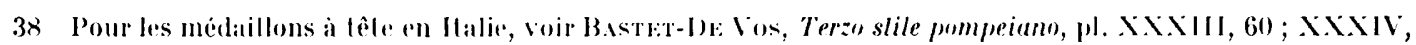

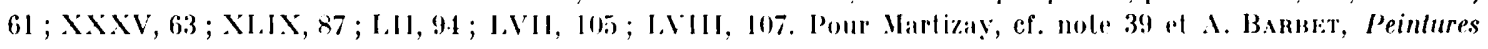

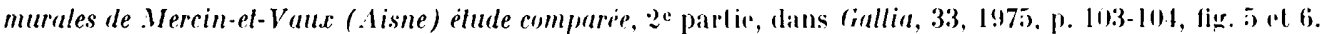

39 Cf. Bastret-De Vos, op. cil., pl. XXXII, 59. Nous remercions M. De Vos qui a mis fin a nos ultimes hesitations pour voir dans cette figure un instrument dr musique dont les cordes se confondent avec des nouds de rubans. 


\section{Datalion slylistique.}

Laissant de côté d'autres décors majeurs de Plassac, et résumant les caractéristiques de la facture, on reconnaîtra un haut niveau technique, une touche miniaturiste caractéristique du IIIe style. La date qu'on peut avancer serait alors l'époque augustéenne et à la rigueur le tout début du règne de Tibère, comme à Vienne, soit le premier tiers du $\mathrm{I}^{\mathrm{er}} \mathrm{s}$. ap. J.-C. Les relations qui se dessinent entre provinces de la Gaule sont encore trop ténues pour qu'on puisse retenir cette date. De plus on ne sait si les échanges se sont produits à l'intérieur de la Gaule ou encore par le canal de la Métropole. C'est toutefois une question qui pourra être posée, lorsque seront mieux connus les décors provinciaux. En résumé si le contexte de la fouille suggère une période d'implantation vers 40 à 60 ap. J.-C., l'analyse stylistique conduit à une période un peu plus précoce, qui paraît difficilement postérieure à $30-40$ ap. J.-C.

On aura noté les imitations de marbres en plinthe, qui sont un héritage direct du II e style et qui n'ont pas totalement disparu, comme nous l'avions écrit dans la première partie de ce travail; aussi bien à Magdalensberg, que sur des décors inédits de SaintRomain-en-Gal, au lieu-dit le Garon, les veinures diverses coexistent avec les mouchetures avant d'être remplacées dans une phase plus évoluée du IlJe style semble-t-il, par des compartiments géométriques ou figurés.

\section{Bordeaux (Gironde)}

Le creusement du sous-sol aux allées de Tourny de 1971 à 1972 en vue de la création d'un parking souterrain, a révélé tout un quartier de la ville antique, malheureusement détruit et englouti à nouveau. Des peintures murales en fragments ont été trouvées dans deux secteurs, les premières, qui nous intéressent, dans une fosse, les autres, dans une grande pièce d'un monument public, pavée d'une mosaïque tardive, et qui sont encore en cours d'étude ${ }^{40}$.

\section{Eléments de datation donnés par la fouille.}

Les débris contenus dans la fosse $\mathrm{n}^{0} 24$ avaient pour environnement un matériel rare, souvent informe et de toute façon mêlé, puisqu'un as fruste du Haut-Empire voisinait avec une pièce du $1^{\mathrm{e}} \mathrm{s}$. D'après le carnet de fouille, on reconnaît une fosse de fondation d'un mur avec deux couches distinctes, une supérieure de remploi avec ossements, près d'un sarcophage sur un niveau médiéval et une fosse proprement dite sous un lit de tuiles. Il n'est pas précisé si les peintures étaient dans le niveau le plus profond. L'occupation du secteur, d'après les trouvailles céramiques (amphores vinaires) remonte à l'époque augustéenne. On ne peut compter sur les seuls éléments fournis par la fouille pour proposer une datation à ces décors très raffinés ${ }^{41}$.

40 Les peintures de Bordeaux nous ont été confiées pour étude par .I. Gauthier, et nous avons été aidée d'abord par H. Froidefond, présente au moment de la fouille, puis par S. Campo, S. Casanave, M. O. Savarit-Dubbick, que nous remercions chaleureusement. Une publication plus complete de ces peintures est prévue dans les Actes des Séminaires de Lisieux-Bordeaux 1983. La restauration a été effecluée par nous-même, assistée par Magda Monraval ainsi que par d'autres étudiants et subventionnér par la ville de Bordeaux. Elles sont désormais exposées au Musée d'Aquitaine.

41 Ci. J. Colpry et M. Galtmer, Sauvelage archéologique à Bordeaux, dans Archeologia, n 47, juin 1972, p. 8-17. Reproduction en couleur p. 35; carnet de fonille du 3/8/71. 
Décors de la fosse $n^{0} 2 t$. Les peintures ont ité réparties en trois groupes dont le premier, le plus important, sera examiné ici. Il s'agil de trois compartiments qui devaient ìtre voisins, séparés les uns des autres par de courts candélabres couronnés de personnages en pied sur fond noir, et compris entre deux frises blanches a motifs ornementaux a base de lotus, de palmetles (?), de motifs en II retourné. Il y a une constante, la bordure interne est faite de traits de couleurs multiples et contrastés, la bordure externe est rouge vermillon dans deux cas et ocre jaune dans le troisième.

Compartiment $A$. C'est le plus riche du point de vue iconographique. sur un fond bleu de ciel qui s'assombrit vers le bas pour devenir ocre jaune, des silhouettes, esquissées de façon impressionniste, s'acheminent vraisemblablement vers un sanctuaire de plein air (fig. 16). Sur la droite, dans un chaos de rochers, on reconnaît une statue de Priape au pied de laquelle sont posées des ofirandes. Plus loin vers la gauche, deux autres personnages, lraités en silhouettes sombres, s'avancent vers un troisième qui est penché en avant. Au fond, deux ombres violettes, voilées, se dessinent, ailleurs les pattes d'un chien courant subsistent encore. Nous avons là un thìme de paysage idyllico-sacré caractéristique. Le compartiment est limité de part et d'autre par un champ noir vertical ; d'un court candélabre émerge une ombelle qui porte, à droite, un éphèbe nu, et, à qauche la partie inférieure d'une femme habillée jusqu'aux pieds. In dessous, une frise à fond blanc est ornée de lotus simplifiés, de II accostés de demi-disques retournés, d'un motif triangulaire à volutes que nous retrouverons sur les autres compartiments.

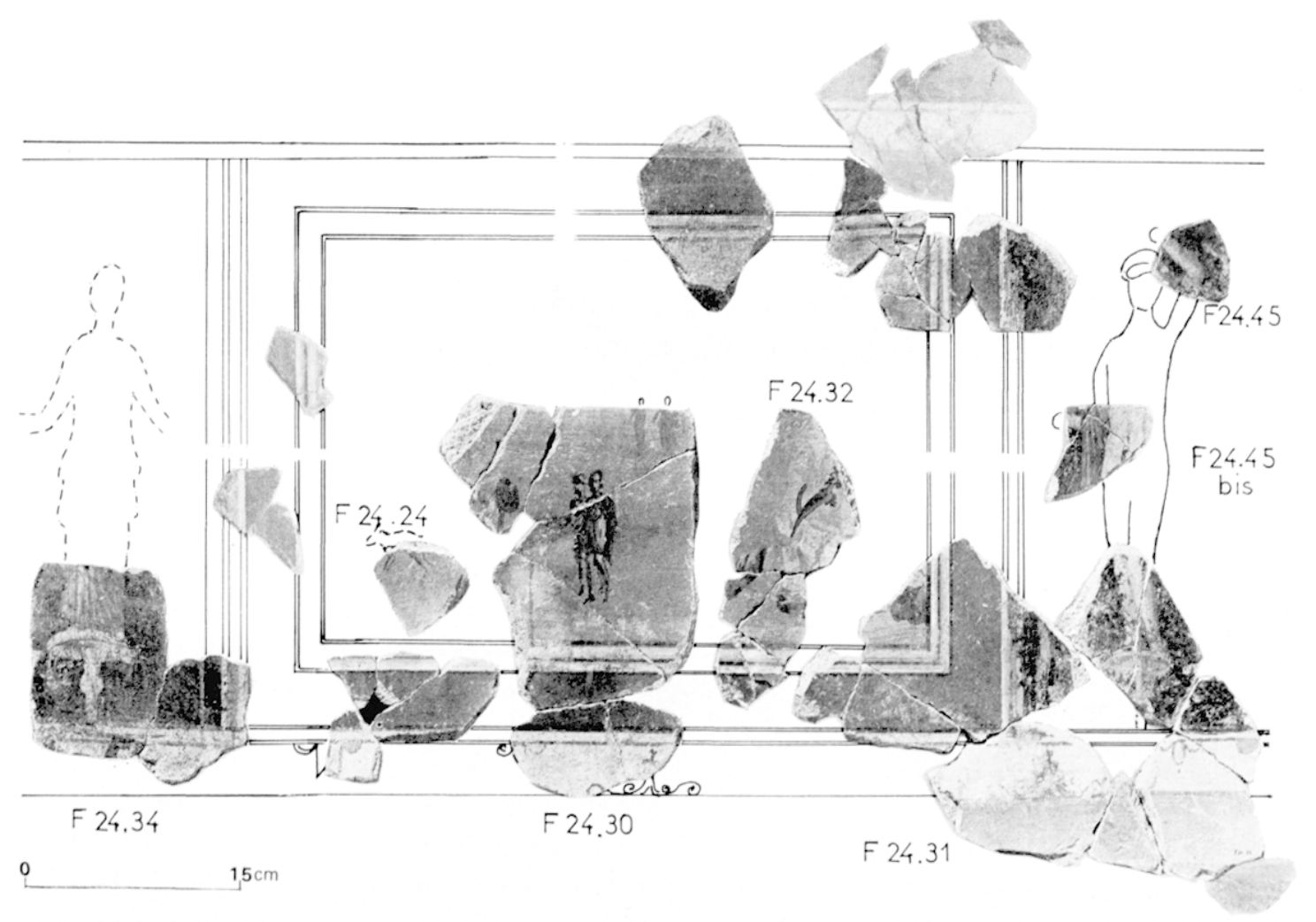

16 Bordeaux, Allees de Tourny, fosse no 2., compartiment A.

Compartiment B. Également entouré de bordures doubles identiques au compartiment $\mathrm{A}$, le sujet à l'intérieur du champ, uniformément ocre jaune, est plus simple. On devine le fond d'un objet rond, marron, sur une ligne de sol, que nous avons placé á grauche, sans doute un vase comme 
l'oenochoé brune, à lumierres vives el anse haute près d'une colonne tronquée qui a ćté placée à droite en raison des collagges opérés avec l'angle (fig. 17). La frise ornemenlale blanche horizonlale n'est conservée qu'en haut, mais elle nous donne lien toujours la mème carlence des trois molifs déja reconnus. Ln clamp noir incomplet se poursuil all-dessus.

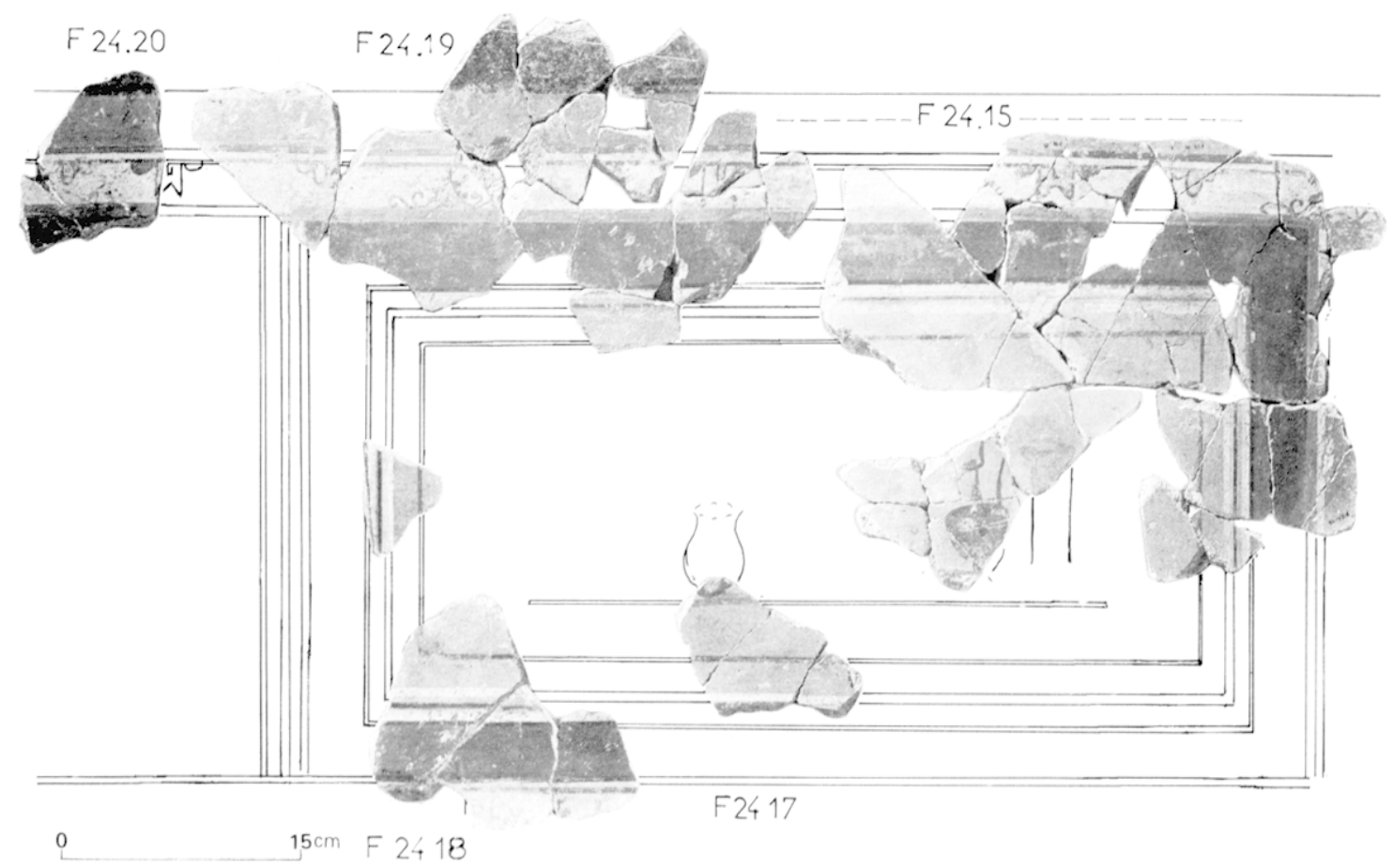

17 Bordeaux, Illees de Tourny, fosse no 24 , comparliment 13.

Compartimenl $C$. Il se distingue des deux précédents par une inversion des couleurs. Celle fois-ri le fond est rouge vermillon, assombri par l'oxydation, el le pourtour de la bordure externe ocre jaune, tandis que la bordure interne est toujours un jeu de traits de couleurs contrastées blanc, jaune et brun (fig. 18). Un support d'objet métallique sur une base de pierre est conservé (F 24.28) sur lequel on distingue deux des griffes du trépied supposé. Nous l'avons mis en relation avec un vase à verser bleuté, à anse garnie à l'altache d'une palmelle sculptée. Silleurs devait prendre place un oiseau sur le bord d'un vase, qui pourrait être une vasque ou un canthare. Les mímes frises ornementales a fond blanc encadrent le petit tableau qui posside un trait d'encadrement inlérieur, comme le panneau B, mais jaune au lieu d’ètre brun. Cne particularité nous intéresse : au-dessus, deux bordures existent, une premiire verte un peu bombée et qui cache le joint de mortier d'une journée de travail, une deuxième au-dessus, noire, aver des aspérités sur le bord supérieur. qui correspondent. à l'emplacement d'une moulure en stur, dont des débris sont encore adhérents. Cet indice est précieux pour retrouver l'emplacement d'origine sur la paroi.

\section{Reslilution graphique.}

Elle se réduit à l'existence d'une suite de petits compartiments proches d'une moulure en sture et du joint de mortier d'une journée de travail. (iràce à ces observations lechniques el aux sujets représentés, on peut imaginer leur place juste au-dessus des panneaux principaux d'une zone 
moyenne. Il faut restituer sur res panneaux médians des candélabres très minces, dont le sommet dépassait la limile supérieure de la zone 2 pour s'achever en début de zone :3, comme il est courant à Pompéi, ainsi que nous le verrons.

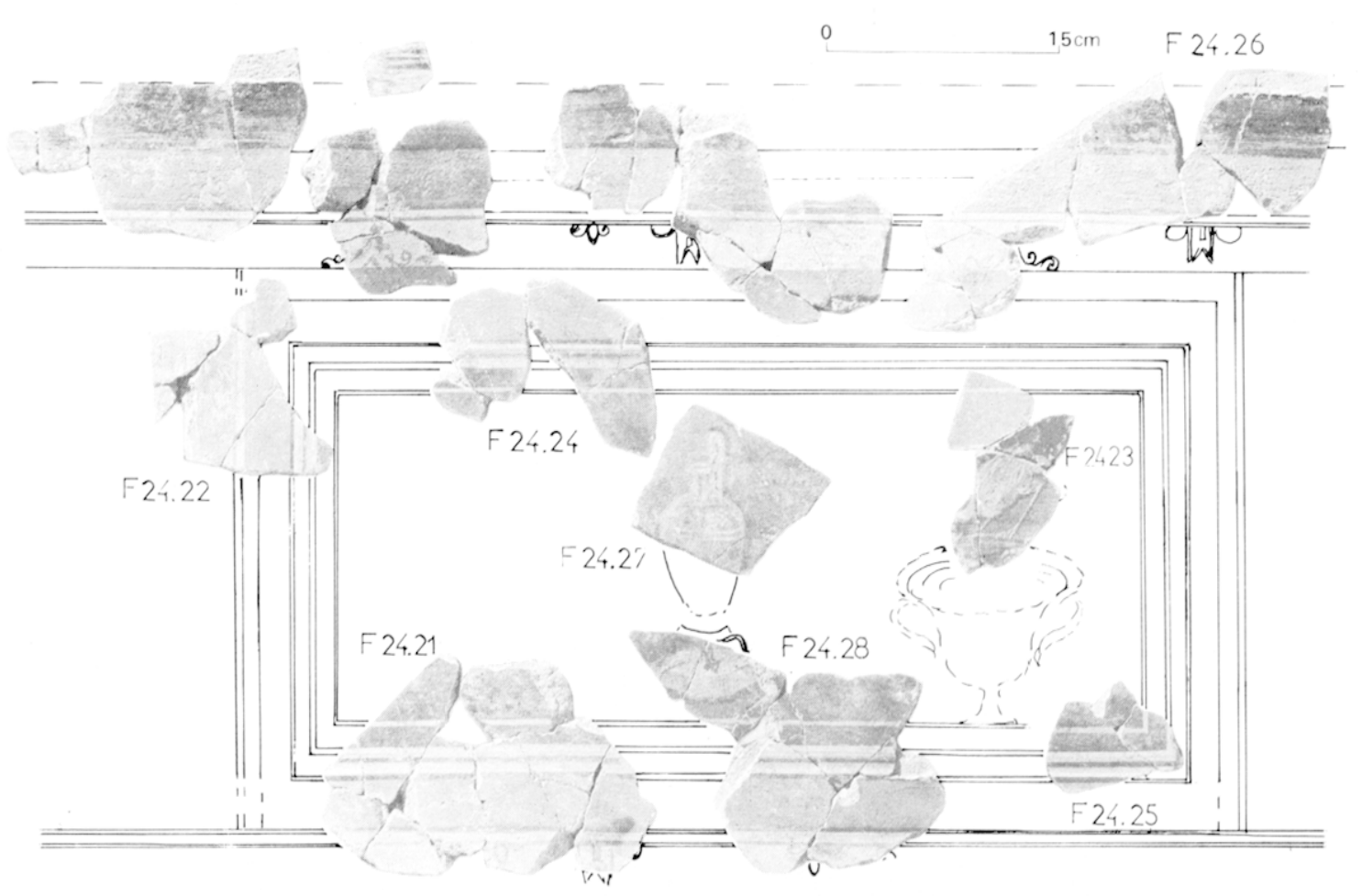

18 Bordenux, Allees de Tourny, fosse no 24 , compartiment $c$.

\section{Élude slylistique.}

Ce qui frappe une fois de plus dans ce déeor, limité mais cohérent, c'est l'emploi de formules décoratives typiques dans une facture toujours miniaturiste et soignée. On jugera du coup de pinceau du décorateur de la scène idyllico-sacrée d'après la reproduction en coulcur qui en a paru (cf. n. 41). Les premiers plans sont plus sombres, les lointains aérés et clairs pour donner un effet de profondeur. Les détails des ciselures des vases sont donnés, ainsi que les plis des vêtements de la femme sur le candélabre, malgré l'échelle toute menue. Les points de comparaisons sont nouveaux par rapport à la série étudiée jusqu'ici en Gaule.

Paysages idyllico-sacrés. Bien qu'il en manque une grande parlie, c'est-i-dire toute la moilié gauche, où devait se trouver un sanctuaire, les signnes distinctifs du thème sont bien lisibles, avec, à droite du sancluaire principal, un lieu d'adoration à Priape au milieu des rochers. La vogue en est très ancienne ; le paysage apparaît à grande échelle, à la fin du II e style, dans ces grandes fenêtres ouvertes au milieu des parois ; ensuite, il est transformé a petite échelle dans des vues panoramiques a multiples personnages qui s'animent au milieu de constructions diverses et se perpétue au IIIe style, dans des petits tableaux ${ }^{42}$. 
Des exemples célèbres de la villa d'A grippa I'oslume à Boscotrecase viennent à l'esprit, mais il faut parcourir le musée de Naples, pour en voir d'autres, où toujours les mêmes édifices, les mêmes silhouettes se répètent accompagnés d'animaux, le plus souvent des chèvres gardées par un berger. Le thème est apprécié également au IVe style, comme le démontre un fragment inédit d'une maison de l'Insula Occidentalis à Pompéi : le compartiment est un rectangle très allongé, avec des volets repliés qui ont été simulés sur les còtés ; Priape occupe une position dominante en haut d'un rocher et, au bas, s'agitent de petites silhouettes autour de plusieurs sanctuaires.

Candélabres à ombelles el à figures entre deux zones. C'est là un détail de l'ornementation du III ${ }^{\mathrm{e}}$ style déjà relevé à propos de la villa Impériale et pour le IIIe style précoce, qui s'inspire directement du style-candélabre né dans les années 20 av. J.-C.43. Plus tard le candélabre reste dans les limites de la zone moyenne qu'il encadre, alors qu'au début de l'évolution et pendant le IIIe style, c'est un trait d'union entre zone 2 et zone 3, comme ici à Bordeaux peut-être (fig. 19).

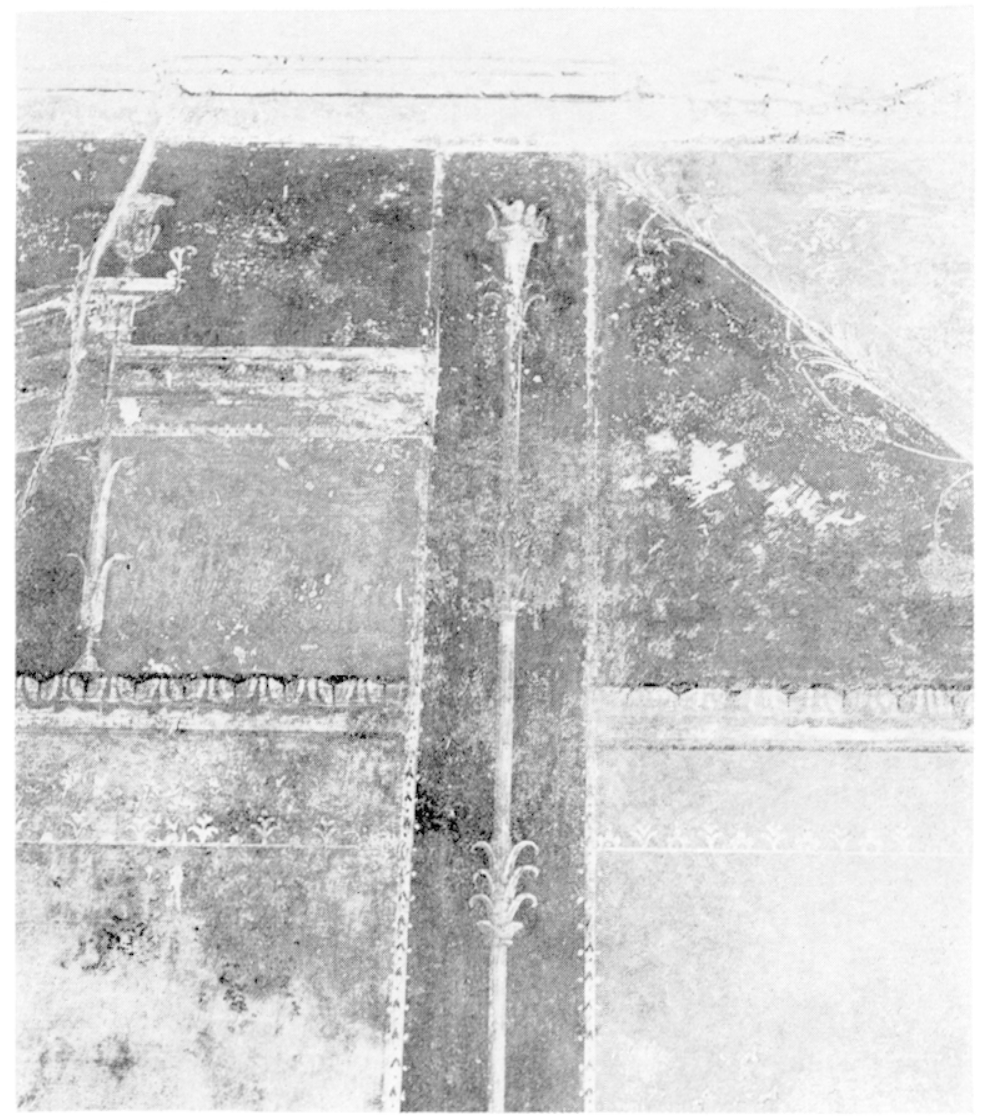

19 Pompéi, maison du .liroir, cecus, mur de droitr.

I.XVII, 1977, p. 1-16. L'auteur examine les paysages de la fin de la République dont il reconnaît les caractères principaux : petits batiments éparpillés à différents niveaux par réduction d'échelle et changements d'atmosphère, détails pittoresques apportés par des silhouettes diverses, attribués à Studius; cf. pl. V, 3, stucs de la Farnésine oủ apparaît un hermès de Priape.

43 Les principaux décors qui utilisent ce dessin du style-candélabre visibles à la Farnésine et dans la Caserne des Gladiateurs sont tous du III style, cf. BAsteT-IJE Vos, pl. VII, I1; XIV, 25; XXX, 56 ; XLI, 73; les exemples avec figures humaines sont constants. 
A Pompéi les ombelles sont rares, au IIIe style comme au IVe. L'exemple donné ici de la maison du Miroir, de III style mûr, présente plusieurs caractères intéressants : candélabre montant en zone 3 . galon brodé, tige séparant deux zones de couleur.

Les vases décorés. Nous avons déjả parlé de cette vogue des natures-mortes avec vases, dans des petits compartiments, en milieu de panneau ou en compartiments placés en zone 3 , immédiatement au-dessus de la zone moyenne. On citera le cubiculum $\mathrm{C}$ de la maison des Ceii à Pompéi $(\mathrm{I}, 6,15)$, surtout danミ la maison d'Orphée, le triclinium 1 (VI, 14, 20), mêlé à des masques, de même l'édifice d'Eumachie (VII, 9, 1), où le compartiment au-dessus d'un panneau médian est encadré par des candélabres montants qui dépassent la zone 2 . On retrouve aussi dans ce décor pompéien la frise ornementale à fond clair, mais d'un seul còtét4.

Pour les vases posés en vignette, librement dans le champ, parmi les plus beaux exemples, on retiendra celui de la chambre rouge de la villa des. Mystìres, dans le quartier refait en II ${ }^{e}$ style $^{45}$. Tous ces vases présentent une caractéristique commune, ils sont luisants, et imitent une vaisselle d'or ou d'argent, parfois de bronze, lorsque le fond n'est ni or ni bleuté mais verdàtre ou cuivré ; ils sont toujours très fins et de petite taille.

Frises ornementales. En l'absence d'un vocabulaire descriptif adéquat, on rappellera succinctement l'existence de lotus d'un type voisin un peu partout à Pompéi ; de même l'ornement en II renversé ou droit, plus ou moins agrémenté de courbes annexes est fréquent. Enfin le triangle orné de petites barbelures et qui se prolongent en volutes fait songer à des ornements plus ramassés en verticale dans la maison des Ceii $(\mathrm{I}, 6,15)^{46}$.

D'après l'éventail des comparaisons qui couvre la période précoce et de plein épanouissement du IIIe style, une datation de la fin de l'époque d'Auguste et du début du règne de Tibère devrait convenir (fig. 20). Les éléments de galon brodé à cœeurs et points très simples, dont nous n'avons pas encore parlé et qui proviennent du groupe III, ne contredisent pas cette chronologie établie par comparaison.

\section{Ile Sainte-Marguerite (Iles de Lérins) (Alpes-Maritimes)}

Il est pour l'instant impossible de décrire longuement les décors qui ont été retrouvés par G. Vindry (fig. 21). En effet, l'étude et la reconstitution ont été entravées par le manque de locaux. F. Monier et A. Barbet sont chargées respectivement de la restauration et de l'étude des vestiges. Nous y ferons allusion brièvement, car on y a reconnu quelques-uns des sujets nouveaux apparus en Gironde, à Plassac et à Bordeaux ${ }^{47}$.

Un thème nous retiendra c'est celui du tableautin à fond bleu, à bordure de traits de plusieurs couleurs el sur lequel se détachent deux personnages ; l'un dans le coin supérieur gauche tient une lance et parait debout, l'autre à droite semble assis sur un rocher cubique et tient un sceptre (?) (fig. 21). Scène historique à petits personnages, sans nul doute, cet exemple vient enrichir notre connaissance d'une série très rare jusqu'ici en Gaule.

44 I!id., pl. XXV; XVIII ; LV, 99 ; pl. XIII.

45 Cf. Bastet-De Vos, Terzo slile pompeiano, p. $56-57$.

46 Ibid., spécialement pl. LVI, 103 ; voir aussi pl. XVI, XVII, XVIII, XX, XXIV, XXV, XXVII, XXVIII, XXX a XXXVI, XL, XI.I, XLIV à XIVII, XLIX, L, LVII.

47 Rapports daclylographies, 1975 par S. Pannoux qui identifie sept groupes différents ; 1976 par A. Barbet et $F$. Monier qui affinent ces identifications et précisent l'existence d'une niche peinte d'une coquille ; 1977 par F. Monier qui décrit le groupe à fond vert d'eau avec slatuettes peintes, natures-mortes avec vases, architectures et stucs. Le travail est quasiment interrompu depuis 1978 . 

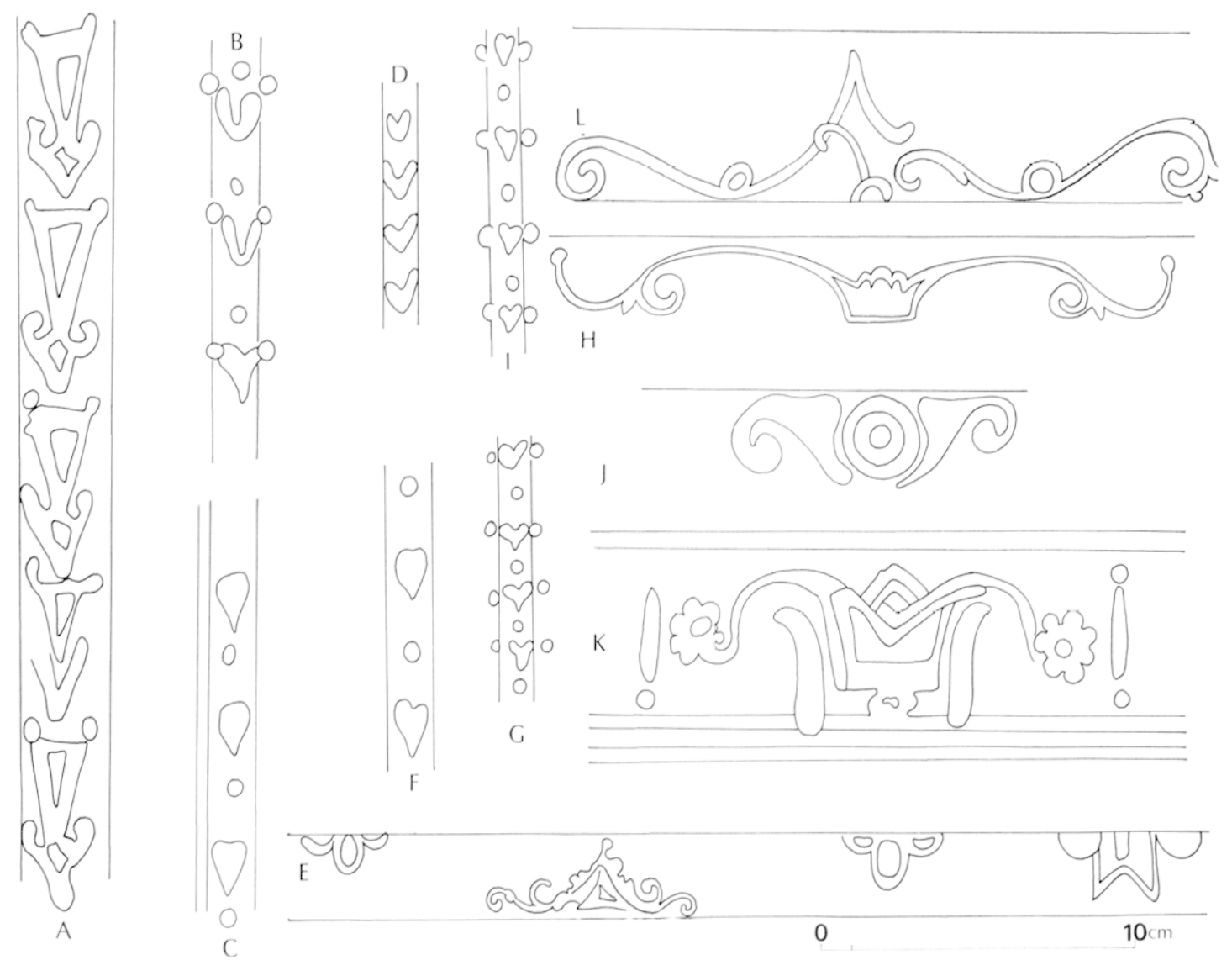

20 A à C : Rorquelaure ; I), E : Bordeaux ; F : Champlieu ; G, II : Périgueux ; I, J : Vienne ; K : Ribemont ; L : Neury-Pailloux.

Un autre sujet intéressant pour nous est celui de la nature morte avec supports et vases de formes diverses, exécutée toujours de façon miniaturiste très soignée el, celte fois-ci sur un lumineux fond vert émeraude parfaitement lissé. On ne sait si les oljets étaient encadrés ou flottant comme une vignette au milieu d'un panneau.

Il existe bien d'autres éléments mais les deux que nous venons d'analyser, avec leur facture typique, ne laissent aucun doute sur l'époque où la peinture entière à laquelle ils appartenaient a été exécutée. Notons que les cryptoportiques retrouvés sous la citadelle ont été assignés au règne d'Auguste et l'on peut proposer la même date pour notre décor ${ }^{48}$.

\section{Vaison-la-Romaine (Vaucluse)}

Lors des fouilles pratiquées autour de la cathédrale, dans un terrain menacé par la construction d'un parking, une nouvelle zone d'habitat a été mise en évidence par B. Liou

48 Cf. C. Goldixac, Informations archénlogiques, dans (iallia, 35, 1977, p. 505-507, fig. 19, qui précise l'existence de niveaux pré-augustéens en sondage profond, eux-mèmes mièx définis depuis : ibid., dans Gallia, 39, 1981 , p. 543. 


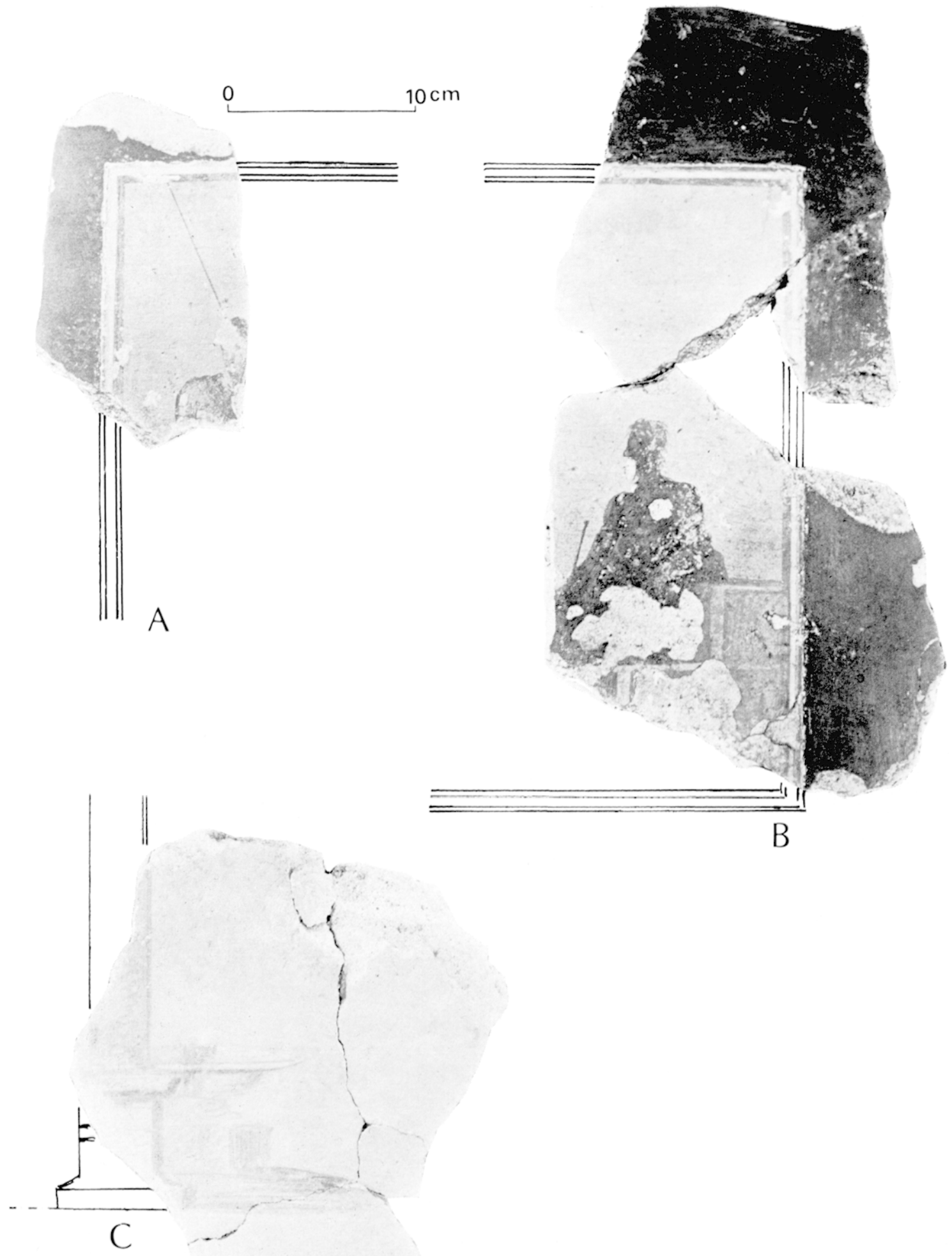

21 Ile Sainte-Marguerite, décors ichelles diverses!. 
(fig. 29). L'abondance des fragments de peinture a nécessité plusieurs campagnes de ramassage; les premiers nettoyages sont prometteurs. Là aussi, faute de place, les remontages ont été arrêtés, mais nous pouvons déjà en proposer une première analyse ${ }^{49}$.

\section{Éléments fournis par les fouilles.}

Deux états ont été reconnus : le premier d'époque augustéenne, dont les constructions en petit appareil ont été remplacées par des structures à l'appareil moins soigné du milieu du $\mathrm{I}^{\mathrm{er}} \mathrm{s}$. ap. J.-C. Les peintures ont été trouvées dans des pièces conservées en demi sous-sol, sur $2 \mathrm{~m}$ de haut et déjà enduites de blanc. Les décors proviennent donc de l'étage au-dessus ou d'ailleurs, et, au plus tard, du deuxième état du milieu du I $^{\mathrm{er}} \mathrm{s} .^{50}$.

\section{Restitution d'ensemble.}

Un podium de $86,5 \mathrm{~cm}$ de haut a pu être remonté ; il est à imitations de moulures et d'écailles bichromes à fond bleu vert. Dessus reposent des colonnes, dont l'une a été recomposée, à fût finement nervuré de cannelures polychromes. Sur la partie inférieure du fût vient se juxtaposer une prédelle à fond noir où un jardin enclos de barrières d'osier tressé sera en partie reconstituable (fig. 29). Sur le côté gauche de la même colonne, un grand panneau rouge ocre porte une figure ailée. Ce panneau est limité par les filets triples, caractéristiques : deux traits bleus encadrent un filet blanc.

Il y avait plusieurs figures volantes et donc plusieurs panneaux rouges. Nous ont été conservés un génie masculin ailé, portant un vase doré dans la main droite et une palme dans la main gauche, la figure et une partie du torse d'une jeune femme aux cheveux clairs, ramenant un voile au-dessus de sa tête ${ }^{51}$ (fig. 22).

\section{Analyse slylistique.}

Elle sera brève, puisque le dossier devra être complètement repris, lorsque la reconstitution aura été poursuivic et achevée. Certains thèmes nous sont connus et d'autres sont nouveaux. Parmi les anciens motifs il y a l'encadrement par des filets triples, qui ont la particularité de dépasser dans les angles pour former une croix ponctuée de boules pour chaque branche. Des traits fins parallèles aux triples filets en partent de chaque côté. La ressemblance avec un agencement quasiment identique à Lyon, rue des Farges, est frappante y compris les petites boules aux extrémités et à quelque distance des deux branches, qui sont légèrement pattées à Lyon ${ }^{52}$.

Podium à écailles. Si le motif des écailles bichromes nous est familier sur des colonnes, il est plus rare en partie basse de paroi, à moins qu'il faille l'interpréter comme une claustra à écailles,

49 Les travaux ont été suivis par S. Pannoux, I. Reddé-Gabard, A. Kaufmann, Y. Roumegoux, et F. BartaudGalliou au début, continués par Y. Roumegoux et F. Galliou, avec l'aide de A. Barbet, C. Allag, A. Le Bot-IIelly et E. Deniaux.

50 Cr. B. Liou. Fouilles dans la région de la calhédrale, dans $I X^{\mathrm{c}}$ congrès de l'Union Internalionale des Sciences Prèhistoriques et Protohisloriques, Nice, 1976, p. 143-145.

51 Cf. F. Salviat. Informations archéologiques, dans Gallia, 35, 1977, p. 534, fig. 25.

52 Voir fig. 13, première partie de cet article dans Gullia, 10, 1982, p. 67. 

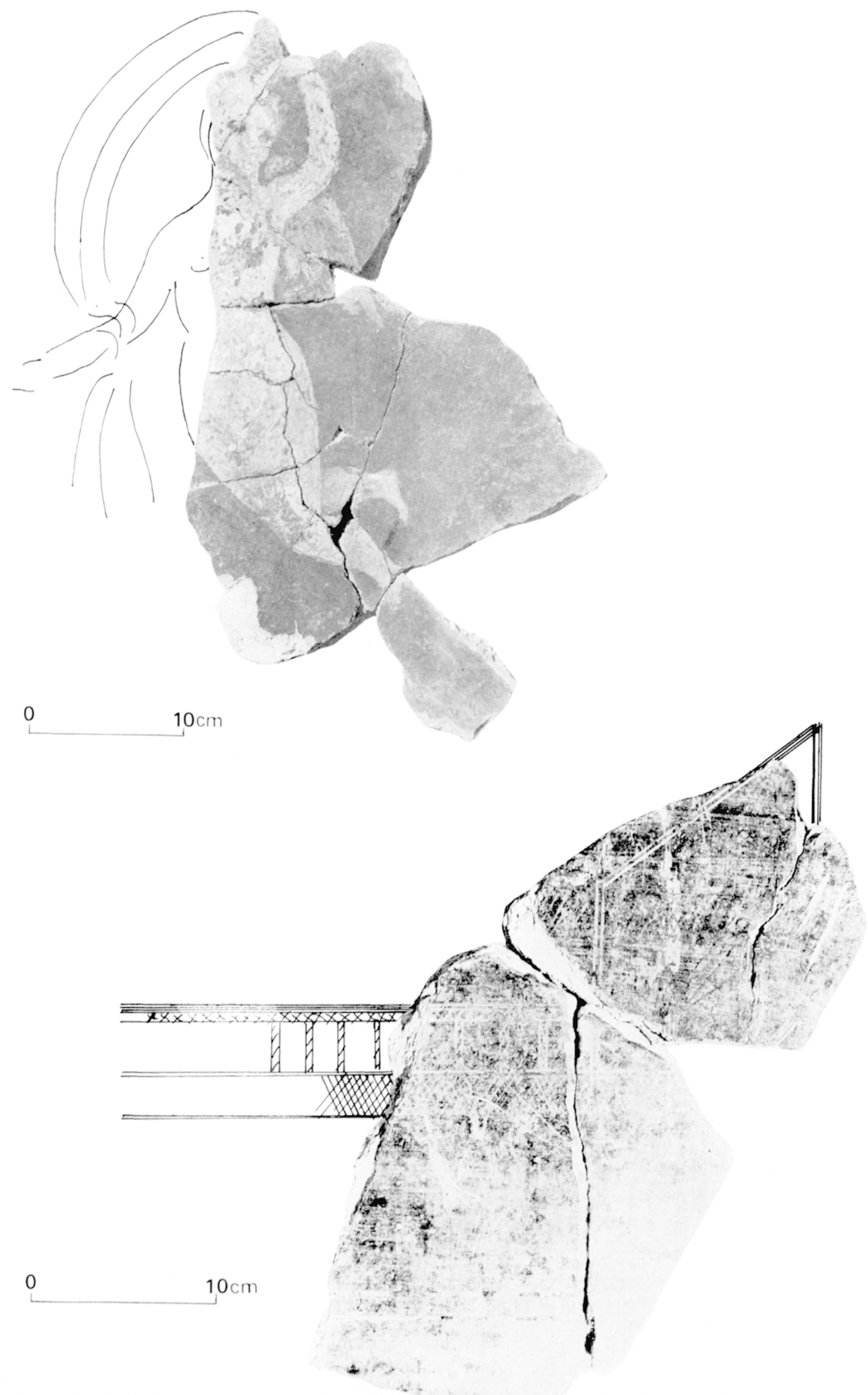

22 Vaison-la-Romaine, fouille près de la cathédrale, figure volante et hortus conclusus. 
comme celle qui figure sur le podium de la maison des Griffons sur le Palatin ${ }^{53}$. Une transcription un peu de même facture est à noter sur la clòture réelle de l'amphithéâtre de Pompéi, dont des gravures du $x_{1 X}{ }^{e}$ s. nous restituent l'image ${ }^{54}$. Pour l'instant l'exemple de Vaison reste à notre connaissance unique en Giaule.

Colonne à cannelures mullicolores. Le rendu décoratif des cannelures par un jeu de traits colorés contrastés, qui ne vise pas à un rendu réaliste, est typique sur certains décors pompéiens du IIIe style, comme sur la très belle colonne conservée au Musée National de Naples et de provenance inconnue ${ }^{55}$. Des bagues décoratives enrichissent le fût, comme à Vaison où elles ne sont pas complètes.

Prédelles noires avec jardins enclos. Nous y avons fait allusion déjà pour des motifs perdus dans les décors des panneaux I el III de Roquelaure. C'est un schéma très reconnaissable, avec un jeu de lignes de fuite qu'il faut restituer comme des panneaux en saillants et en rentrants; ils sont faits d'un matériau léger de vannerie, dont les croisillons fins, rendus en traits jaunes, évoquent l'osier. Il y en a de beaux exemples à Pompéi, dans la maison du Citariste (I, 4, 5-25) dans la pièce dite des Ménades, dans la maison d'Lipidius Sabinus (IX, 1, 22) dans la pièce $t^{\prime}$, dans l'Auditorium de lécène a Rome, dans la maison d'Orphée (VI, 14, 20), dans celle de Lucrelius Fronto (V, 4, 11), la seule peinture qui nous soit parvenue en bon état, ou encore dans la maison de Syurius .Mesor (VII, 3, 29). $A$ chaque fois l'enceinte du jardin est un quadrilatère donné en vue cavalière, avec, en général, un hémicycle dans la clôture du premier-plan, encadré par deux exèdres quadrangulaires ${ }^{56}$. La prédelle est toujours comprise entre le podium et la zone moyenne. Le décor a été utilisé au centre d'un panneau de zone 2, sur une peinture de la maison de Cérès $(I, 9,13)$. Dans la maison du Verger le thème a été repris à une grande échelle, mais toujours entre zone basse et zone moyenne ${ }^{57}$.

Le sujet a été rarement identifié dans les collections de musćes français, car il est nécessaire de s'en référer à la peinture italienne pour le comprendre lorsqu'il est fragmentaire. C'est ainsi qu'il est passé inaperçu à Roquelaure et sur un petit. fragment exposé à l'envers au musée de Limoges (inédit) ${ }^{58}$ (fig. 2:3). Il est vraisemblable qu'il a existé à Martizay, d'après deux fragments retrouvés. C'est un motif de prédilection des peintres de l'époque augustéenne qui est, pour nous, un excellent fil conducteur.

Figures ailées. On a oublié que la mode des figures ailées au milieu de panneaux de zone 2 a été introduite au IIIe style tellement elle est fréquente au IVe style. Elle est excessivement précoce puisqu'elle apparaît dans la pyramide de Caius Ceslius à Rome, datée par une inscription dans les années précédant 12 av. J.-G. Il suffira de feuilleter le répertoire de Bastet et de Vos pour se convaincre de l'abondance du thème au $11 l^{\mathrm{e}}$ style ${ }^{59}$.

La peinture de Vaison-la-Romaine, trouvée près de la cathédrale, appartient au IIIe style pompéien, mais sa facture est médiocre. Pour proposer une date plus précise, on attendra li confirmation donnée par l'analyse des éléments complets du décor et ceux du

53 Cf. G. E. Razo. Le pilture della casa dei grifi, dans . Ionumenti dello Piltura antica scoperti in Italia, Rome, 1936. I. I. 1.

51 C. G. Niccolsix, Le case ed i monumenli di Pompei disegnali e descritli, Naples, 1854-1891, vol. III, pi. 111.

55 Cf. BastrT-1)E Vos, Terzo slile pompeiano, pl. XXXVIII, 69.

56 Ibid., fig. $1 / 2,11,12$, pl. XXV, 47 ; XXX, 56 ; XLVII, 84. Voir également le tableau synoptique p. 135.

57 Pour M. De Vos, le jardin clos est typique oe l'époque augustéenne et il est utilisé d'abord en socle, puis en prédelle et en dernier all centre du panneau, ef. De Vos, Casa di Cerere, p. 194; cf. eganalement fig. 15 et pl. XXXVIII, 70 .

58 Trouvailles rue du clos-chatudron à limoges, ef. Informations archéologiques, dans Giallia, 23, 1965, p. $383-38.4$.

59 Cf. Bısтют-[): Vos, Terzo stile pompeiano, lableau svnoplique p. 135, qui prouve l'utilisation du thème dess la phase la dans la maison du Cithariste à Pompéi, pl. XIII, 23; XXIN, 46 ; XXV1, 48 ; XXXV, 64; XXXIX, 7I; XLJII, 76 ; LVII, 105; LVIII, 106. 


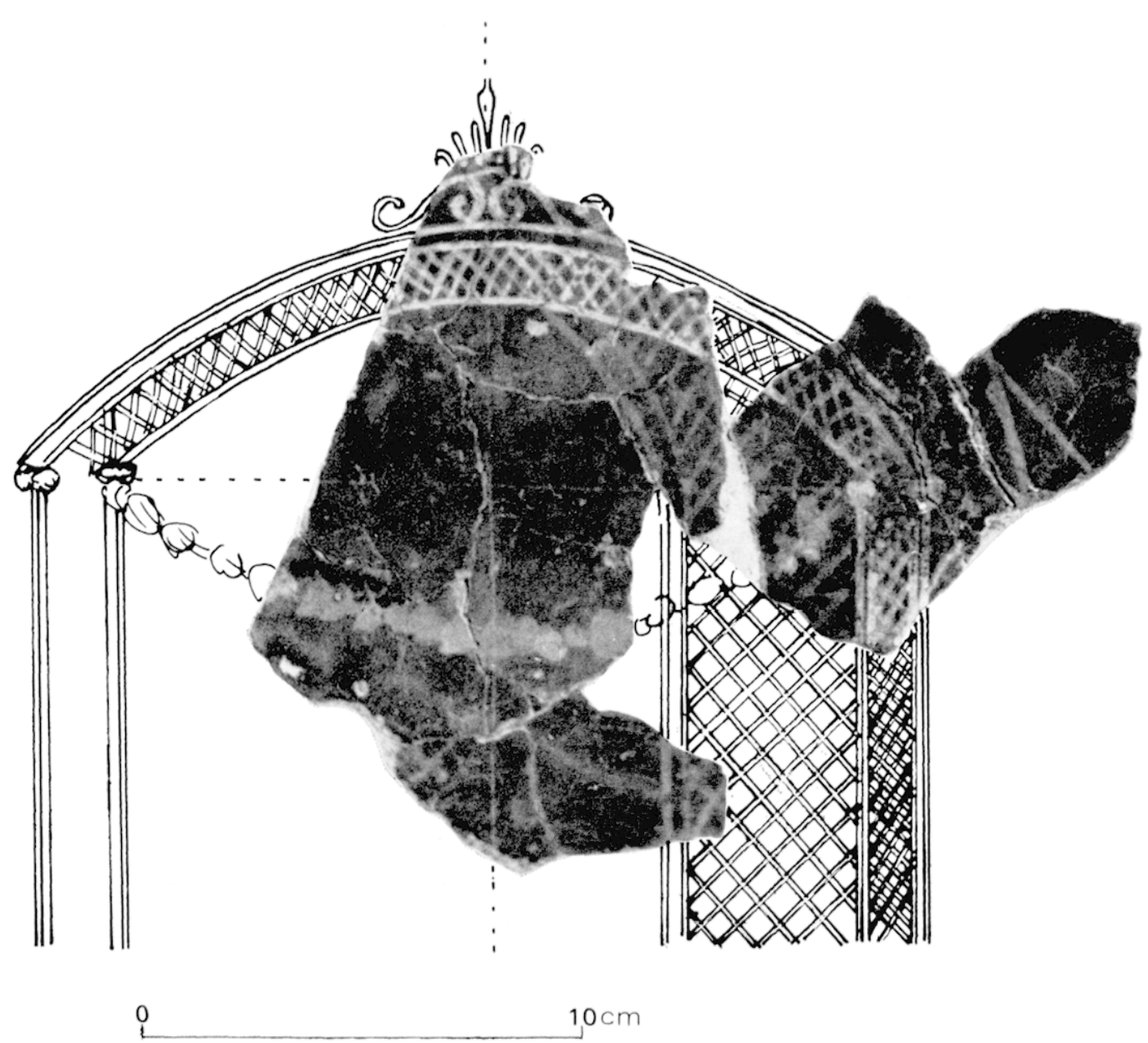

23 Limoges, rue du Clos-chaudron, une tonnelle de jardin reconstituée.

matériel archéologique trowé en même temps, qui doit se relier aux structures mises au jour. Sous réserve d'analyse plus approfondie, un peu avant 40 ap. J.-C. semblerait une date ultime.

Si nous quittons le Sud de la Gaule, où traditionnellement les influences romaines ont èté les plus précoces et peut-être les plus profondes, retrouverons-nous des exemples de décoration du IIIe style ailleurs? Pour le Centre de la Gaule cela ne fait aucun doute si l'on se rappelle les décors du IIe style schématique et de IIIe style retrouvés à Martizay.

\section{MARTIZAY (Indre)}

Dans la pré-publication, effectuée lors de l'étude des peintures de Mercin-et-Vaux, nous avions souligné la présence d'un niveau augustéen à Martizay et d'un niveau postérieur, du début du II ${ }^{\mathrm{e}}$ s. (fig. 29). Nous avions conclu à des motifs du IIIe style ${ }^{60}$. Après une étude

60 Cf. A. Barbl:t, Les peinlures romaines de Marlizay (saint-Romain), dans Cahiers historiques de Marlizay, $n^{\circ} 9,19 \times 1$, fig. 19. p. 2:2. 
des possibilités de restitutions graphiques et en fonction du répertoire de ce style en Gaule, qui s'est mieux défini petit à petit, nous avons bien affaire à des décors du premier tiers du ${ }^{\text {er }}$ s. ap. J.-C. (fig. 24). On y retrouve le type de candélabre qui a précédé la mode de celui à ombelles à teinte verte dominante, plus simplifié, de la deuxième moitić du ${ }^{\mathrm{er}} \mathrm{s}$ ap. J.-C., les masques "lunaires", mais entourés de feuilles, et les oiseaux à huppe identiques à celui de Champlieu6 ${ }^{61}$ Comme à Plassac, le médaillon perlé à tête est appuyé contre un encadrement horizontal mais peut-être supérieur.

La touche miniaturiste, particulièrement sur les excroissances du candélabre, où de délicats violets et roses sont employés, est encore un trait de facture typique de cette haute époque.

\section{Le Vert (Chizé, Deux-Sèvres)}

Toujours dans cette région centrale de la Gaule, C. Allag avait déjà étudié les décors très brisés d'un établissement dont les éléments de datation restent imprécis ${ }^{62}$. Il y a, dans la restitution graphique tentée, une plinthe mouchetée comme à Lyon, Vienne, SaintRomain-en-Gal, Magdalensberg et Roquelaure; des panneaux noirs avec filets d'encadrement intérieur triple, un noir entre deux bleus. Un petit tableau enferme une tête, comme aux Bolards-Nuits-Saint-Georges, dont il sera question ci-après (fig. 29). Des motifs décoratifs à cercles et pois, ou à petits carrés décorés, servent de bandes de passage; on identifie les restes d'un candélabre à ombelles associées à des oiseaux. C. Allag propose la période entre 15 et 30 ap. J.-C., qui semble une date acceptable.

\section{Neuvy-Pailloux (Villesaison, Indre)}

Une trouvaille faite au $\mathrm{xI}^{\mathrm{c}} \mathrm{s}$., d'une particulière importance, ne doit pas être négligée, il s'agit du tombeau peint de Neuvy-Pailloux; une très bonne relation illustrée nous en a conservé la mémoire ${ }^{63}$. L'intérêt du document vient aussi du fait qu'il se trouvait dans le milieu clos d'une tombe, dont le matériel a été rlessiné et qui se trouve en partie au Nusée du Louvre. J. Santrot et F. Baratte ont bien voulu me donner leur avis sur ce matériel (fig. 25, 26).

\section{Eléments de datation.}

Ils comprennent quelques objets datables dont : une fibule en bronze du type pseudoLa Tène II (Lerat I, B, 3, Etlinger 3) de la période Tibère-Claude, une estampille SALV(eti) sur assiette Drag. 17 (ou 15/17 ?) utilisée par deux potiers, l'un à Yontans entre 40 et 70 et l'autre à la Graufesenque entre 40 et 80 , soit durant une période qui va de Claude à

61 Ibid., fig. 31 avec tableau comparatif des oiseanx à huppe. Pour la justification de la restitulion graphique nous renvoyons à ce cahier. Certains fragments de peinture sont expesés à la Mairie de Martizay.

62 C. Allag, B. Debien et .I. Ré, L'élabiissement gallo-romain du Verl, dans Bullelin de la Sociélé historique el scienlifique des Deux-Sìves, VII, 1974 nos $2-3$ p. 193-214.

63 Thabaud de Linetiére, Essai sur l'origine lu tombeau gaulois on gallo-romain de Neuvy-Pailoux, précédé du rapport de M. des Méloizes, dans Monuments historiques du départemeni dẹ l'Indre, Châteauroux, $184 \vdots$. 


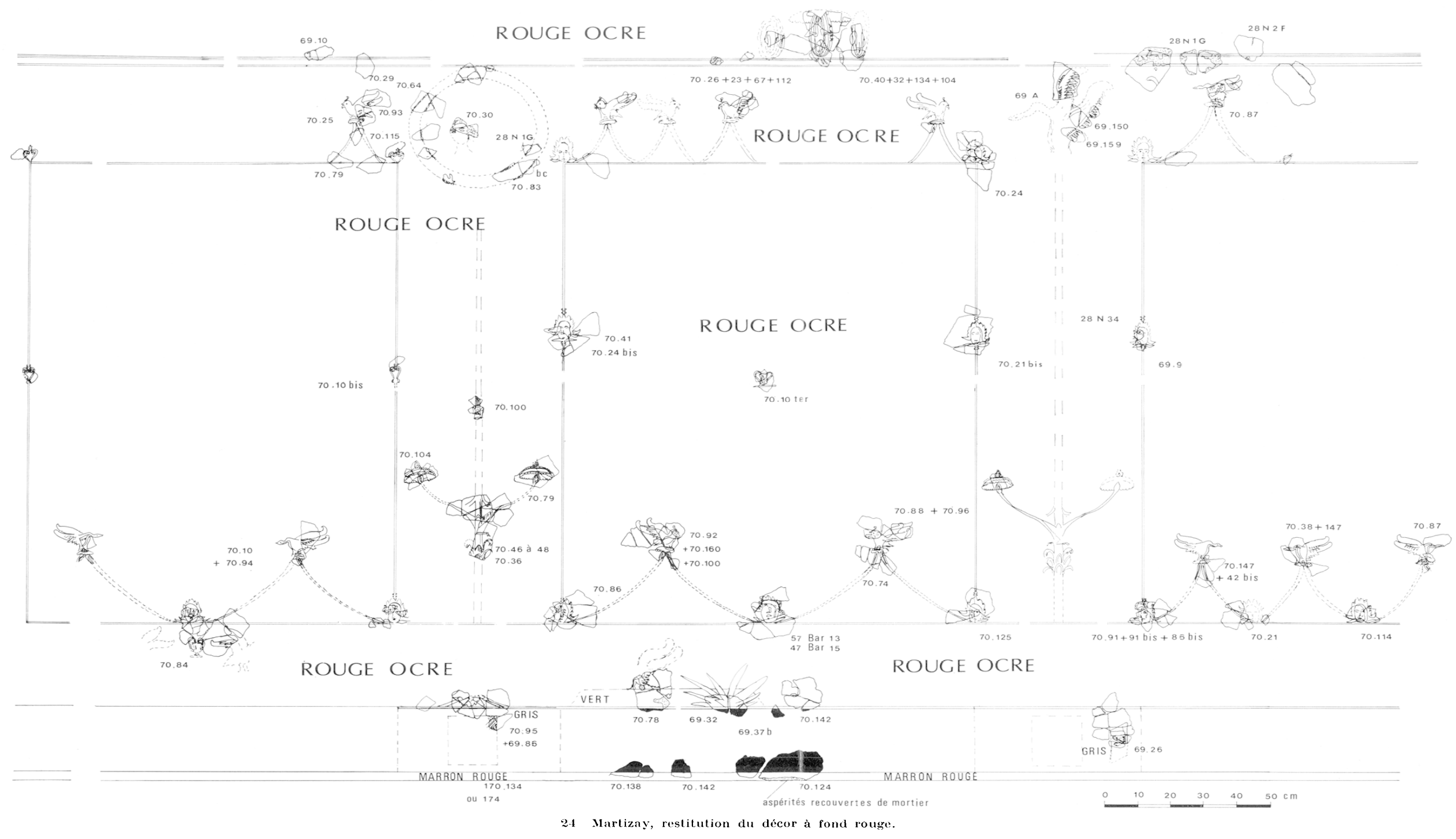


Vespasien. Lne autre estampille, $\mathrm{ACV}(\mathrm{ti})$ sur fond de sigillée, là aussi datable de Tibère à Vespasien. Un fragment de céramique à paroi fine à décor guilloché à la roulette appartient à une production de la période Auguste-Claude, jamais postérieure à Claude semble-t-il ${ }^{64}$.

Une datation des dernières années du règne de Tibère et du règne de Claude semble correcte; le mobilier est homogène car $\mathrm{F}$. Baratte et $\mathrm{S}$. Tassinari consultés confirment la possibilité d'une datation au $\mathrm{I}^{\mathrm{er}} \mathrm{s}$. pour la vaisselle de bronzc. Récemment l'identification de ce monument à un tombeau a été remise en cause, bien que la description du couloir d'accès en pente, et de la pièce soient conformes aux aménagements habituels. Cela n'influe pas sur nos conclusions.

\section{Le décor.}

Sur les murs de la tombe, le décor en place comprenait une sous-plinthe nue, grise, et une plinthe occupée par des touffes de feuillages verts variés, de formes parfois inhabituelles. Lne pseudo-moulure, sans doute à fond clair, portant des motifs décoratifs en noir et bleu, dont le calice à lotus prolongé par des volutes (?) est d'un rendu assez maladroit (fig. 25, 26). Les panneaux médians à fond noir, trois par mur, étaient séparés les uns des autres par des candélabres très simples, sur fond rouge, avec seulement un ornement de feuillages retombant au centre, et un couronnement par une sorte d'ombelle ornée de trois boules. Au sommet, courait une pseudo-corniche en blanc, gris et noir. Au milieu des panneaux, comme une vignette, divers oiseaux en marron clair ètaient disposés.

Sur la planche II de l'ouvrage on reconnait une ligne de sol horizontale avec des échassiers côtoyant un petit édifice et une grappe de cerises, manifestement rendus à des échelles différentes (fig. 25). Alors que l'édifice est plus petit que l'échassier et couronné d'antéfixes en forme d'oenochoés trop grandes pour lui, les cerises sont trop volumineuses et presque égales à l'échassier voisin. Il y avait aussi, sans doute sur un autre mur, un perroquet et un autre volatile près de feuillages et de fruits, disposés sur une ligne de sol.

\section{Analyse slylistique.}

On remarquera une certaine simplicité, voire une sévérité, en accord avec le lieu assez étroit; il y a également des bizarreries, des maladresses, dont on ne sait si on doit les attribuer au peintre ou à l'auteur de la gravure. Il en est ainsi de la zone basse.

Feuillages en plinthe. Nous avons eu déjà l'occasion, à propos des peintures de Vienne-LesNymphéas, de donner l'origine des touffes de feuillages employées en plinthe dès les premiers décors du IIIe style $^{65}$. Nous les verrons, mais de forme plus classique, à Champlieu. Ici il semble qu'on ait voulu reproduire des petits arbres, tous différents par leurs silhouettes générales et par la forme du

64 IRapport dactylographié de J. Santrot du 22 avril 1982, qui fait référence aux pl. IV, fig. 17 et V, fig. 4, 5, 6. L'après ces mêmes planches F. Baratte conservateur du Musée du Louvre, par une lettre manuscrite du 31 mai 1982 a pu réidentifier les bronzes qui sont entrés dans les collections du Louvre Jl apporte d'autres précisions par sa lettre dactylographiée du 28 septembre de la même année : "Dans le dossier d'archives $\$ 416$ avril 1857 une lettre des Meloizes offre de céder les objets trouvés en 1844 à Neuvy-Pailloux dont huit fragments de peintures, le plus grand représente sur fond noir des hérons semblant sortir d'un petit édifice Comme les autres objets mentionnés dans la liste sont bien entrés dans les collections dı Louvre, les peintures ont dủ âlre détachées el données également maais on en n'a pas retrouvé la trace,

65 C.. A. Barbot, loc. cit., dans .Monumenls el Memuires, Fondation E. Piot, 64, 1981, p. 53, oì nous distinguons deux types, l'un à feuilles ondulées, l'autre à feuilles droites et acéries. 

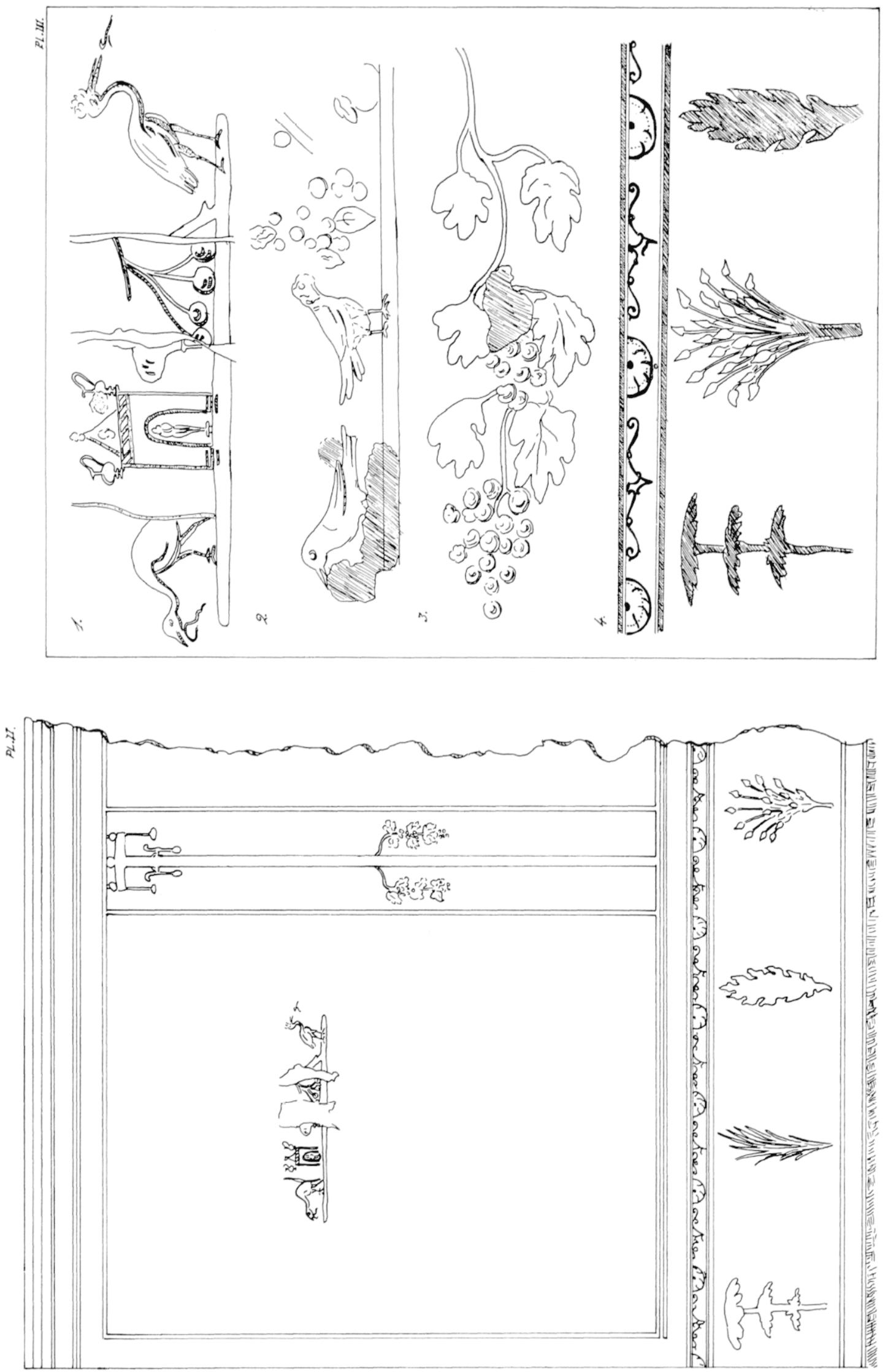

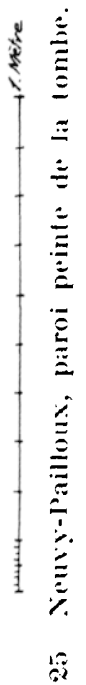


feuillage. L'étrangeté du style peut ètre due à une mauvaise interprétation de l'illustrateur qui, cependant, aurait bien vu les sujets des vignettes moins effacées que les autres sans doute.

Frise ornementale. Elle est, elle aussi, d'un rendu maladroit : l'exécutant aurait mal copié, ou trop vite, des triangles a volutes comme ceux de Bordeaux, et des palmettes dans un demi-cercle? Quoiqu'il en soit, le motif est bien à sa place et bien connu, ainsi que nous l'avons vu à plusieurs reprises en Gaule.

Vignelles en milien de panneau. L'emploi du fond noir est un indice intéressant, de même ces petites natures-mortes placées dans le tiers supérieur du panneau. Il y a dans la maison d'Auguste sur le Palatin, dans une pièce secondaire à fond blanc, un perroquet tout à fait semblable, prêt à picorer des baies (inédit). Yous connaissons, par ailleurs, le succès des petits échassiers dans des décors du II le style et leur emploi abondant a Périqueux, dans le décor de la cave Pinel, nous l'a montré6.

Des différences d'ateliers sont perceptibles dans la place donnée à ces natures-mortes à oiseaux. Dans les villes campaniennes on préfère le plus souvent les placer en prédelle, ou dans des compartiments symétriques aux prédelles, au-dessus des panneaux de la zone moyenne. Toujours la ligne de sol figure, ainsi que des touffes de feuillages, des fruits divers à une échelle souvent démesurée par rapport aux oiseaux, qui sont à peine plus gros. L'originalité du petit édifice à vases en couronnement est indéniable à Neuvy-Pailloux.

Candélabres. Celui dont l'image nous a été conservée se réfère à la série précoce du IIIe style, semble-t-il, où le fût est laissé nu avec un couronnement inspiré d'un modèle métallique. Cependant il s'intègre à la zone moyenne et ne se prolonge pas en partie supérieure.

Grâce au matériel enfoui dans la tombe décorée, dont le style est lui aussi très explicite, l'époque de Claude ou de Tibère est certaine. Le décor peut-il être légèrement antéricur au mobilier enfoui avec le mort ? Le tombeau et la peinture ont-ils été réalisés bien avant le jour de l'enfouissement? Dans l'état actuel de notre perception du IIIe style en Gaule, on ne peut se prononcer, mais le schéma employé est typique du premier tiers du Ier s. ap. J.-G. Nous avons là un des rares repères daté indiscutablement, qui conforte bien la diffusion du III style dans le Centre de la Gaule avant le milieu du er $^{\text {e }}$ s. ap. J.-C. L'examen de ce document oblige done à rouvrir des dossiers pour lesquels les discussions autour de la chronologie étaient restées ardentes.

\section{Le Monument d’Úcuetis, Alésia (Côte d'Or)}

La reconsidération du décor du monument d'Lcuetis disparu, dont seules des aquarelles nous ont conservé l'image, nous pousse à proposer la première moitié du $\mathrm{I}^{\mathrm{er}} \mathrm{s}$. ap. J.-C. en concordance avec la date d'édification première de la salle, sur le mur de laquelle ces plaques avaient été trourées ${ }^{67}$. Le vocabulaire décoratif identifié est celui du II Ie style, avec compartiments géométriques semblables à ceux de la villa d'Agrippa Poslume à Boscotrecase. Le scepticisme qui nous arait été opposé s'expliquait largement

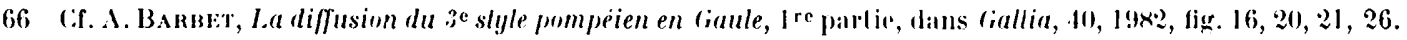

67 A. Barbit, Peintures murales d'Alesia: Problèmes de dalalion slylistique, dans Revue archéologique, 1978, p. 175-180, renvoi a la bibliographie antérieure, note 2 et à la discussion. Nous avions cru a un amalgame entre IIJe et IVe style, du milieu du ${ }^{\text {er }}$ s. ap. J.-C. car nous n' connaissions pas alors les tresse's croisées de l'Insula 18 à Avenches. 
par la méconnaissance que l'on avait du phénomène et de son ampleur en Gaule. Nous pouvons donc, maintenant, conclure plus fermement qu'il s'agissait là d'un témoin d'un décor du II Ie style, vraisemblablement antérieur au milieu du $\mathrm{I}^{\mathrm{er}}$ s. ap. J.-C.

\section{Golmier-Le-Bas (Haute-Marne)}

Situé au nord-est d'Alésia (fig. 29), cette villa avait conservé quelques débris de peintures, que le $\mathrm{D}^{\mathrm{r}} \mathrm{J}$. Harmand et nous-même avons étudiés et publiés ${ }^{68}$. Nous retiendrons deux motifs utiles, une tête féminine de profil sur un fond bleu, dont l'encadrement très proche de la tête suggère qu'il s'agissait d'un petit tableau, analogue à ceux de l'Ile SainteMarguerite. Le deuxième élément est très convaincant, il s'agit d'une petite guirlande en feston qui représente des feuilles de laurier réunies autour d'un cabochon rectangulaire central, attaché à des supports disparus, par des nœuds en coques dont les pans retombants sont faits de perles enfilées (fig. 27). Le tout, traité de façon très fine dans une gamme d'ocres, se détache sur un fond rouge bordeaux.

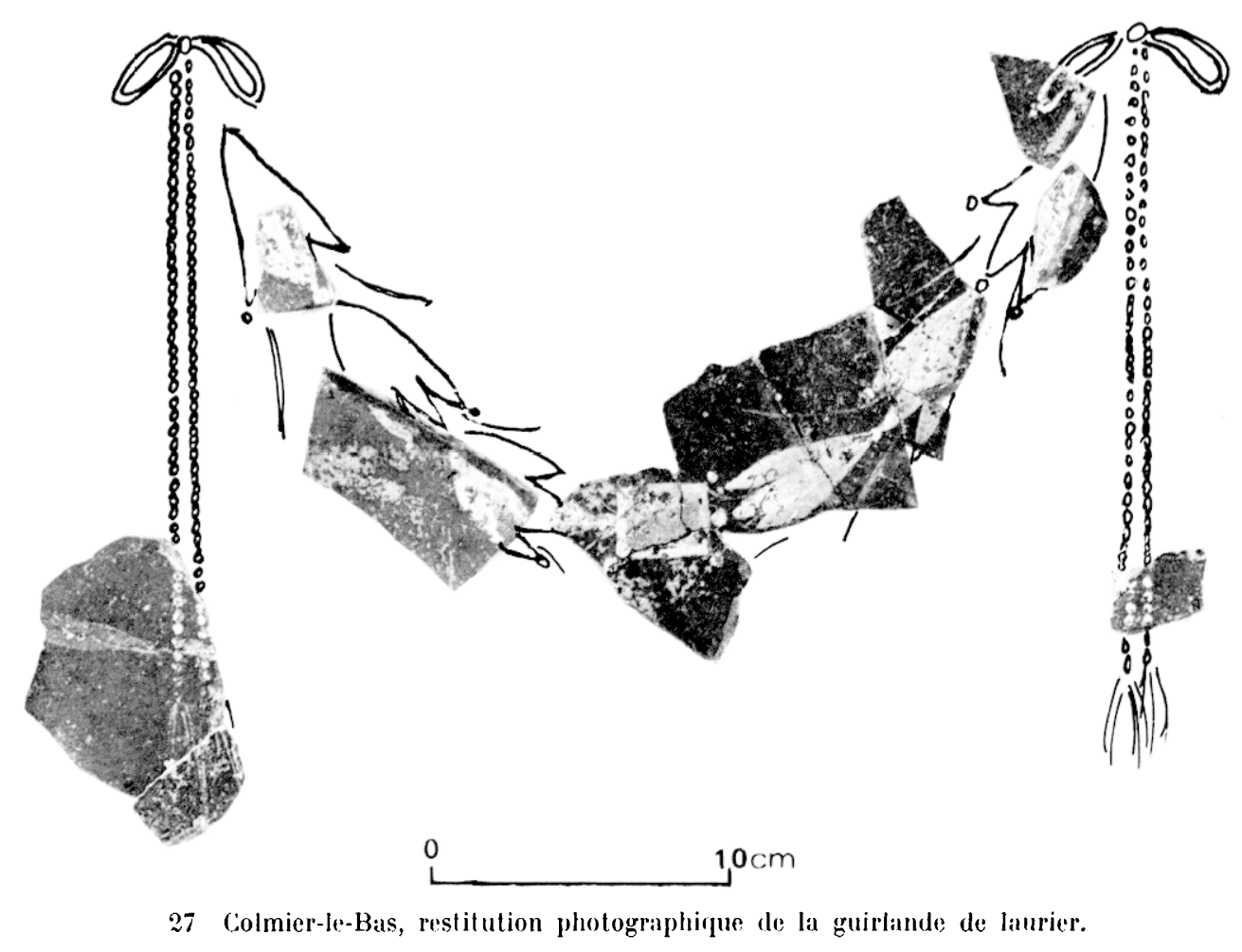

Les comparaisons possibles nous orientent inévitablement vers le style-candélabre, en transition entre II et III Ie style, soit dans les années 20 av. J.-C. Nous avions conclu à une date ultime du début du $\mathrm{I}^{\mathrm{er}}$ s. ap. J.-G., sans oser trop nous avancer, puisque les éléments recueillis en fouille étaient

68 A. Barbet et Dr J. Harmand, avec la collaboration du Chanoine J.-r.. Didier, Les peinlures murales de la villa gallo-romaine des "Cloisels" à Colmier-le-Bas, dans Mémoires de la société hislorique el archéologique de Langres, 1980, p. 285-303. La guirlande restaurée est exposée au musée de Langres. 
inexistants. S'il est imprudent de proposer positivement une datation dès les années 20 av. J.-C., notons qu'elle n'est plus aberrante, compte tenu de ce que nous savons maintenant de la diffusion des styles en Gaule. L'époque augustéenne est donc envisageable.

$\mathrm{Au}$ sud-est d'Alésia l'étude minutieuse des peintures trouvées au sanctuaire des Bolards, près de Nuits-Saint-Georges, a permis à D. Plateau de confirmer une fois de plus la présence de peintres très au fait des modes propagées dans l'Empire romain au début du $\mathrm{I}^{\text {er }}$ s. ap. J.-C. (fig. 29).

\section{Les Bolards (Nuits-Saint-Georges, Côte d'Or)}

De tous les thèmes présents dans les décors reconstitués à grand peine, et qui seront très prochainement publiés, nous ferons allusion à ceux qui s'intègrent de façon évidente à la même série que nous étudions ${ }^{69}$.

Ainsi, on trouve un canthare, minutieusement peint sur un fond rouge, qui pouvait être cnfermé dans un cadre ou posé en milieu de panneau. Une tête féminine au regard fixe de masque, était enclose dans un minuscule carré décoré de fines rayures. La minutie du traitement, l'échelle très réduite ne laissent pas de doute sur l'identification d'une facture du III e style; ces fragments n'ont pas un contexte archéologique très précis. Enfin un autre décor présente un candélabre d'une extrême minceur, nu, excepté des disques lisses, ornés de boule au-dessous et au-dessus, pour celui du sommet, comme à Neuvy-Pailloux. Sur les disques intermédiaires des oiseaux à longues pattes et à longue queue se font face (fig. 28). Des cordons perlés représentent les pans retombants de nœuds qui garnissaient les extrémités. Au bout des cordons perlés, une perle ronde est accostée de trois plus petites en croix. Il y a le même détail de facture sur le candélabre du Vert (Chizé).

Les éléments de datation ne sont pas toujours explicites, mais pour les candélabres, les fragments étaient enfouis dans le péribole du temple, ce qui nous concède une datation haute dans la chronologie relative du site. Le temple, qui a entraîné la destruction des peintures, est daté de 54 ap. J.-C. Ces décors d'un bâtiment non déterminé, civil ou religieux, seraient donc antérieurs au milieu du ier s. ap. J.-Ci.

Ainsi, après le Sud de la Gaule où les peintures du III'e style sont abondantes, riches et parfois datées, nous avons vu que le Centre et l'Est possédaient aussi des documents dont seul l'un d'eux est daté de la dernière période du IIIe style de façon certaine et deux de façon probable (fig. 28). Le phénomène est parfaitement apparent sur d'autres sites voisins, en Suisse où ont été trouvés également des décors adhérant aux mêmes principes décoratifs. Près de la frontière actuelle, le temple d'Izernore recélait des peintures dont de nouvelles photographies nous ont été communiquées par C. Lemaître qui a bien voulu y attirer notre attention. Sans erreur possible, certains fragments appartiennent au IIIe style. Des éléments de chronologie relative seront exploitables car les débris ont été trouvés sous le temple lui-même daté de l'époque augustéenne ${ }^{70}$.

69 Les décors des Bolards ont èté confiés pour étude et restauration à notre Centre. D. Plateau en a pris la charge en vue d'un mémoire de maîtrise, soutenu en novembre 1982 et intitulé : Les peinlures murales du vicus gallo-romain des Bolards à Nuils-Saint-Georges (Cốle d'Or). Les travaux ont été suivis par C. Allag et moi-mème tant à Paris qu'à Soissons. La publication interviendra dans les Actes des Séminaires de Lisieux-Bordeaux 1983.

70 C. Lemaitre, qui prépare une thèse de III e cycle sur Izernore, nous a communiqué oralement ces renseignements. 


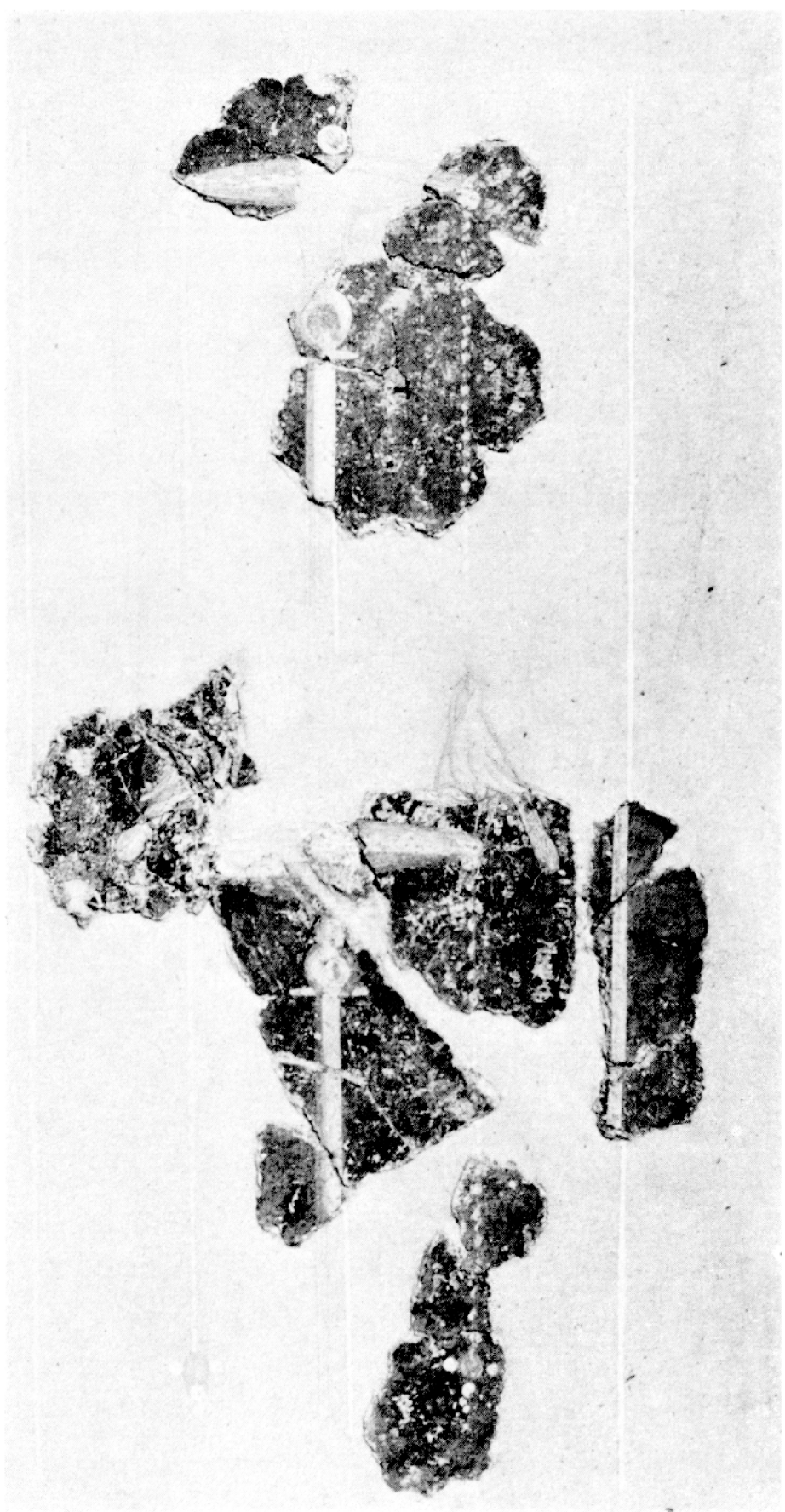

28 I.es Bolards Nuits-Saint-Georges, le haut du candélabre.

\section{Commugry (Suisse)}

Les peintures de la villa de Commugny ont été publiées par W. Drack dans son recueil des peintures de la Suisse et l'on soulignera encore certains aspects des décors reconstitués, dont une partie nous est déjà familière et l'autre nouvelle pour les provinces ${ }^{71}$. La colonne à écailles imitant

71 W. Drack, Römische Wandmalerei der schweiz, Bàle, 1950, p. 66-75, pl. 1 à VI, dépliant I. 


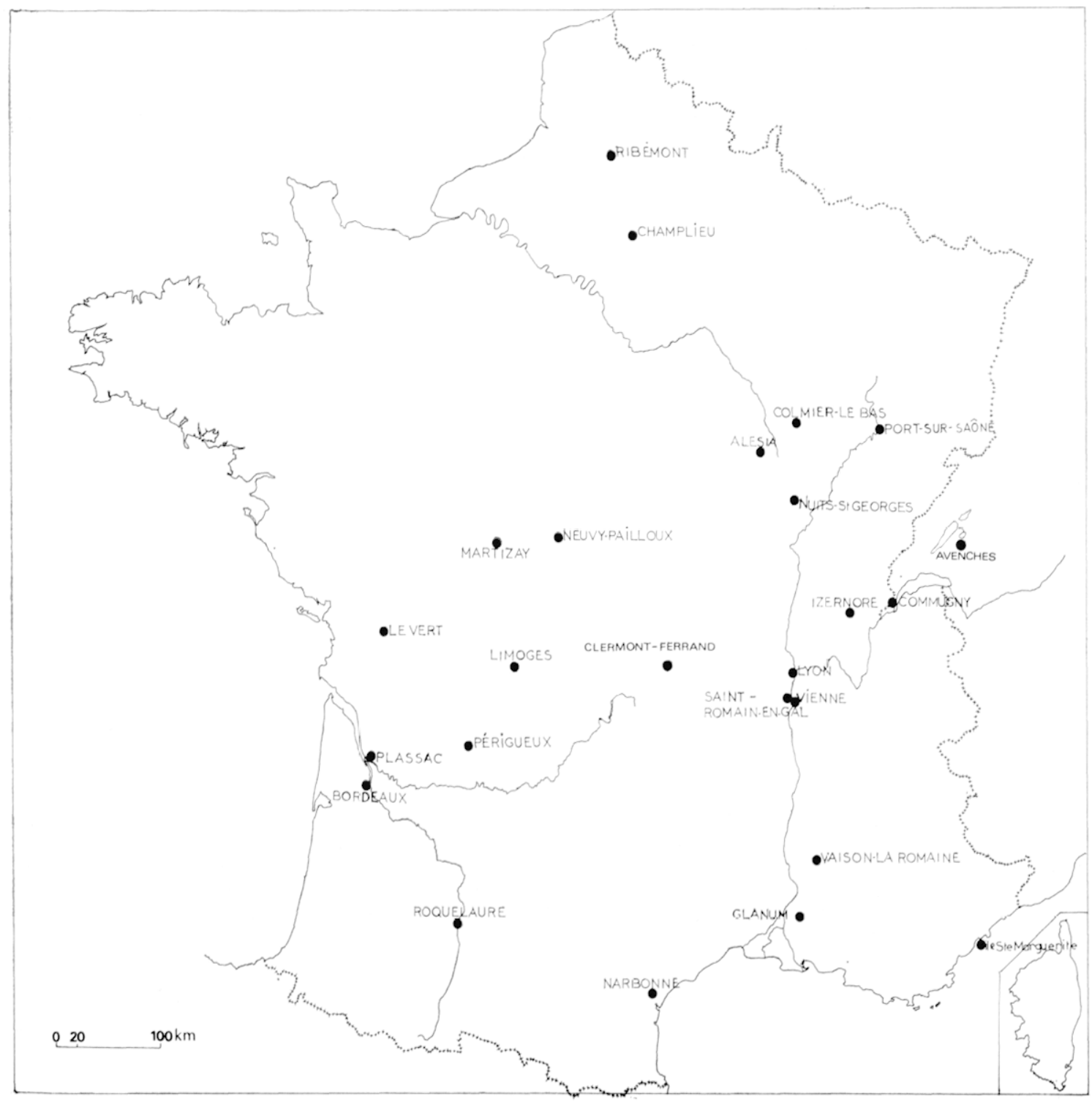

29 Carle de la diffusion du IIJe style en Gaule (liste non exhaustive).

le tronc d'un palmier, les galons brodés de motifs miniaturistes font partie du vocabulaire recensé pour la Gaule; il faut y ajouter le canthare d'où sort une pyramide de feuilles et de fruits, fait qui est nouveau. Le candélabre à ombelles et coussinets qui est présent à Commugny l'est également ¿ Vienne (paroi du Globe), à Vienne-les-Nymphéas et nous le verrons dans le Nord à Ribemont.

Un essai de présentation théorique des peinlures de Commugny a été tenté au musée de Zurich $^{72}$. Elle ne nous paraît pas fiable car dépourvue de toute logique : ainsi les candélabres à ombelles ne peuvent flotter en l'air sans une base, les pyramides florales semblent trop hautes, les syrinx attachés par des rubans sont à relier à un support, inexistant sur la restitution. Des festons très ténus de petites feuilles venaient en courbe se nouer à ces supports disparus. Quoiqu'il en soit,

72 H. Chateinax, La villa romaine de Commugny, dans Heluelia Archaeologica, 26, 7, 1976, p. 39-57; en particulier la restitution sur la figure p. 45. L'article donne la chronologio des fouilles faites depuis le débul du siècle et dresse un plan de la villa mais ne donne pas de datation. 


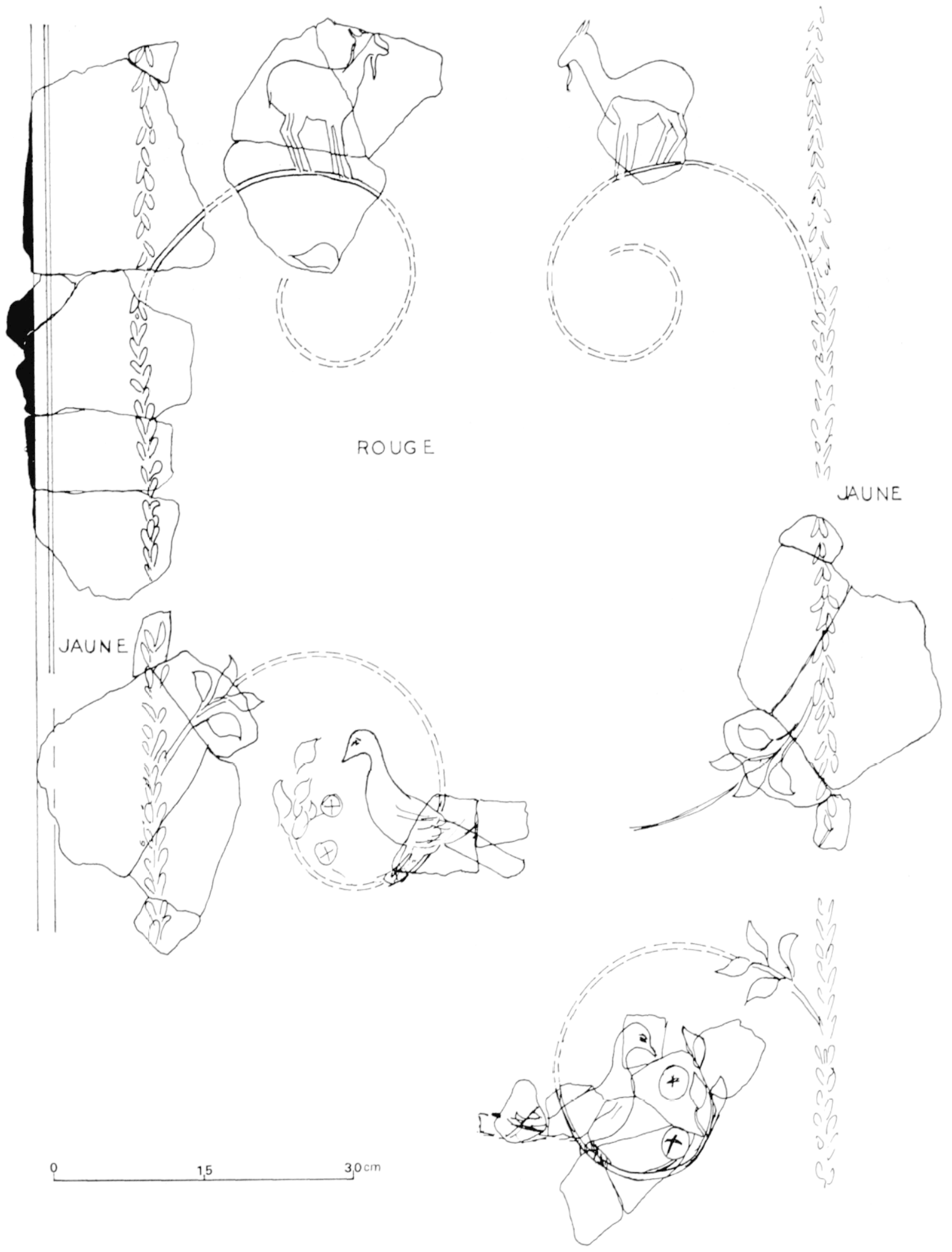

30 Commugny, restitution à partir des eléments d'un décor rouge et jaune. 
les thèmes majeurs sont là, les décors mineurs aussi, tels ces dauphins aftrontés sur une ombelle décorative au-dessus d'une bordure, et qui nous rappellent ceux de Roquelaure et de Narbonne, dans une position et une utilisation décoratives analogues ${ }^{73}$.

Nous suggérons, pour les décors rouges et jaunes, d'y voir peut-être un bord de panneau rouge médian séparé de larges bordures jaunes au moyen d'une guirlande rigide de petites feuilles vertes serrées, d'où, à intervalles inconnus, jaillissent des tiges peuplées de petites chèvres et d'oiseaux, picorant des baies ménagées dans l'enroulement en volute de ces tiges (fig. 30).

La datation avancée reste asse\% floue, mais tout de même de la première moitié du ${ }^{\mathrm{er}} \mathrm{s}$. ap. J.-C. Plus précisément W. Drack propose la fin du deuxième tiers du $\mathrm{I}^{\mathrm{er}} \mathrm{s}$.

\section{Avexches (Suisse)}

La fouille récente d'un édilice dans l'Insula 18 a porté à la connaissance d'un nouveau décor partiellement en place et reconstitué au musée. Au-dessus d'une plinthe à imitations de marbres, on trouve un décor monochrome rouge avec division par des supports minutieusement exécutés : tresse croisée, colonnette de feuilles serrées et de baies, agrémentées de rubans flottant et d'objets, médaillons, guirlandes en festons de minuscules feuilles, bref un répertoire bien ròdé. La tresse croisée rappelle en plus riche celle d'Alésia, la colonnette de feuilles serrées celles de Périgueux. Relevons deux détails qui nous intéressent plus particulièrement, le motif cordiforme surmonté d'une plume de paon, la tête lunaire dans un petit cadre (fig. .31). Le motif cordiforme existe aussi à Colmierle-Bas et la tête lunaire sur plusieurs peintures de la Gaule, déjà analysées (fig. 13).

La maison d'Avenches a été nivelée au début, du ${ }_{1} \mathrm{e}^{\mathrm{e}}$ s. et remplacée par une installation thermale ; W. Drack admet une datation de la deuxième moitié du ${ }_{1}^{\text {er }}$ s. ap. J.-G. qui peut être remontée au milieu du i $\mathrm{er}_{\mathrm{s}}{ }^{74}$.

Nous achèverons ce long périple par le Nord de la Gaule qui nous réserve, lui aussi, quelques surprises. Deux sites nous concernent, le premier, déjà publié, est un petit décor reconstitué du sanctuaire de Ribemont-sur-Ancre, le deuxième appartient à la galerie extérieure du temple de Champlieu (fig. 29).

\section{Ribemont-sur-Ancre (Somme)}

La reconstitution des éléments et l'étude ont été menées par $\mathrm{A}$. Quillet? ${ }^{75}$. La plinthe appartient. au type attesté en Gaule uniquement à Alésia, de compartiments à découpagres géométriques simples, sur fond noir. La zone moyenne est occupée par des panneaux plats, à bordure ajourée à un còté libre, et séparés les uns des autres par des candélabres à ombelles et coussinets du type rencontré en Suisse à Commugny. Une bande ornementale où l'on reconnaît encore raguement des lotus et des ornements en II a été grossièrement peinte (fig. 32).

Le fond n'est pas lissé, les stries sur la bande ornementale vont de pair avec des contours épais et maladroits. L'exécution ne correspond pas du tout au soin que nous avons rencontré sur toutes les autres peintures.

Les éléments de datation sont clairs : un premier grand temple a été construit à l'époque de Tibère, détruit ensuite; lui succède un sanctuaire de remplacement avec exèdre peinte, daté de

73 (.f. W. InAck, op. cil., pl. VI.

74 W. Drack, Neu entdectile römische Wandmalereien in der schweiz, dans Antike Well, 3, 1980, p. 4 à 7 at fig. 4 à 9 . Nous reviendrons sur d'aut res motifs d'Avenches identiques à ceux d'un décor inédit de Périgueux fouilles av. Bertran-de-Born' qu'il faut ajouter d’ores et déjà à la liste du Il le st şle en Gaule.

75 C. A. QunLet, Les enduils peints du sancluaire gallo-romain de Ribemont-sur-.1ncre, dans Bulletin de la sociéle des antiquaires de Picardie, 1974, p. 287-313 ; repris par J.-L. Cadoux, dans Lalomus, 37, 2, 1978, p. $361-363$. 


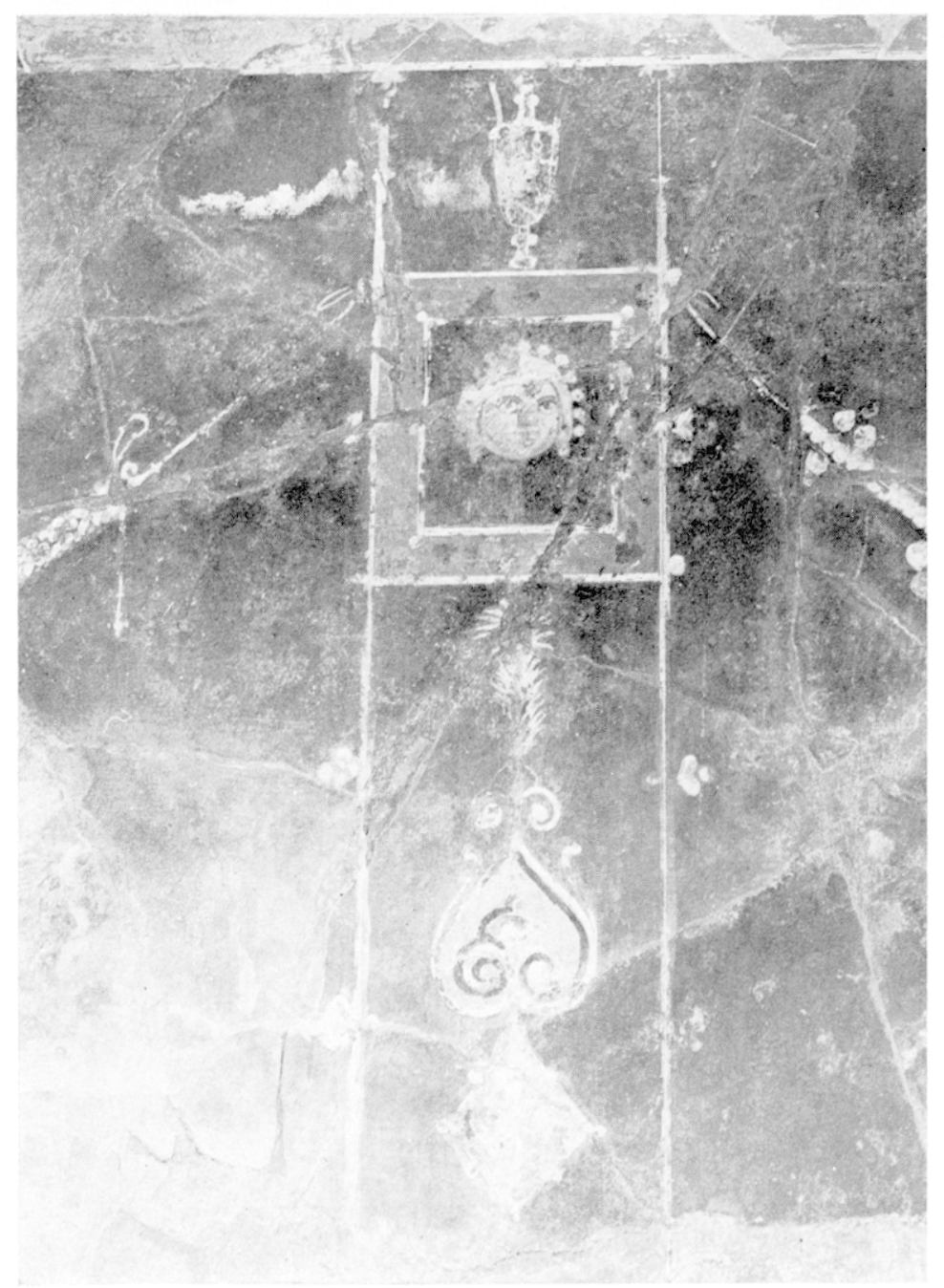

31 Arenches, insula 18: deitails d'ume paroi.

l'époque flavienne, soit du dernier liers du $\mathrm{I}^{\mathrm{er}} \mathrm{s}$. ap. J.-G. Enfin le grand temple est reconstruit sous Marc-Aurèle. Les peintures reconstituées, dont la plinthe géométrique étail en place dans l'exédre. ne sont donc pas antérieures aux années 70 ap. J.-C., soil de l'époque ou les principes décoratifs du IVe style rìgnent déjà en Italie et se sont mème répandus en Gaule. Nolons que la bordure ajourée apparaît au IIIe style mûr vers 40-45) ap. J.-G. Nous sommes donc en présence d'un décor de III style mûr, de facture très médiocre, dont l'auteur n’était sans doute pas italien. .ous poserions volontiers comme hypothèse la présence d'un peintre gallo-romain qui a appris son métier avant. le milieu du $\mathrm{e}^{\mathrm{er}}$ s. et qui a perpétué durant toute sa carrière un style désormais désuet. I'n certain éloignement des grands rentres artistiques peut expliquer cet archiïsme.

\section{Champlieu (Oise)}

Le temple de Champlieu, mis en évidence au xixe s. par Viollet-le-l)ur, cachait un antre temple du type fanum qui a été retrouvé par (i.-P. Woimanl par de minutieux sondages straligraphiquesĩ.

76 Cf. à Pompéi, uniquement sur des décors de la phase IIt, Bastet-1)e Vos, Terzo slile pompeiano, pl. IVII, I.YIII, 106.

77 G.-P. Woimant termine une thise de Ille cycle sur ee sujet. 


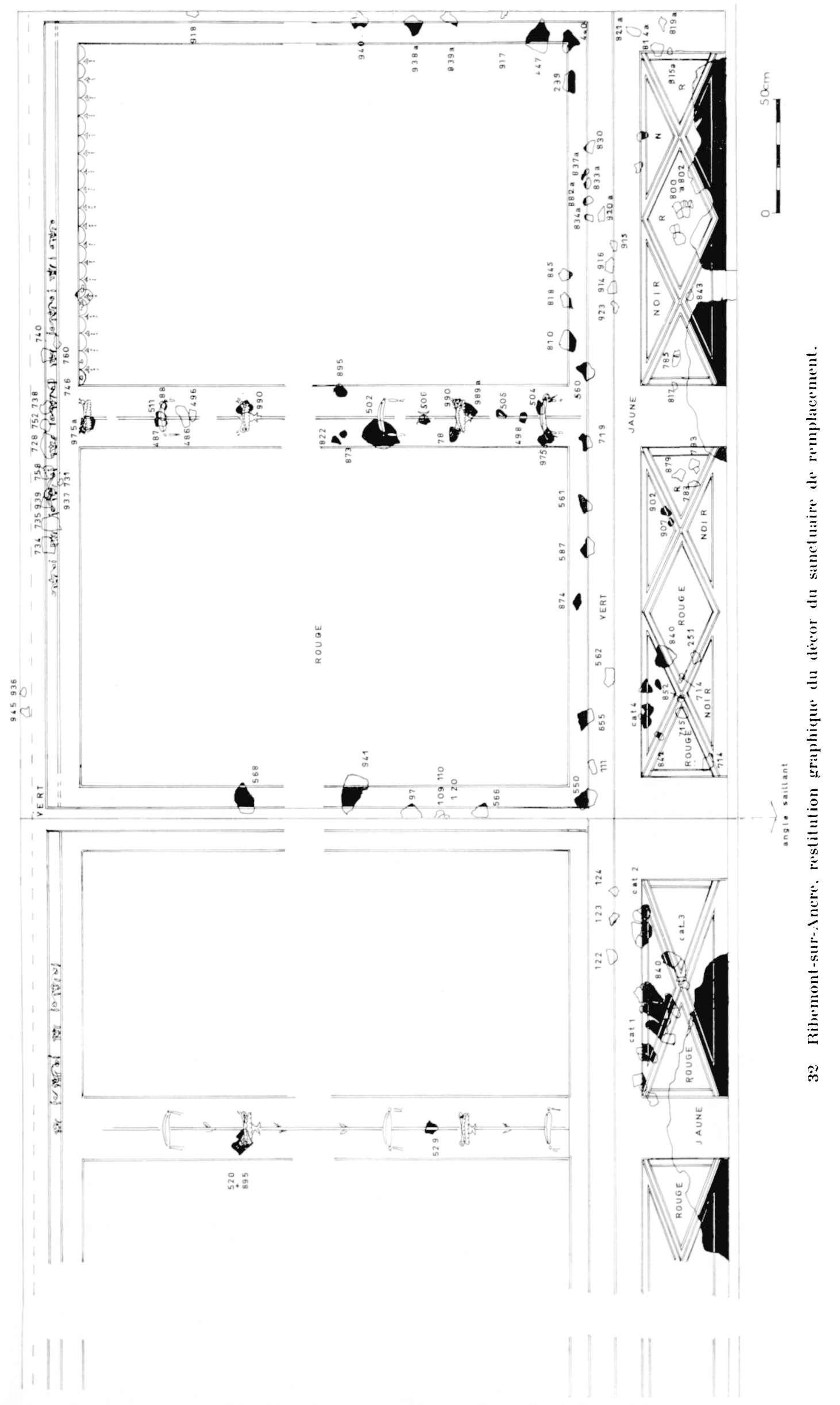


Au cours de ces travaux, des peintures fragmentaires ont été soigneusement recueillies et recomposées ; elles proviennent de la galerie nord, du mur de séparation entre la cella et la galerie. Elles nous ont été confiées pour étude finale et restauration et présentées dans une exposition itinérante en Picardie-Normandie ${ }^{78}$.

Eléments de datation fournis par les fouilles.

Le fanum est d'époque tibérienne tardive en raison du lerminus posl quem qui l'accompagne. En effet, un niveau "pré-fanum " montre un dépòt monétaire de pièces mi-romaines et mi-grauloises dont les plus récentes ont pu circuler jusqu'au règne de 'Tibère. De surcroît, dans le fanum, un témoin de mosaïque en opus tesselalum noir et blanc présente un décor géométrique de carrés et d'étoiles à huit losanges du milieu du $\mathrm{e}^{\mathrm{er}} \mathrm{s}$. Le fanum et sa décoration sont contemporains ou postérieurs de très peu au règne de Tibère, et sûrement postérieurs au règne de Claude. L'édifice a été détruit au début du ${ }_{1 I}{ }^{\mathrm{e}} \mathrm{s}$.

\section{La reslitulion graphique.}

Nous y avons porté tous les éléments à notre disposition en mêlant ceux qui proviennent de la galerie nord à ceux de la galerie sud qui sont individualisés par des astérisques (fig. 33). On ne sait s'il existait une sous-plinthe mais elle est probable. line plinthe est proposée, à grands compartiments noirs, bordés de minces traits jaunes, qui alternent avec des champs rouges étroits. Dans les compartiments noirs il y avait des échassiers dont un seul spécimen, bec vers la terre, est conservé (OCH 79.22) et des touffes de grands feuillages acérés á bords droits (OCH 79.21 et 21 bis). La plinthe est séparée de la zone médiane par une moulure de corniche imitée en tons crème et beige usuels et par une bordure verte.

La zone 2 se divise en panneaux rouges d'une certaine ampleur et en champs verts a colonnes. Les panneaux rouges sont ornés par des triples filets, en guise d'encadrement intérieur, qui se composent d'un filet noir entre deux traits blancs. La bordure externe est large, noire et des touffes de petites feuilles, agrémentées de fleurs sur les còtés verticaux (OCH 79.4) ou de fruits (OCH 79.6) sur le còté horizontal inférieur, alternent avec des couples de deux feuilles trifides, un peu à la manière d'une bordure de panneau à Roquelaure (panneau II).

Les bandes de séparation sont vertes avec une colonnette imitant un tronc écailleux de palmier, sur lequel est accroché un petit tableau peu lisible et auquel se rattachent des tiges de feuillages retombant (OCH 79.1 el 2). Des animaux se juchaient sur de petits supports adjacents : on reconnait les pattes avant d'un cheval (OCH 79.10), l'arrière-train et la longue queue d'un singe ou d'un chien (OCH 79.9). Le petit tableau accroché semble avoir porté une tête lunaire; il est surmonté d'un oiseau à huppe aux ailes de profil qui devait avoir un pendant en symétrie. On ignore le décor de la partie haute disparue.

Parmi les petits décors non placés dans ce schéma, il y a les débris d'une bordure à galon brodé de cours et de points (fig. 20).

\section{L'analyse slylistique.}

Un aspect frappe immédiatement, c'est le soin extrême de l'exécution sur un support de mortier, malheureusement pauvre en chaux, qui s'effrite, mais dont la surface avait été parfaitement lissée. Chaque ornement est peint avec minutie et rigueur selon la meilleure tradition. Les motifs employés nous sont tous connus, que ce soit la plinthe à touffes de

78 Cf. C. Aliag, A. Barbet, La peinture murale romaine de la Picardie à la Normandie, catal. expo. Paris, 1982, notice par A. Barbet, p. 45-48. 


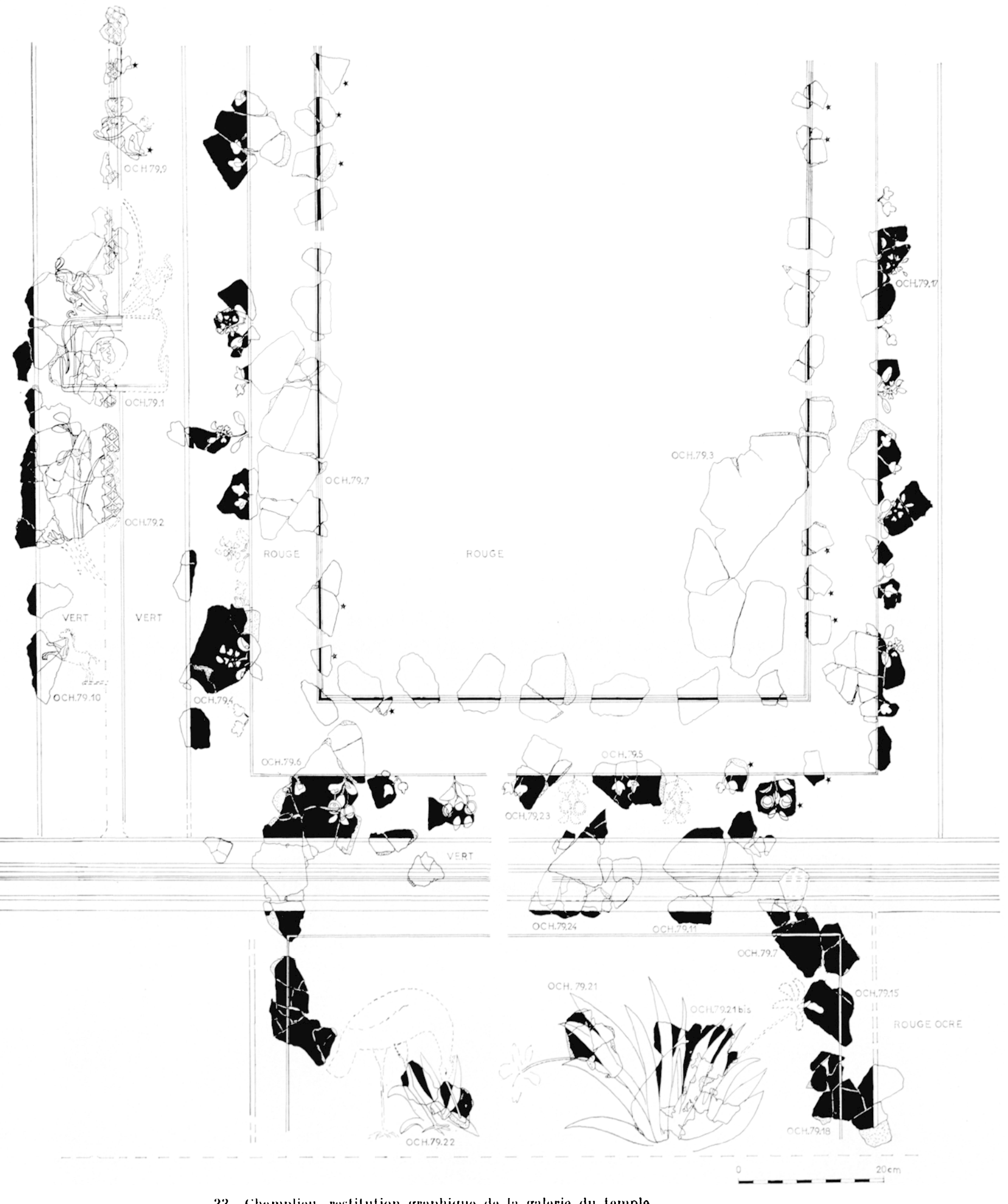

33 Champlieu, restitution graphipue de la galerie du temple. 
feuilles et à échassiers, comme à Vienne, les panneaux à encadrement par filets triples, comme à Lyon, Glanum, Vaison, l'Ile Sainte-Marguerite, Chizé, Périgueux (inédit), Soissons (inédit) ou Bordeaux ${ }^{79}$. De mème les petites feuilles piquées à angle droit sur la bordure des panneaux médians, et la colonne à tronc de palmier, ou l'oiseau à huppe.

Pour nous la peinture de Champlieu, si raffinée, et qui se rattache si bien à une mode artistique, reste profondément originale. La présence du petit singe ou du chien serait unique à ce jour, de même que la forme de la tige à feuilles retombantes noires avec demidisque enchàssé rouge vermillon contre le tronc du palmier. ('est là un détail qui nous rappelle les disques-oscilla de Vienne (Nymphéas), les demi-courbes d'un rinceau à Plassac, dont nous n'avons pas parlé, toujours à fond rouge vermillon. La solution est la même à Champlieu, même si le parti décoratif diffère.

\section{Dalation.}

Nous avons vu que le contexte de la fouille, interprété avec rigueur par le responsable lui-même, nous fournit une datation relativement tardive dans notre sćrie, soit le règne de Tibère. Doit-on en conclure à une introduction plus tardive du IIIe style au Norl de la Gaule qu'au Surl? En attendant d'autres documents qui confortent cette hypothèse, elle nous paraît vraisemblable (fig. 29).

\section{Ciaractéristigues du ille style en Gavle}

Il est peut-être imprudent de proposer déjà une synthèse du IIIe style en Gaule et elle se comprendrait mal si on la coupait des réalisations provinciales qui l'entourent; cependant on peut tenter un premier tableau synoptique, à la manière de celui qu'a réalisé H. de Vos pour Pompéi, afin de résumer les thèmes principaux utilisés en Gaule, sans préjuger d'éventuelles modifications.

\section{Tableau synoplique.}

Nous avons reporté les rubriques ornementales sur le côté horizontal et la liste des principaux décors connus en Gaule sur le côté vertical. La lecture s'effectue d'elle-même et le nombre de petits ronds pour une même rubrique indique sa popularité. Parmi les thèmes populaires, lo candélabre est en tête pour les périodes les plus précoces.

Ce tableau donne une idée du répertoire le plus courant, puisque les motifs employés une seule fois ne figurent pas en principe dans cette table. Les sites ont été ordonnés autant que possible de façon chronologique, les plus anciens au début et les plus récents à la fin. L'ordre d'analyse proposé procède des partitions majeures aux détails mineurs. ("est ainsi qu'on observe certains faits :

79 Cif. A. Barnet, Recueil général des P'einlures murales de la diaule, (ilanum, XXVIle suppl. à Gallia, laris, 1974, Pl. III. 
Dans la première période du Ille style en Gaule, phase simple et sévère, avec peu d'ornements. les plinthess sont à imitation de marbre ou mouchetées, les candélabres sont fins à pied apparent, à fùt lisse orné de disques, sourent à monochromie stricte; ils viennent directement des prototypes mótalliques.

la deuxième génération de peintres utilise un répertoire plus riche, dès le tiers du Ier s. ap. J.-C., à Vienne. Périgueux (deuxième groupe), Plassac. Sans ombelles ou avec ombelles, le candélabre se végétalise et s'arcompagne de petits oiseaux ou de quadrupèdes, il ne possède plus apparemment de pièl, sauf à Plassac où nous avons une sorte de base de rolonnette. Les plinthes sont animées d'échassiers, de plantes, bien que les imitations de marbres subsistent rnoore. à còté des autres thèmes, commer les thyrses, employés une seule fois. Une certaine fatune envahit le champ : cygnes, oiseatux a huppe, echassiers; les guirlandes légères sont tris ulilisées, tandis que les médaillons figurés ou les petits tableaux encadrés font leur apparition dans le sud ot lo Centre de la Gaule. Les galons brodés apparaissent aussi bien dans less régions du Nord que du Suil, mais peut-être un peu plus tard (?), la bordure ajourée n'existe que sur l'exemplaire surrement tardif de Ribemont. La pseudo-moulure hianehe entre plinthe et zone moyenne, ornée et ombrée de simples traits an dégradtés, ast la solution décorative adoptée de facon continue durant toute la période.

Certains objets ont ete reproduits surtout dans le sud, comme les petits vases métalliques, les masques lunaires; Martizay, dans le Cantre, représente une zone limite d'influence et celle introduction s'est fatite alors à la deuxieme génération. Les fonds monorhromes sont rouges ou noirs at la plinthe à compartiments géométriques visible dans deux cas, provient de sites du Nord, dont l'un est plus réeent que tous les autres. On ne sait encore si cette constatation a une valeur ou non.

En résumé, on décèle une ertaine érolution stylistique dans le choix des compositions et des thèmes durant ces deux générations de peintres, entre .20 et +40 et on pressent des répertoires locianx où certains motifs semblent avoir été utilisés plus que d'autres. Actuellement, on ne peut aller plus loin dans l'analyse, car certains décors sont inédits, pas encore reconstitués at il faut attendre leur étude complete pour remplacer bien des points d'interrogation; il en va de mème pour les décors qui nous sont parvenus très mutilés, au point qu'on ignore la plus grande part de loordonnance générale, mais, dans ce cas, il n'y a pas d'espoir d'une information ulterieure.

Certaines de ces peintures sont des arureses de luxe, chères du lait de l'emploi de substances et de thèmes qui requièrent des peintres plus talentueux. Ainsi à Roquelaure, les tableaux mythologiques au centre des parois supposent la présence d'un peintre spécialisé, mieux payé que le décorateur d'ensemble; il s'agissail vraisemblablement d'un pictor imaginarius ${ }^{80}$. A l'lle-sainte-Marguerite nous arons noté, sous le tableau à personnages, que le mortier noutait pas le mème; la place du tableau avait été laissée en réserve

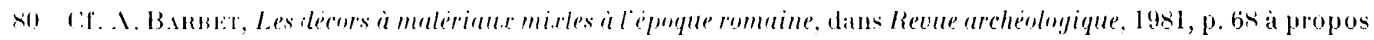

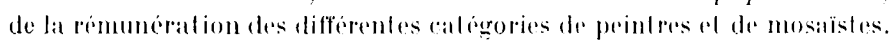




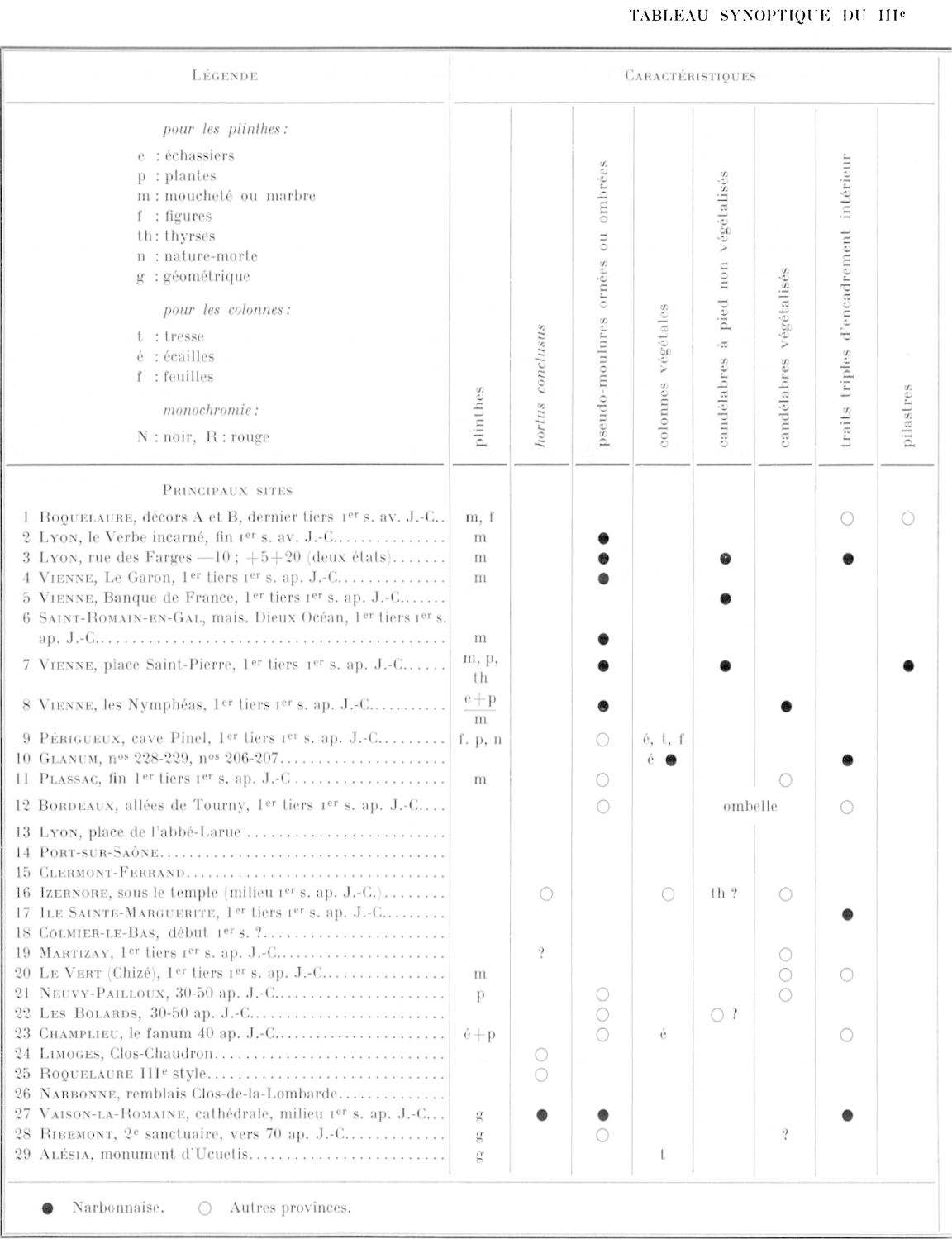

STYIE POMPEIEX EN GQUHE

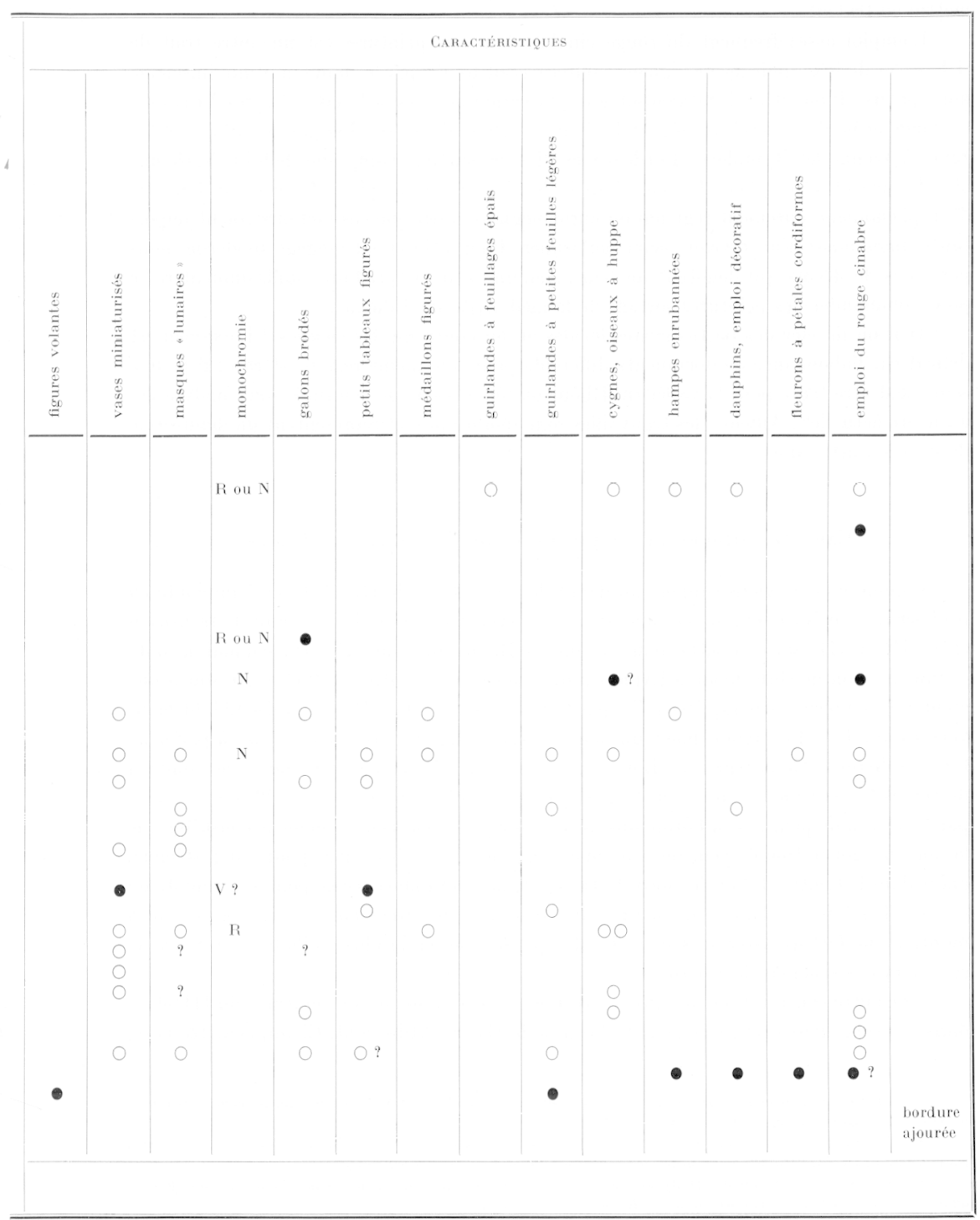


at un mortier frais. appliqué au moment mème de l'arrivée du peintre spécialisé, prèt à se mettre au travail.

L'emploi assez fréquent du rouge cinabre dans ces peintures est un autre trait de richesse et de luxe, puisque e pigment roùteux etait fourni par le commanditaire lui-mème nous précise Pline et qu'il nécessitait une protection spéciale à la cire, d'après Vitruvest. Ce rouge brillant est employe en grands champs à Roquelaure et à Périqueux, sur de petites zones à Vienne-les-Nymphéas, Bordeaux el Plassale. sur un champ non défini à Narbonne et à limogeses. et en général ignoré dans le Nord satuf à Champlieul. Il ne s'agit done pals d'un phénomène purement régional ou chronologique, bien que ces facteurs soient imporLants. mais aussi d'un niveau social particulier. Pour utiliser un langage moderne. nous parlerons de décors qui dénotent un bon "standing " du propriétaire, suffisamment, riche pour commander des peintures sortant de la médiocrité quotidienne.

Doit-on déceler des particularités locales ou au contraire des latunes? L'examen est délicat car l'abondance de documents différents pour une mème région est rare; il pourra seulement ètre tenté pour la vallée du Rhòne où une dizaine de peintures sont analysables à l'heure actuelle ${ }^{83}$. Ailleurs, les trouvailles sont sporadiques of représentent un demi-siècle de création artistique.

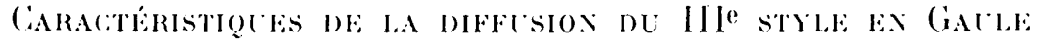

Comme nous l'avions supposé au début de cette étude. le Il le style s'est implanté en premier lieu en Narbonnaise, et ce n'est pas un hasard si le seul décor connu de transition entre lle et IIJe style se siture dans le Sud, à Roquelaure (fig. 29) On connait la date d'implantation de cette mode à Lyon. capitale des Gatules, entre - 10 et +10 . soit à une épocque très précoce par rapport à l'apparition de cette mode à Rome, vraisemblablement. vers 15 av. J.-6. Le rayonnement du nouveau style miniaturiste a pu se faire à partir de foyers différents, de la région de Bordeaux. de celle de Lyon. sams que l'on sache combien de temps l'impulsion, venue de métropole par des peintres italiens. s'est diffusée et diluée par le moyen de peintres gallo romains, formés sur place. On peut seulement constater que la nouvelle génération de peintres, succédant aux peintres italiens de l'époque augustéenne, opère dans le Centre cet dans le Nord de la Gaule, où Champlieu recoit pour son temple un décor à l'époque de Tibère. L'exemple du sanctuaire de Ribemont, tardif, est le seul à montrer une facture assez grossiere; il fait supposer une main plus malhabile, provinciale, recopiant des schémas déjà périmés.

Ine autre constatation, délicate à interpréter. est la presence de peintures du IIIe style dans des sanctuaires religieux pour le Nord de la Gaule: Ribemont, Champlieu, lzernore,

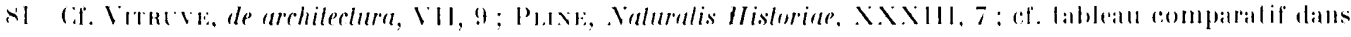

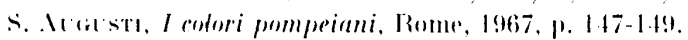

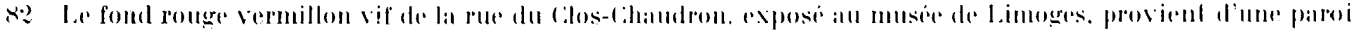
courbe ou d'une voùte comme lineurvalion de la surface de plusienrs fragments l'indiguer.

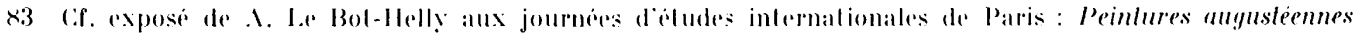
dans la rallée du Rhône, à paraitro daus la Revere de varbmnnaise. 
peut-être Les Bolards, sont autant de sanctuaires ou de temples qui ont reçu cette parure rafflinée. Le Monument d'l'cuetis à Alésia, est sans doute une salle de culte et le tombeau de Neury-Pailloux arait aussi une fonction religieuse. Ces coüncidences peurent s'expliquer par des faits historiques : au début du $\mathrm{I}^{\mathrm{er}}$ s. ap. J.-C.. l'implantation des villas n'est pas celle qui eut cours ensuite et les vestiges d'époque précoce sont précisément les monuments religieux.

En revanche, dans le Sud, où la romanisation est plus ancienne, les maisons domestiques à la romaine, ou les villas, sont déjà nombreuses au début de notre ère, d'où d'abondants vestiges de peintures retrouvés dans ces habitats.

Le but de cet exposé était une mise au clair d'un phénomène de diffusion artistique complètement méconnu jusqu'à ce jour, au point que, dans son tableau du IIIe style dans les provinces, M. de Vos n'avait pu en signaler que quatre exemples pour la Gaule, ce qui était très loin de l'impact réel de ce style dans notre pays. Nous arrivons largement à une trentaine de décors différents, sans compter les quelques inédits que nous connaissons et dont nous n'avons pu parler ici. Cette mise au point aura nécessairement besoin d'être remise à jour pour nous permettre un bilan régulier utile.

Ainsi se dessine peu à peu l'histoire de la peinture décorative de la Gaule et se précisent les styles provinciaux dont la connaissance du répertoire permettra de conforter de mieux en mieux des chronologies souvent trop vagues.

Nous avons repéré à peine cinq sites qui nous aient conservé des peintures du Ile style, concentrés en Narbonnaise exclusivement; pour le III style, il y en a déjà six fois plus, répandus dans la Gaule entière; il y a là un événement important et c'est vraiment sous Auguste que l'art pictural prend son essor dans notre pays.

Alix Barbet

(C.N.R.S.)

N.B. ... Toutes les illustrations sont de l'auteur, sauf : fig. l, d'apres le plan de Cantet et Péré, carnet de fouille; fig. 4, R. Prudhomme; fig. 9, d'apres . Volizia degli Sccavi di Anlichilà, 1929, fig. 30, p. 408; fig. 13: A, II. Laviagne; B, R. Prudhomme; D, Ciallia, 22, 1964, fig. 10, p. 383 ; E, A. Audin ; fig. 21, S. Pannoux ; fig. 24 el 25, d'apres louvrage de Thabaud de linetiere el des Meloizes; fig. 32, restitution d'A. Quillet complétée par $A$. Barbet. 